Policy Research Working Paper 2024

\section{Re-Engineering Insurance Supervision}

Lawrie Savage
The old approach to

supervising the financial

sector - covering a broad

range of issues and devoting

considerable energy to

verifying data - must be

replaced by a more focused

approach, getting supervisors

to focus on management

performance and business

strategy in high-risk firms.

The World Bank

Financial Sector Development Department

and

Inter-American Development Bank

Infrastructure and Financial Markets Division

December 1998 
Policy Research Working Paper 2024

\section{Summary findings}

The insurance industry is underdeveloped in many of the world's emerging markets and transition economies, sometimes because of restrictive regulations or inadequate supervision of insurance companies.

Many countries are considering reforming regulation of their insurance systems and strengthening supervision. Savage's analysis is designed to help them choose the program of regulation and supervision that best fits their circumstances.

He draws on experience in industrial countries that have examined the reasons financial institutions failed. He concludes that the old approach to supervising the financial sector - covering a broad range of issues and devoting considerable energy to verifying data - must be replaced by a more focused approach that targets insurer solvency by getting supervisors to pay attention to management performance and business strategy.
Financial supervisors in jurisdictions that have updated their systems with this approach in mind now see their main task as gauging the financial risk or risk profile of each company and allocating most of their resources to the higher-risk situations.

In doing so, their objective will be to understand a firms's business strategy, to assess the firm management's competence and appetite for risk, and to assess the firm's outlook and financial viability.

Savage highlights the special role played in supervision by industry specialists such as the auditors and actuaries who support insurance companies.

He identifies the priorities needed in the reform of insurance supervision and suggests steps needed for change - and helpful ways for officials to organize.

He discusses not only issues associated with the supervision of solvency and financial strength but ways to protect consumers.

This paper - a joint product of the Financial Sector Development Department and the Infrastructure and Financial Markets Division, Inter-American Development Bank - is part of a larger effort to study policies that promote financial sector development. Copies of the paper are available free from the World Bank, $1818 \mathrm{H}$ Street NW, Washington, DC 20433. Please contact Hedia Arbi, room F6P-266, telephone 202-473-4663, fax 202-522-3199, Internet address harbi@worldbank.org. The author may be contacted at 1salawrie@ibm.net. December 1998. (117 pages)

The Policy Research Working Paper Series disseminates the findings of work in progress to encourage the exchange of ideas about development issues. An objective of the series is to get the findings out quickly, even if the presentations are less than fully polished. The papers carry the names of the authors and should be cited accordingly. The findings, interpretations, and conclusions expressed in this paper are entirely those of the authors. They do not necessarily represent the view of the World Bank, its Executive Directors, or the countries they represent. 
Re-Engineering Insurance Supervision

\author{
Lawrie Savage
}




\section{Re-Engineering Insurance Supervision}

\section{CONTENTS}

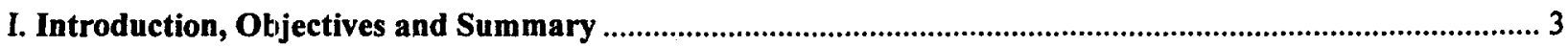

A. Introduction: Emerging Demand for High Level of Supervision .............................................................. 3

B. Objectives of Paper: Best Practices in Re-engineering the Supervisory Function in the Developing Country Context

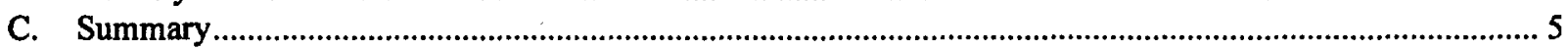

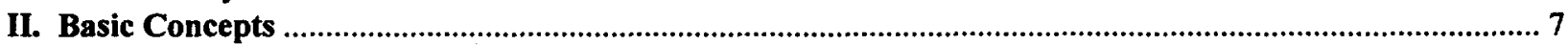

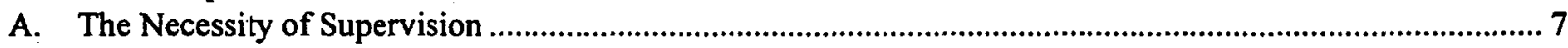

B. The Role and Importance of Insurance Supervision in Developing Countries..................................................9

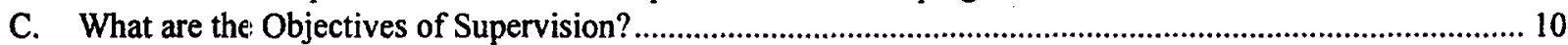

D. Typical Supervisory Challenges in Developing Countries ...................................................................11

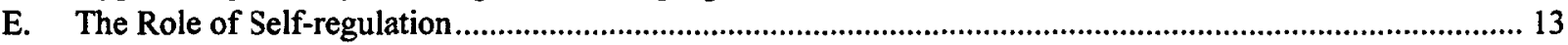

F. The Role of External Auditors and External Actuaries in the Supervisory Process......................................... 14

G. Time Horizons and Prioritizing of Key Issues, Challenges ......................................................................... 15

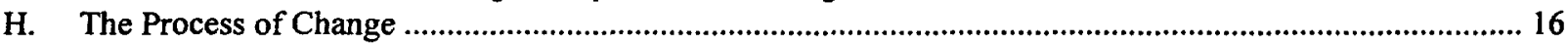

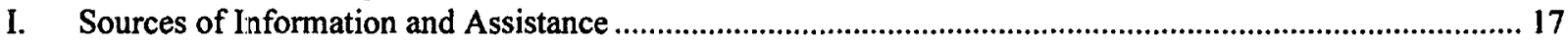

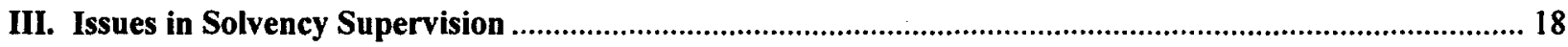

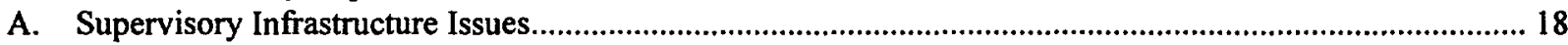

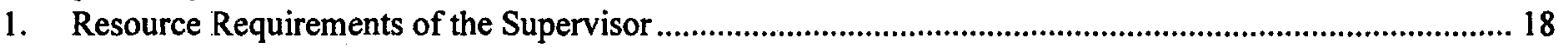

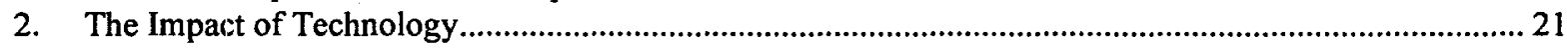

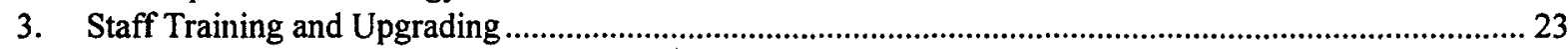

4. Economies of Scale and Other Benefits of Working on a Regional Basis ............................................... 25

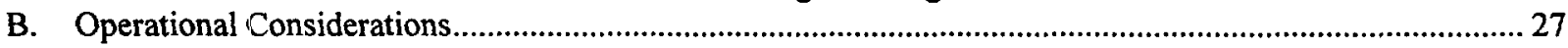

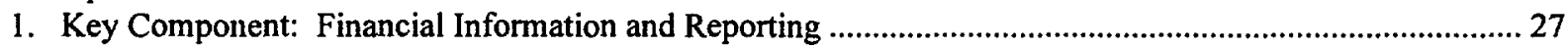

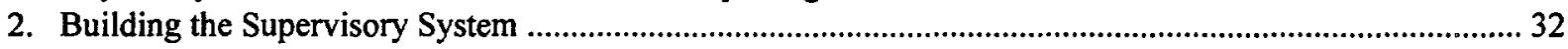

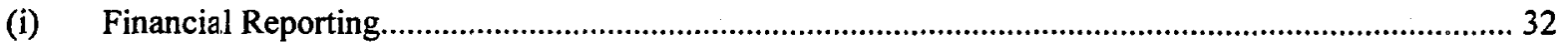

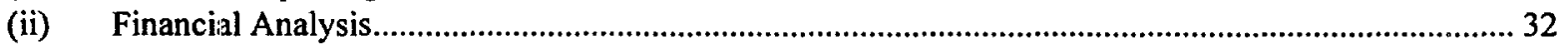

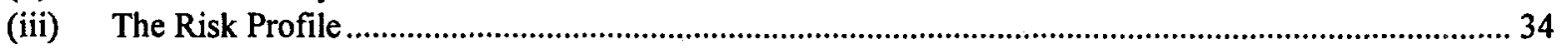

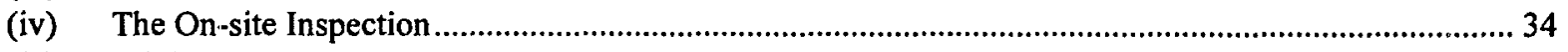

(v) Minimum Capital and Surplus Requirements and the Trend Towards Risk Based Capital ................ 37

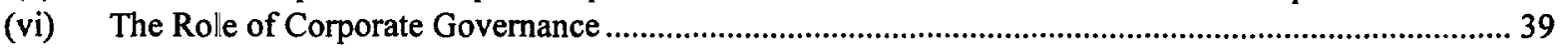

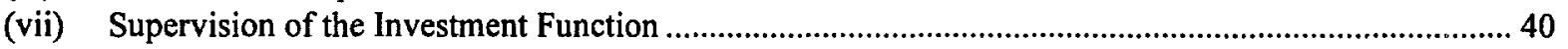

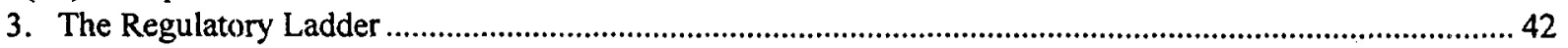

4. Property/Casualty Insurance: Specific Supervisory Issues ...................................................................... 44

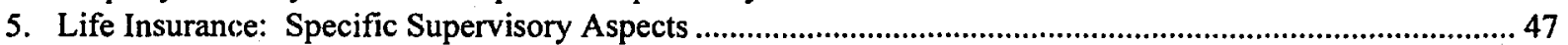

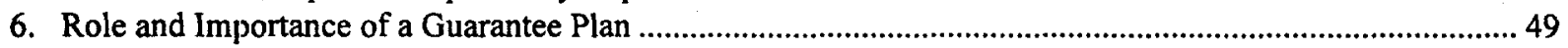

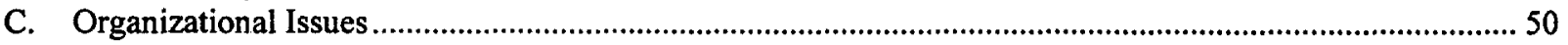

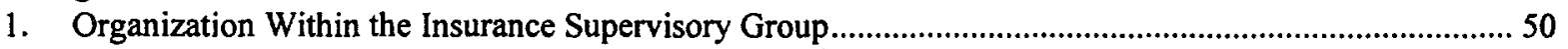

2. Relationsh.p of Marketplace Supervision to Solvency Supervision ...................................................... 53

3. Insurance and Banking Supervision Within Same Organization ................................................................ 54 


\section{Re-Engineering Insurance Supervision}

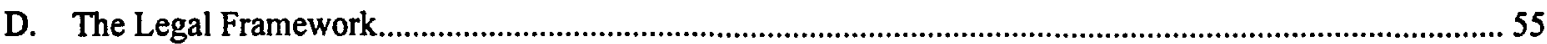

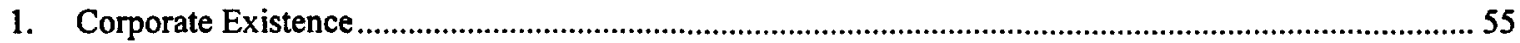

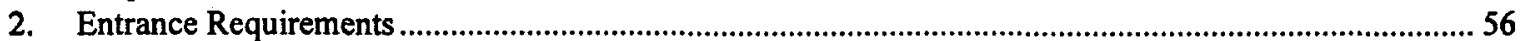

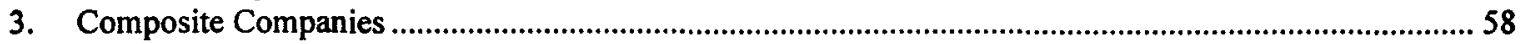

4. Minimum Capital Requirements............................................................................................................. 58

5. The Role of Corporate Governance: The Canadian Model .................................................................61

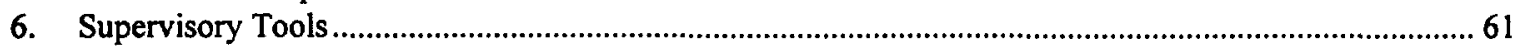

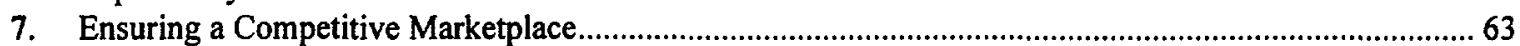

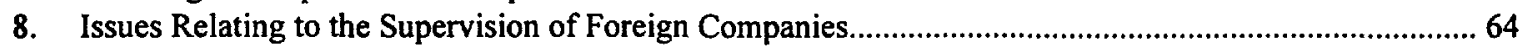

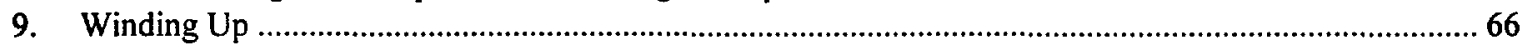

E. The Time Horizon: Developing a Supervisory Strategy ..........................................................................67

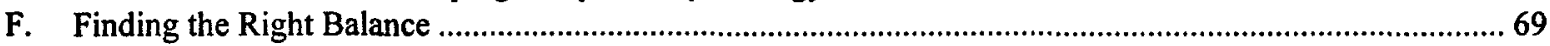

IV. Issues in Marketplace Supervision ....................................................................................................... 70

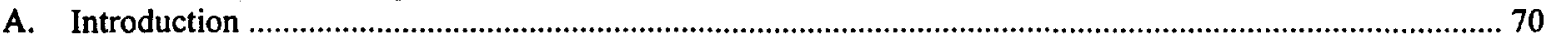

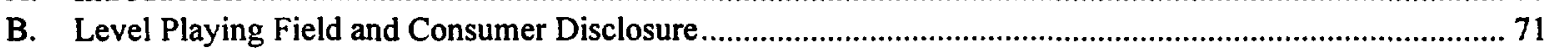

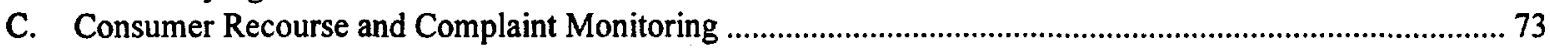

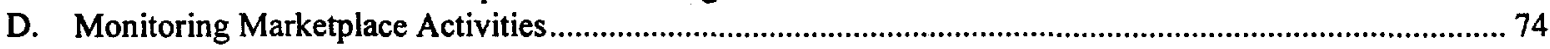

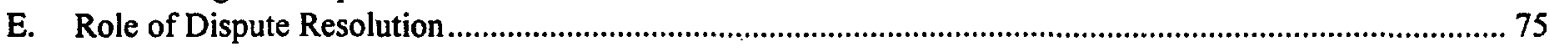

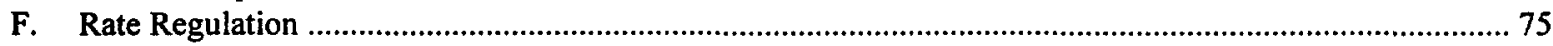

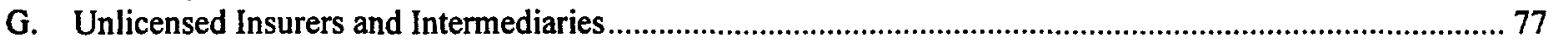

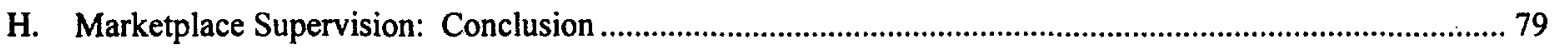

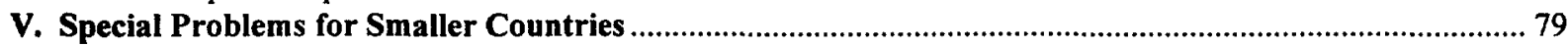

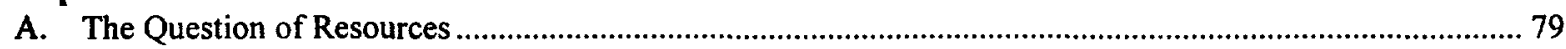

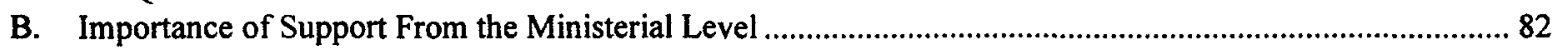

C. Building Professional Support for the Supervisory System..................................................................... 83

VI. Special Supervisory Requirements in the High Inflation Environment..............................................

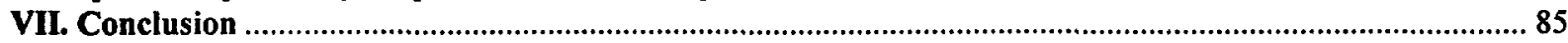

Appendix $1 \quad$ Corporate Governance As a Key Supervisory Approach

Appendix $2 \quad$ Early Warning Ratios for P/C Insurers

Appendix 3 The Regulatory Ladder

Appendix $4 \quad$ The Claims Run-Off Exhibit

Appendix $5 \quad$ Staffing and Organizational Structures

The author would like to express his appreciation for the support, review and helpful comments ha has received during the preparation of this paper. In particular he would like to thank Kim Staking at IDB and Don Mclsaac, Rod Lester and lan Webb of the Insurance Practice Group at the World Bank. 


\section{Introduction, Objectives and Summary"}

\section{A. Introduction: Emerging Demand for High Level of Insurance Supervision}

The insurance industry in Latin American, the Caribbean and other emerging markets will continue to expand with the widespread emphasis on private sector development. Risk transfer services are increasingly in demand, and attention is increasingly being focused on the potential fragilities in the industry and the role of insurers as financial intermediaries. There are a number of important factors leading to this surge in demand for insurance products:

The development of private pension funds that depend on a vibrant, competitive insurance industry both for the provision of disability insurance and more especially for the provision of life annuities based on the built up value of the pension reserve;

$凶$ A movement towards the privatization of insurance services traditionally offered by the government (e.g. health insurance, worker's compensation, etc);

冈 Privatization of state owned enterprises (which as privatized entities will demand access to insurance coverages);

$凶$ Rapid growth in the private sector generally;

冈 A growing middle class which will increasingly seek insurance protection for their assets and savings products for their future; and

冈 Increasing availability of foreign investment capital to fund development.

Much of the demand will be for competitively priced risk transfer and risk management services offered by property/casualty insurers. After all, the primary function of property/casualty insurance is to transform the uncertainty inherent in a situation having a low probability of catastrophic loss (for example, the slight chance that all of a business's capital is lost as a result of a fire), to the certainty of a small loss (the business pays an insurance premium to protect against loss by fire). Without access to the risk spreading mechanism of insurance coverage, the chance of catastrophic loss would curtail major capital projects and business ventures.

\footnotetext{
- Lawrie Savage is a former Superintendent of Insurance for Government of Ontario. Lawrie has over 30 years of experience in the insurance industry and has held senior positions in both life and property/casualty insurance fields. He was CEO of a life insurance company for several years and for 8 years directed the Federal Government's supervision of property and casualty insurance companies in Canada. More recently, he has managed a number of consulting assignments in developing countries, assisting with the 're-engineering' of the insurance regulatory function.
} 


\section{Re-Engineering Insurance Supervision}

An additional challenge is that many countries have recently privatized or liquidated state-owned insurers and/or reinsurers (or are in the process of doing so) and are encouraging competition in both primary and reinsurance markets. Thus in many countries we have the dual problems of an insurance industry having to adapt to the new realities of a private marketplace, while at the same time attempting to meet the rapidly increasing need for insurance referred to above.

In these circumstances there will be significant pressures on insurance supervisory systems. Unfortunately, however, in many cases the sophistication of government insurance supervision does not reflect the growing importance of the insurance business to the countries concerned. Many supervisory agencies are considered ineffective and are not ready to take on the additional responsibilities associated with growing and changing markets. There is often a lack of clarity regarding primary supervisory tasks and how these can best be accomplished. Many agencies do not have adequate financial resources nor the operational independence needed to undertake effective supervision. Information gathered by the supervisor is often inadequate, both in terms of the quality of data and the timeliness of reporting. As well, information technology is generally not utilized to increase the efficiency and effectiveness with which financial data can be analyzed and acted upon. Likewise, supervisory agencies are often lacking (in both number and quality) the well trained, motivated personnel needed to oversee the insurance industry.

Thus in these countries we have on the one hand, surging demand for private sector insurance facilities, and on the other, a frequent inability of governments to ensure that the subject institutions will actually be in a position to fulfil the needs they are intended to serve. In developed countries it has been found by experience that a sound insurance supervisory system, encompassing concerns related to both solvency of insurers and their conduct in the marketplace, is an important factor in maintaining public confidence in the financial sector and ensuring that foreign investment is not discouraged.

One can argue that insurance supervision in the emerging country context is even more vital than in developed countries: there is greater need to build public and international confidence in the quality and soundness of financial institutions. Insurers must be able to fulfil their role in the spreading of risk, thereby protecting invested capital and facilitating the growth of businesses, as well as providing the public with high quality investment vehicles and life insurance for estate planning and other purposes.

\section{B. Objectives of Paper: Best Practices in Re-engineering the Supervisory Function in the Developing Country Context}

In light of the foregoing, there is a demonstrated need for a comprehensive paper dealing with issues that commonly arise in the development of insurance supervisory systems in emerging countries. Many such countries recognize the importance of this matter and are currently struggling to put in place supervisory systems that will facilitate the growth of a sound private insurance industry within their countries, while also providing protection for consumers of insurance products. 


\section{Re-Engineering Insurance Supervision}

Consumer protection really has two aspects: (1) protection against losses arising from the insolvency of institutions and (2) protection against losses caused by fraudulent practices and other market conduct abuses. Both solvency supervision and market conduct supervision have a role to play in underpinning an insurance industry that is vibrant, financially sound and entitled to the confidence of the insuring public. In turn, an industry having these characteristics will benefit the nation by facilitating foreign investment and providing a sound financial infrastructure that will benefit the economy as a whole.

In the area of insurance market supervision, the Inter-American Development Bank and the World Bank wish not only to be able to document issues and to provide an overview of various approaches that might be considered, but in fact believes that the need is for a more comprehensive cataloguing of best practices in these areas. That is the objective of this paper.

\section{Summary}

The nature of insurance supervision in developed countries has changed considerably in recent years. Governments in the United States, Canada and Europe have conducted extensive investigations into the circumstances which have led to the collapse of major financial institutions. Flowing from these investigations has been a growing recognition that a new supervisory paradigm is required. In the "Legal Framework" section of this paper the Canadian situation is presented as an example -- one the writer happens to be familiar with -- to illustrate how market forces have led to the development of just such a new approach. Whether one looks at the Canadian experience or the experience in other countries, however, there is a common thread running through the conclusions of virtually every developed country that has studied these matters. That is that the old style of financial supervision, which tended to be very broad in scope and highly oriented towards verification of data, must be replaced by a much more focused, higher level approach which targets insurer solvency through attention to management performance and business strategy. The latter areas become the key recipient of supervisory attention. Financial supervisors in these jurisdictions now see their primary task as gauging the financial risk or risk profile of each company, and then allocating the bulk of their available resources to the higher risk situations.

As they look at these higher risk situations their objectives will be to understand the business strategy, to assess the competency of senior management and their appetite for risk, and to generally be in a position to assess the future outlook and financial viability of the companies. An underlying assumption is that the independent auditors and actuaries will be doing their jobs, which provides the supervisor with a high degree of confidence that the data being reported to the supervisor is reasonably accurate and that reserve amounts are within professionally acceptable tolerances. (Naturally there will still be some checking of the data by the supervisor in order to confirm that the confidence has not been misplaced.)

It is probably fair to say that this new supervisory paradigm has developed in two stages. In the first stage one typically sees a number of well thought out amendments to insurance acts, increasing the powers of the supervisors, limiting the extent to which insurers are able to enter 


\section{Re-Engineering Insurance Supervision}

into transactions with related parties and introducing more sophisticated and more stringent minimum capital requirements. The second stage tends to have been driven by a combination of increasing fiscal pressure on governments, so there is a perceived need to limit the cost of regulation on the one hand, and, we think even more importantly, by a recognition that many insolvencies could not have been prevented by the supervisors, even if substantially greater resources had been available to them.

On this latter point, one sees ample evidence that most of the problems of financially troubled companies are attributable to the introduction of (what turn out to be) unprofitable products, uncontrolled expansion, self dealing and other circumstances related to the institution's business strategy and internal culture. Concerns in these areas are of a sort which do not lend themselves to straightforward legislative solutions. Nor can one expect that these types of difficulties would be adequately remedied merely by having more supervisory staff, or better computers, or more supervisory resources in other areas. Thus the need to limit the cost of supervision, together with the realization that company's business plans and strategies were central to the achievement of supervisory objectives, has led supervisors and governments to conclude that supervisory resources need to be more focused, and especially more focused on the assessment and evaluation of the company's management and business strategy.

This paper discusses the upgrading of the supervisory function in emerging and developing countries from the perspective of the new supervisory paradigm. There are two distinct components of the upgrading process, although portions of each component can proceed on an independent basis. One component is to upgrade the legislation in order to give the supervisors additional powers corresponding to those that have been recognized as necessary in developed countries. The second component is to improve the efficiency and effectiveness of the supervisory process itself. The paper describes both components in detail and discuss strategies for design and implementation.

On the legislative side, in addition to strengthening the powers of the supervisors in specific ways, we recommend an approach which stresses improved transparency and higher standards of corporate governance -- the placing of more responsibility on boards of directors and management for ensuring that their institutions are operated in accordance with standards of sound business and financial practice. This of course implies the existence of appropriate sanctions on boards of directors and managers that do not maintain such standards.

In terms of increased efficiency and effectiveness, the focus of the paper is on techniques that will improve the supervisor's ability to understand the financial institution and its business strategy and so to be better able to anticipate the onset of financial difficulties. We recommend the use of the Regulatory Ladder as a means of formalizing the supervisory approach to financial risk and ensuring consistency of response over time and relative to the risk profile of the insurer. We strongly encourage the establishment of regional supervisory organizations which will help lead to greater harmonization of supervisory techniques and especially, to harmonization of the financial filings required from insurers. We discuss resource requirements and sources of information and assistance to the supervisory authorities. Techniques for financial and ratio analysis are described, as are some of the ratios themselves, as well as the processes and 
procedures pertaining to the on-site inspection of companies. The roles of the independent auditor and actuary are also important in the modern approach to supervision, and this is an area where emerging countries often face a significant difficulty. Frequently, entrance qualifications and standards of practice for auditors and actuaries are not at the same level as in developed countries, so developing country supervisors may not be able to place the same degree of reliance on their work. Nevertheless, our consulting experience in smaller and developing countries leads us to believe that fairly rapid progress can be made in raising the standards -- it is clearly in the interests of these professional groups to be able to assume more responsibility in the overall supervisory process.

The time horizon for change is also discussed. It is important to remember that major change cannot be effected overnight. On the other hand, new approaches can be phased in over time, and as will be pointed out, much can be done relatively quickly, so that in our estimation, within one to two years most jurisdictions should be able to advance to the point that the majority of their goals have been accomplished. Some aspects, such as raising the standards of auditors and actuaries, are within the realm of influence of the supervisor but not direct control, and a longer period of time may be required to achieve objectives in these areas. Another area for attention over the longer term is the need for improved co-ordination between banking and insurance supervisors. Likewise, time is needed by the supervisors to gain experience in the exercise of the new techniques and to build confidence in their dealings with the industry.

Developing countries are in an excellent position to benefit from the supervisory experiences of countries such as the United States and Canada. For developing countries especially, access to resources is a primary concern, and corporate practices are often strongly in need of improvement. Therefore supervisory methodologies that maximize efficiency and effectiveness of resource utilization, and which require companies to adopt higher standards of corporate governance, go to the heart of the problems faced by developing country supervisors. We believe they can move quickly, and hopefully on a harmonized basis with neighbouring countries having the same concerns, to implement the key attributes of these new approaches to insurance supervision.

\section{Basic Concepts}

\section{A. The Necessity of Supervision}

A system of insurance supervision is a system of oversight which is intended to ensure that to the greatest degree possible, (1) insurers will have the financial resources required to pay all claims as they become due (i.e. solvency supervision) and (2) insurers will treat consumers in an equitable manner in all financial dealings (i.e. marketplace supervision).

Supervision can, at one end of the spectrum, be through a governmental agency administered by public servants or, at the other end of the range, through self-regulation by insurers and their trade organizations. In between, there are many possible combinations where supervisory responsibilities can be shared by governments; by insurers' boards of directors through 


\section{Re-Engineering Insurance Supervision}

appropriate procedures of corporate governance; by independent auditors, actuaries and other professional advisors to the insurers; and by industry associations that can advocate member codes of ethics and other behaviour that will reinforce the objectives of supervision. This paper will comment on the extent to which possible interrelationships between these approaches can result in a more satisfactory system than one which relies on any one approach.

The business of insurance has a number of special features which make financial supervision particularly important. In transacting the business of insurance, the insurer receives premiums from persons and corporations seeking coverage. In the aggregate these premiums, together with investment earnings, should be sufficient: (1) to pay the claims that will be incurred during the terms of the policies, (2) to cover administrative and other expenses associated with the writing and distribution of the product, and (3) to generate a satisfactory rate of return to the shareholders of the insurance company or to fund future growth in the case of a mutual insurer (i.e. an insurer which is owned by its policyholders).

Because premiums are paid now, in return for a benefit which may not occur until many years in the future, the purchaser of insurance is entirely reliant on the expectation that the insurer will still be in business at that unspecified future date and that it will then have sufficient financial resources to discharge its obligation. In this changing and uncertain world it is not a foregone conclusion that this will always be the case, particularly having in mind the difficult and volatile economic circumstances that are frequently characteristic of developing countries. Nor can one rule out the possibility that negligence or unscrupulous behaviour, rather than difficult economic circumstances, will be the cause of the company's inability to pay. It is not surprising then that a system of supervisory oversight is required to help assure that a company having such important responsibilities to the public will be able to meet its financial obligations when called upon to do so.

In terms of marketplace characteristics there are also particular features of the insurance business, different from other types of financial institutions, which suggest that a supervisory system will be required. When a consumer deals with a deposit taking institution such as a bank or credit union, there is not a great likelihood of dispute -- the consumer has made a deposit, has evidence of having done so, and the institution is clearly obligated to return the deposit upon demand or subject to the particular conditions governing the transaction.

By contrast, an insurer is providing indemnity with respect to circumstances that are often much more complex than a banking transaction and to protect the company, many exclusions and other terms of coverage usually apply. (These terms of coverage also protect the consumer in the sense that for an open-ended contract providing extremely broad coverage, the claims payments will be extremely high, in turn giving rise to very high, if not prohibitive, premium levels.)

Unfortunately, these contractual complexities tend to put the insurer in a position of strength when it comes time to settle a claim. The insurer has the legal and financial resources to dispute a claim, even if on a technicality. Also, the insurer has possession of the funds and the policyholder is dependent on the insurer to gain access to them. By unfairly resisting claims an irresponsible insurer is therefore in a position to retain funds rightly due to policyholders and it 


\section{Re-Engineering Insurance Supervision}

can be difficult for policyholders to protect themselves against such abuses.

Thus we see that in assessing the risk of both insolvency and unfair consumer treatment, there are special reasons why insurance supervisory systems are important in building public confidence and providing the stability of financial infrastructure that every country finds desirable.

\section{B. The Role and Importance of Insurance Supervision in Developing Countries}

Developed countries have a long tradition of insurance supervision. For example, in Canada the first federal Superintendent of Insurance was appointed in 1876, only nine years after the country was formed. Countries in Europe witnessed the growth of the insurance industry from the early 1700 's and along with that, experienced many practical difficulties in terms of losses to the public and various financial scandals. Thus they had many years in which to learn about the benefits of a sound supervisory regime.

Developing countries are in the difficult position of trying to "catch up" in an economic sense with the developed countries. They therefore face the huge challenge of having to bridge within a few years, a transition which the developed countries managed in several hundred.

Nevertheless, most developing countries are now of the view that to meet these challenges, they must not be left behind as countries world wide scramble to participate in the global economy.

Realistically, this brings with it a need to ensure a stable financial environment; otherwise foreign capital will be reluctant to find a home in the country. While it is widely recognized that appropriate standards of banking supervision are critical in this regard, our observation is that insurance supervision also plays an important role in meeting the needs of foreign investors.

There are two reasons for this. First, sound programs of risk management are seen by modern businesses as an essential part of their corporate responsibility. As has been described above, given the nature of the property/casualty insurance product, insurance protection tends to play a central role in their risk management programs. Therefore today's corporations attach considerable importance to the insurance regime. As with banking, they see the health and financial strength of the insurance industry as a proxy for the financial stability of the country itself.

The second reason that insurance supervision is so important in a developing country is that the world is changing very rapidly, and lost opportunities at this juncture may be opportunities that will never come again. Where the insurance industry has seen public outcry and suffering as a result of a large number of insurer insolvencies, it is a red flag to prospective investors. Those who control large flows of capital in developed countries know that their shareholders expect careful stewardship of their funds. They will be loathe to commit their financial expertise and money in any environment which lacks financial stability. If they do so they will be open to criticism from shareholders and possibly even exposed to legal liability if the corporation suffers any major losses as a result of its activities it the jurisdiction. 


\section{Re-Engineering Insurance Supervision}

\section{What are the Objectives of Supervision? Are Objectives Different in a Developing Country from those in a Developed Country?}

One might be inclined to quickly venture that the objective of insurance supervision is to make sure that insurance companies remain solvent and that insurance consumers are fairly treated. Obviously that's an important part of it, but in our experience such a simple statement over estimates the capability of an insurance supervisory system. It's a complicated world we live in, and insurance regulators certainly don't know all the answers (anymore than anyone else does).

A supervisory system that is overly conservative -- designed to avoid failures at any cost -- will stifle competition, rule out foreign expansion by domestic firms and give rise to excessive supervisory expense, which in the long run will have to be borne by the public. Systems which attempt to regulate every aspect of corporate activity are, in our view, doomed to failure as they overlook the necessity of innovation and creativity in any corporate system that is to be vibrant and healthy.

At the other extreme, an overly permissive system will lead to an increase in the number of company failures. The costs will show up as direct losses to the public by way of unpaid claims, along with a general loss of credibility and confidence in the financial infrastructure of the country as a whole, with potentially incalculable loss.

The objective is to develop a set of rules that will strike an appropriate balance between the public policy aims of ensuring strong financial institutions and public protection on the one hand, and competitiveness, entrepreneurial spirit and efficiency, on the other. We see this as an objective which is independent of the current state of economic development in the country concerned. In fact, given the fragility of the economies in many developing countries, one can argue that these concerns are more important in those circumstances than in the robust economic environments of most developed countries.

Having said this, at a level of detail there will certainly be differences between developed and developing countries in terms of what is practicable, depending on the stage of development of the country and its insurance system. For example, in Appendix 1 of this paper we provide a summary of the Canadian approach to financial supervision, which draws heavily on procedures of corporate governance and the role of the independent auditor and actuary. While such a system has many advantages, there are also aspects of this system which present difficulties for some developing countries in terms of current implementation.

While imported solutions from developed countries may not be instantly applicable, neither should they be dismissed too quickly. Because financial institutions in developing countries are probably subject to more stresses and strains than in other countries, the supervisory system must be robust, containing checks, balances and incentives that will lead to a healthy financial sector. We believe that a system which incorporates an increasing component of self regulation through procedures of sound corporate governance is more likely to be able to cope with the growing complexity of a rapidly emerging financial sector (particularly given the scarcity of government resources that are typically allocated to the supervisory system) than is one which relies more or 


\section{Re-Engineering Insurance Supervision}

less totally on government supervision. In other words, even what may at first appear to be quite a sophisticated supervisory system from a developed country, may be able to provide a highly relevant model for a developing country, subject to the need for the phasing in of certain aspects over a period of time.

As mentioned, developed country models generally place considerable reliance on the role of the auditor and actuary. This type of approach can also be relevant in the developing country context because national organizations of accountants, auditors and actuaries in each country tend to be extremely supportive of upgrading the professional skills and standards of their members. Not surprisingly, they will be prepared to dedicate resources to approaches that result in a more significant role for their members. Even so, it will take time for professional organizations to upgrade the standards for their members to a level commensurate with the responsibilities envisaged in the developed country models. In thinking about the achievability of this objective, one should keep in mind that most major professional firms are represented in developing countries and these firms typically do have local personnel whom they have trained to their firm's world wide standards. As well, these firms have significant financial resources on an international basis to support the development of their organizations.

We believe the odds are good that programs can be put in place that will, over a reasonably short time horizon, lead to the development of a professional advisory group which will be able to assume an increasingly responsible role in the supervisory structure. In most countries we think the fundamental conditions are in place to make the emergence of a so called "developed country" model feasible, perhaps not today, but quite possibly in the near future.

In summary, we think it is important to design supervisory systems in developing countries in such a way as to lay the foundation for systems which will be as efficient and effective as possible in the future. Thus we favour supervisory approaches that recognize current realities, but which have the potential to evolve fairly quickly to more modern supervisory techniques.

\section{Typical Supervisory Challenges in Developing Countries}

The following areas typically represent the key challenges for supervisory systems in developing countries:

Unreliable data or absence of data from insurers, needed by the supervisor for proper analysis and monitoring of the industry;

ॠinancial data that is not timely, either when it is received by the supervisor or by the time the supervisor is in a position to take action on it;

囚 Outmoded legislative requirements that do not reflect the attributes either of a modern supervisory system nor recognize the needs of a healthy, vibrant insurance industry; 


\section{Re-Engineering Insurance Supervision}

\istorical lack of determination in pursuing those who fail to comply with existing rules, so that even if rules are updated, the supervisor lacks the confidence or doesn't have the experience needed to enforce them;

The legal system itself may contribute to a lack of determination by the supervisor if the enforcement of legal contracts within the country tends to be a frustrating and difficult process;

\ Supervisory personnel require training and upgrading of skills;

Supervisory personnel are not adequately compensated, even by the standards of their own countries, so it is difficult to attract and retain high calibre personnel;

$凶$ Professional standards of financial reporting, auditing and actuarial reporting are not consistent and cannot be relied upon by the supervisor;

凶 Boards of directors frequently lack independence from shareholders and management and so are often not in a position to provide direction and leadership; and

凶 Supervisory personnel require greater access to computer systems in order to analyse and monitor financial information efficiently and effectively.

These are fairly serious potential issues. Nevertheless, with reasonable allocation of resources and goodwill, all can be overcome. With many of these issues, important improvements can be effected relatively quickly. Others are more systemic in nature. In the case of issues that can be dealt with relatively quickly, it is often just a matter of the regulators having the opportunity to work with someone who can provide guidance and assistance as to the steps that need to be taken. In other cases there will have to be an investment over time, as new skills are learned and the ground work is laid for the implementation of new ways of doing things. And as we've already noted, changes will not be limited to the supervisory body: insurers and their professional advisors also have an important role to play in the upgrading process.

One issue not listed above, but which in practice is extremely important, is the tendency in many small and developing countries to have insurance supervisory personnel graded at very low levels in the overall structure of the public service. It will obviously be very difficult to retain competent staff when job grades, and therefore pay levels, are low relative to the responsibilities inherent in the positions. This has typically not been a problem for bank supervisory personnel, because of widespread recognition of the importance of having sound bank regulation. However, insurance supervision is also important to the overall financial health of the country. Insurance supervisors must be compensated on a scale which is reasonable within the context of the government concerned and which is also not extraordinarily out of line with pay scales in the insurance industry. This point is discussed in more detail in Part V of this paper, "Special Problems of Smaller Countries". 


\section{Re-Engineering Insurance Supervision}

\section{E. The Role of Self-regulation}

We are not aware of many self-regulatory models for solvency supervision, although one could argue that the corporate governance model described later in this paper is actually a step in that direction.

In terms of market conduct supervision, however, self-regulatory organizations are quite common in developed countries. We are speaking here of special purpose organizations having self-regulation as their only responsibility, as opposed to a trade associations, which tend to be in a conflict of interest position if they have self-regulatory responsibilities. Self-regulation of intermediaries can have a number of important benefits:

Мembers of the industry will almost always have a better sense than a government supervisory body as to where the real problems lie.

冈 An enlighteried industry will recognize that poor practices reflect badly on all, and that it is in the long term interests of the industry to raise the standards.

\elf-regulation may cost the system less than government supervision because it may tend to be more efficient (although this is not necessarily the case).

囚 Self-regulation shifts the cost burden of supervision more directly to the industry, reducing the need for governments to allocate resources to this area (although some government oversight will usually be considered desirable).

The self-regulatory organizations with which we are familiar are created by statute and are subject to oversight by the Superintendent of Insurance or corresponding official.

A potentially major disadvantage of self-regulatory models is the extent to which they can actually carry out their responsibilities in an unbiased manner. If the industry group is mature and professional the problems will be less. On the other hand, if the group responsible for selfregulation see their involvement as a means of achieving an advantage over their competitors, or as an opportunity to bend the rules to their own benefit, then the self-regulatory environment may well be worse for the public than a totally unregulated regime. The critical point is for the regulated group to recognize that an environment which is supervised in an unbiased and professional mariner is good for both the industry and the public.

To assist with the realization of this concept, it is usually beneficial to have a significant component of the self regulatory organization's board of directors comprised of public members who are chosen by the government. To maximize the credibility of the organization the government should establish criteria for public members. We have two suggestions as a starting point: (1) public members do not have a background, directly or indirectly, in the insurance industry and (2) public members have distinguished themselves as citizens. The latter could 


\section{Re-Engineering Insurance Supervision}

include someone who has taken a leadership role in a charitable organization, a business person, a lawyer, a doctor, nurse, school principal, teacher, etc. The public component is required to ensure both fairness and the perception of fairness by the public.

In some cases it may be possible to facilitate the creation of a self regulatory infrastructure by offering to the supervisory staff currently involved in agent/broker affairs, the opportunity to transfer to employment with the new self regulatory organization. If specialized software has been developed for use in intermediary licensing or related applications, a new self regulatory organization may be interested in exploring the possibility of acquiring it rather than having to find or develop new software.

Usually the supervisor will have to go part way down the path towards self regulation, by way of working groups, hearings and so on, in order to form an opinion as to whether there is a reasonable possibility that self regulation is a real alternative, given the nature of the group involved. Often there will be a certain amount of controversy amongst the agent/broker group as to whether self regulation would be a good thing, especially if there are concerns about fair treatment.

\section{F. The Role of External Auditors and External Actuaries in the Supervisory Process}

As with self-regulation, the interposition of other professionals into the supervisory process can save considerable resources of governments and leave the supervisors with more time to deal with the important issues -- such as assessing the business prospects of insurers and working closely with insurers to overcome identified problem areas.

We make the point several times in this paper that the "old style" system of insurance supervision was largely based on verifying figures, checking numbers, making sure everything balanced and other similar activities. These activities were data focused rather than analysis focused, they contributed little towards helping the supervisor gauge the extent of financial risk present in a company, and most importantly, they had little impact on changing the behaviour of companies. The "new style" of insurance supervision focuses resources at a high level within the company, on the areas of greatest financial risk, and tends to use supervisory resources for the purpose of effecting positive change in the supervised company. When we speak of "high level" we mean areas such as management decision making and planning, and we are concerned with such supervisory techniques as business plan analysis, discussion of business alternatives with management, financial analysis, the company's strategic planning process and so on.

In order to move from "old style" to "new style" supervision, much greater reliance will have to be placed on the professional auditors and actuaries. The checking and verifying of data, the assurance of appropriate financial control systems and the like are their professional responsibility. The supervisor will not be able to devote the required resources to the types of activities described generally in this paper if most of the supervisory staff are still employed in activities related to the checking and verifying of data. Most often the supervisor hasn't made the transition to the new style because of a belief that the professional advisors do not have sufficiently high standards that they can be relied upon to carry out the responsibilities described 
above. In many developing countries this may be correct. Steps that can be taken to help bring about the necessary transition are discussed further in a number of sections of this paper.

Note also that the shift in supervisory paradigms outlined above mirrors what has occurred in the area of banking supervision, and for the same reasons.

\section{G. Time Horizons and Prioritizing of Key Issues, Challenges}

Considering the issues and challenges discussed in the above three sections, we can say that upgrading the financial package for filing with the supervisors, modernizing the legislative framework and providing an appropriate level of technical support, are all areas which can be readily addressed and in which significant improvements can be effected within a relatively short period of time, say over the course of one to two years. Upgrading of professional skills can also be accomplished within this time frame if suitable arrangements can be put in place. The establishment of a self regulatory organization capable of supervising agent/broker affairs may take somewhat longer because there is usually no existing infrastructure upon which to build. Also, if the supervisors are busy with other elements of the change process, there is only so much that can be done at one time. The aspect of the upgrading process that is likely to take the longest time to accomplish is the improvement of professional standards for auditors and actuaries. This is a process that the supervisor can encourage and facilitate, but which ultimately will have to be driven by the professional organizations involved. We discuss this transitional process in more detail below, but we are optimistic that with the experience of the developed countries to serve as a model, the process may take place much more quickly than was the case in those countries..

In terms of priorities, the upgrading of the financial reporting package is a good place to start. This is because it is usually within the authority of the supervisor to modify, and as mentioned earlier, sound decisions cannot be made without sound information. The ability to carry out ratio analysis and monitor other financial trends is a matter of training and understanding, but cannot take place if the basic information is not being received by the supervisor. If supervisory training programs are organized too early in the re-engineering process, the new learning will not be able to be applied until other changes have been made, by which time much of the impact of the training may have been lost. For example, if training in computer based financial analysis is provided before the financial reporting package has been redesigned to provide the required information for analysis, there will be nothing for the newly trained employees to work with. If there are then delays in effecting the required modifications to the financial reporting package, some of the trained employees will have moved to other positions and those remaining will have forgotten much of what was learned. Problems such as this can greatly reduce the effectiveness and increase the overall cost of upgrading the supervisory system and it is important that they be avoided.

Working with the professional associations to improve their standards is also a high priority because as mentioned, the shift from a data focused style to a high level, risk based style of supervision is going to be somewhat dependent on the supervisor being able to rely on the work 
of the auditors and actuaries. The supervisor can encourage and facilitate this process by means of appropriately constituted working groups and so on, in parallel with the other changes discussed above. Therefore, if all goes well, during the several year period which will likely be required to move through the entire process of regulatory re-engineering, the professional associations will have been able to revise their standards of practice and qualification requirements and will be ready to assume a higher level of responsibility in the new supervisory system.

\section{H. The Process of Change}

It is well known that the process of change is difficult and always gives rise to uncertainty and concern for employees. A major undertaking such as broadly re-engineering the supervisory process will certainly be seen as a major change by all who are concerned with the supervisory system, including the supervised companies.

It has been found by researchers that one of the most powerful ways of dealing with the anxieties brought about by wholesale change, is communication. When engaged in the processes described in this paper it will be extremely important to continuously update employees about what is happening and what is expected to be happening in the coming periods. Training opportunities should be especially emphasized because many employees will have concerns about whether they will be able to understand or master the "new procedures". This is especially true when computers and automation are involved, so considerable reassurance should be given. One project handled this problem by establishing an internal working group for each key functional area within the supervisory organization. The consultant then worked directly with the working groups as change occurred, and since the working groups were comprised of a cross section of employees from all levels of the supervisor's office, there was always a good understanding amongst staff members as to what was being done, when it would be done and why it was being done. This type of direct involvement provides ample opportunity for input and discussion and can have a major impact on the ultimate success of the project. The opposite end of the spectrum is when an outside consultant works closely with only one or two senior people in the supervisor's office, and those senior people don't communicate at all with their staff about the changes being discussed.

Industry members will likewise have to be kept fully abreast of what is happening. They should be aware of the objectives of the process because they should have played an important role in determining the changes that should be made. Incidentally, industry organizations are generally supportive of supervisory upgrading because they recognize that modern approaches to supervision are beneficial to the insurance industry. Nevertheless, in order to keep them in a supportive mode, frequent progress reports and periodic face to face meetings will be helpful. 


\section{Sources of Information and Assistance}

The office of the supervisor does not have to work through this process of re-engineering without the assistance of others.

Normally a consultant with direct experience in financial supervision and with experience in the upgrading of supervisory systems will need to be involved, if only for the purpose of having had hands on experience in a number of similar situations. The outside consultant should work with the supervisors (including a cross section of supervisory staff as mentioned above) as a resource person and provide an on going sounding board for discussion of ideas and issues as they surface. The outside consultant should provide overall guidance without dictating how the project should be carried out.

Supervisors in other jurisdictions will also be able to be of assistance and in most cases are glad to lend a hand, either in terms of training or in terms of discussing their own experiences in supervisory upgrading. The outside consultant will likely have many contacts in the supervisory world with whom he or she can put you in touch.

There are also a number of organizations that can provide assistance. Most notable at the present time is the International Association of Insurance Supervisors (IAIS), which is very much concerned with the processes being discussed in this paper. The IAIS was founded in 1994 and has become a leader in the whole area of supervisory upgrading. Recent papers published by IAIS include "Principles Applicable to the Supervision of International Insurers and Insurance Groups and Their Cross-Border Establishments", "Guidance on Insurance Regulation and Supervision for Emerging Market Economies" and "Insurance Supervisory Principles". IAIS also has an internet web site, which is at http:/www.naic.org/otherinf/iais/iaistoc.htm. The web site includes newsletters with information about supervisory changes taking place in various jurisdictions and other information of interest to insurance supervisors, especially those in developing countries. Because of the pressures and trends mentioned at the outset of this paper, many governments are presently interested in modernizing their insurance supervisory systems. The work of the IAIS reflects this trend and the web site material includes many cross references to work being done by other organizations and governments.

Industry associations can also provide assistance to supervisors. As we have mentioned, industry groups tend to be supportive of supervisory upgrading and will almost certainly be pleased to be consulted about any changes being considered. We believe supervised companies can be a very good source of advice, especially in terms of designing processes that will meet the needs of the supervisor while minimizing additional expense required for the insurers. (At the same time, we also believe the supervisor should not refrain from requiring the insurers to provide information which experience from elsewhere has shown to be invaluable for both the supervisors and the supervised. An example is the tracking of claims incurred by both year of reporting and year of occurrence, so that claims reserving can be accurately monitored.)

Professional organizations such as institutes of actuaries and accountants will also generally be agreeable to carrying out research and obtaining information from their members. This is 


\section{Re-Engineering Insurance Supervision}

especially true when they believe it will help to modernize the supervisory system and lead to an opportunity for their members to play a broader role in the supervisory process in the future.

\section{Issues in Solvency Supervision}

\section{A. Supervisory Infrastructure Issues}

\section{Resource Requirements of the Supervisor}

An insurance supervisory system can be thought of as corresponding to an investment advisor, mutual fund or other business that has as its objective the identification of investments that are expected to outperform the market. In the case of the financial supervisor, however, the task is to identify the companies that will under perform the market. But very similar techniques can be applied in each case. The investment advisor will use computer screening techniques to identify companies that have particular characteristics which, will, in the analyst's opinion serve as indicators of potentially superior performance. The financial supervisor will similarly consider various ratios and other financial indicators which experience, and sometimes more formal studies, have shown to be worthwhile indicators of approaching problems. As well, the larger mutual funds and other commercial investment advisors do not confine their investigations to a review of historical financial information and ratios. They know that one of most powerful ways to gain insights into a company and its prospects is to actually go to the company's premises to meet with management, assess their business strategy and generally "size them up".

Correspondingly, financial supervisors around the world have found that the on-site inspection is an invaluable tool in the identification of potentially problematic financial institutions.

It is with the key supervisory functions of analysis and inspection in mind that we must think about resource requirements. More specifically, the two functions are:

囚 On-site examinations or inspections: This work represents the "eyes and ears" of the supervisory process. One cannot have a real understanding of what is happening in a company without visiting its main office, meeting the management and observing how the business is being conducted.

×inancial analysis: The supervisor must assess the financial data for the institutions involved so as to identify disturbing or unusual trends which could lead to more serious difficulties.

The staff involved in these two functions are the heart of the supervisory system. Each area can in turn be further described in terms of required skills and training:

冈 On-site Inspections: Here our objective is to find out about a company's business, in real time. How is the company being managed? What is the culture in terms of its business practices, financial controls and other important characteristics of a soundly operated institution? 


\section{Re-Engineering Insurance Supervision}

How does the company market its products? Does the company have an explicit strategy for moving forward? These and many other questions can only be answered by going to the company, observing its operations and talking to the management.

(In some countries there is a differentiation between financial inspectors, who are primarily focused on financial controls and the accounting area, and actuarial or technical inspectors, who are particularly concerned with the accuracy of the company's reserve calculations and adequacy of pricing. For the purpose of this discussion we assume that one group of on site inspectors will be sufficient to deal with all the functional areas within the companies. However, the comments would not be significantly changed if the on site inspectors were comprised of several specialized sub-groupings.)

As to the backgrounds of such individuals, on the academic side we favour a mix of areas of specialization. 'This could include inspectors having university training in areas such as business, accounting, actuarial science and economics. For inspectors, industry experience is also a particular plus, for three reasons. First, company officials may be more forthcoming with someone whom they recognize as having "real world" experience. Second, the person with an industry background is liable to be more attuned to subtle environmental indicators within the company that could suggest the existence of problems beneath the surface. And third, with company experience, an inspector may be less likely to be deceived by unusual transactions which are intended to make it difficult for the supervisor to recognize what is actually happening.

At least as important as academic training or working background, however, we see the ideal inspector as a person who has a good understanding of industry practices, is well versed in the technical side of the business and, very importantly, is personable, friendly, outgoing and inquisitive. These latter characteristics are particularly beneficial for the inspector because his or her primary job is meeting with people and talking to them about their work, all with a view to understanding their business and learning about any prospective problems. Inspectors who spend all their time "checking numbers", to the exclusion of discussing issues with company management, are generally going to make a less significant contribution in terms of finding out about the business and gaining information about developing problems. As well, as part of the process of change, one of the objectives is to put processes in place which will lead to professional auditors and actuaries assuming more responsibility in terms of data verification.

\inancial Analysts: Here the emphasis is on financial and operational statistics, so rather than people who are skilled in drawing out information through discussion with others, one should generally be looking for persons who have the insight to recognize trends in ratios and other indicators which will give an indication of what may lie ahead. (Of course as in any job, an outgoing and friendly manner is never a disadvantage, whether one is an inspector or an analyst.)

As to academic training, particularly useful backgrounds can include finance, economics, investment analysis, mathematics, actuarial science and other similar disciplines. The persons concerned should be skilled in reading financial statements and knowledgeable about the various financial ratios and trends that are indicative of potential financial problems. (Much of the 


\section{Re-Engineering Insurance Supervision}

specific knowledge about the insurance industry will be learned on the job, as their are few academic programs that focus on this industry.)

$凶$ Information Technology Support Staff: Depending on the extent of computerization available, some specially trained IT staff may be required to keep the technology functioning properly.

In some marketplaces, reinsurance arrangements are crucial, either because primary insurers have not yet developed to the point where they have meaningful capacity, or because there are environmental factors such as a potential for earthquakes, hurricanes and so on, which make reinsurance an especially vital commodity. In markets such as these, and if the resources are available, a reinsurance specialty group (or person) can be very helpful to the supervisory organization. This is because reinsurance is a particularly complex area and the nature of the reinsurance arrangements can make a big difference to a company's financial results and its ability to withstand future financial stress. Evaluating these arrangements requires detailed knowledge and expertise. It is an area where industry experience is highly desirable.

Depending on the importance of the life insurance business in a particular marketplace, more or less emphasis may be placed on actuarial training for personnel. With such a large part of the life insurance balance sheet consisting of actuarial reserves, a certain number of actuarial specialists are required in the effective supervision of these companies. This is not only because of the actuary's special training and knowledge, which is obviously important, but in our experience also for credibility purposes in case of serious disputes. An inspector or other supervisory official, highly knowledgeable in the field, may be at a disadvantage when a serious disagreement with a company arises, simply because they do not have formal accreditation as an actuary.

It is important to note that the two key functions mentioned above, inspection and financial analysis, do not necessarily have to be carried out by different individuals. In many cases there will simply not be sufficient resources to permit the existence of two separately trained groups. With the growing sophistication of specialized software for financial analysis applications, it is becoming more feasible to have the inspectors also carry out the financial analysis work. However, if resources permit, it is generally considered desirable to use separate personnel for each function, primarily because different skills and aptitudes tend to make each group more effective in what they do. (See also "Organizational Issues" below.)

We have not mentioned a separate category of "administrators" but of course a certain number of support personnel will be needed to round out the organization. And all inspectors and analysts must have good administrative abilities.

Clearly, as with all organizations, at the senior levels financial supervisory staff must have excellent general management skills and the ability to deal effectively with people, both in the supervised companies, within their own organization and within the government as a whole. 


\section{Re-Engineering Insurance Supervision}

In addition to the need for sound training and appropriate credentials, it is extremely important for each functional group within the supervisory organization to communicate clearly and frequently with each other. The identification of higher risk companies, and the areas within those companies that are the most likely to give rise to difficulties, is an activity akin to completing a jigsaw puzzle. Each group uses its specific skills to obtain information about the companies and their operations. So each group may have a part of the picture, but the whole picture will not be recognized until all the groups contribute their particular pieces of the puzzle. Too often, inspectors and analysts don't communicate effectively, with each group seeming to believe that they alone are in a position to identify the important problems. Of course this is a further argument to support the idea of having one group of inspectors who carry out both the on site inspections and the financial analysis. On balance though, we think effective communications between specialized groups will provide the best results overall

\section{The Impact of Technology}

As mentioned above, one can take the view that the functions and objectives of the financial supervisor are analogous to those of an investment advisor. The ability to screen large volumes of financial information, to analyse trends in ratios and to otherwise monitor large amounts of financial data, can only occur in an effective and efficient way with the use of modern electronic technology. Thirty years ago in developed countries, insurers filed detailed financial statements which were reviewed by analysts armed with pencil and paper (not even calculators!), who looked at a small number of ratios, most likely for the current year only. This was the best that could be expected with the resources available. (At the time it hadn't occurred to supervisors to require the insurers to do the analysis as part of their filing.) Given the large amount of information that was filed and the limited use to which it could be put, one might reasonably ask why the companies had to file it. We suppose the answer would have been "it will be available in case it is needed".

Today, with the help of computerized techniques, all of the data can be analysed in great detail and many important insights can be gleaned from the filings. As with every area of our lives, computers have given rise to an incredible growth in our ability to analyse and screen information.

A modern insurance supervisory office will typically receive electronically a well designed package of financial data annually from the insurers, with supplemental data on a quarterly basis. In many countries there is specific software available to companies, which takes the place of the "statutory form". The software used in Canada is probably representative of other countries, containing literally hundreds of cross checks, so that if the company attempts to make an entry which is inconsistent with something elsewhere in the financial statement, an error message will be generated, along with an indication of what needs to be done to correct the problem. Thus when the financial data is received by the financial supervisor it should be free of error. (Of course this signifies nothing about the underlying accuracy of the information, which is why professional auditors retain their important function.) As well, the software automatically takes care of all the arithmetic operations, carries forward balances and performs the other routine 


\section{Re-Engineering Insurance Supervision}

functions associated with completion of the return, including calculation of a whole series of early warning tests and other financial ratios.

The use of such software has not only been a boon for the companies in terms of completion time, it has also been another way of freeing up of resources for the supervisor -- in the past the task of checking arithmetic and other details of the filings represented a major expenditure of supervisory resources.

Typically the data received from the insurers will be stored electronically in a data base, so that application software can carry out pre-programmed routines such as the calculation of additional ratios and indicators.

Also typically, there will be the ability to carry out ad hoc analysis and screening of information in the data base. This is an important plus, because it is always difficult to say in advance exactly what types of situations might arise which will trigger a need for customized analysis. For example, if a major, publicly traded corporation becomes insolvent, it would be useful to be able to quickly find out which institutions have investments in that entity and whether any investments are sufficiently large to imperil the financial position of an insurer. Or if the supervisor believes there may be reason to be concerned about the financial experience being generated by a particular type of insurance product, specific tests could be developed to test this hypothesis against the companies' financial data.

Computer systems are also widely used in market conduct supervision. Systems are available which allow supervisory personnel in a call centre to receive telephone complaints and enquiries from the public, to enter information while the call is in progress, and to get instant feed back as to similar types of complaints that may have been received with respect to the same company, or different companies. As well, complaints can be tracked and tabulated, so that useful information can be generated in connection with trends and patterns of complaint activity. For example, if there are an unusual number of complaints about slowness in claims paying with respect to a particular company, it may be an excellent indicator of financial problems. Or if a particular company is receiving more than its fair share of complaints in respect of a particular product, the supervisor may want to look into the way the product is being advertised, its characteristics and so on.

We are of course describing here the potential of computerized systems. Most developing countries have not had the financial resources to make the required investment, nor are their personnel trained in the use of such systems. The latter situation is not difficult to overcome, as the move to so-called "GUI" or graphical user interface based systems (of which "Windows" is a good example) has greatly improved user friendliness compared with even a few years ago.

Thus with a week or so of training and some hands on experience, the average person can reach a level of reasonable utility. As well, the proliferation and rapidly decreasing cost of personal computers, which can be networked within an office, has had a tremendous impact on accessibility to computerized systems. 


\section{Re-Engineering Insurance Supervision}

In some countries there are commercial analytical packages, complete with data bases, which are sold commercially to insurance and reinsurance brokers, insurance companies, consultants and other parties who are interested in having the capability to analyse data pertaining to the insurance industry. In Canada there are two such systems. One is actually the entire data base as filed with the financial supervisors, complete with a sophisticated "browser" type software that enables one to look at the data from several different perspectives and then copy it to a spreadsheet for analysis. The other commercially available software includes a relatively large number of ratios and other pre-formated analytical routines, which can then, with a simple "click", be sorted, ranked and so on. Thus we can very quickly look at the performance of one company or a group of companies over time, compared to the industry or another group. We can look at the so-called "early warning indicators" (described in detail below) and many other ratios and financial indicators as well, and in each case have the ability to sort on the basis of different parameters, in ascending or descending order. We are currently exploring the feasibility of having this system redesigned for use by the regulators in a developing country, using the data base for the country's insurance industry. Early indications are that it may be a very economical way of proceeding, at least for a transitional period of a few years or so, which will enable the supervisor's office to gradually build a somewhat more specialized and comprehensive system for its own use.

\section{Staff Training and Upgrading}

We have already mentioned that training is one of the areas where supervisory staffs in developing countries are most in need. In developed countries the most basic training occurs automatically, without much need for special courses or programs. Supervisory organizations in these countries typically have well qualified, seasoned personnel on staff, so new employees are learning on the job under the watchful eye of these experienced staff members. The new employees will have already have the desirable technical and academic backgrounds, and most of the specialized knowledge in the supervisory area will be picked up on the job. Additional skills will be acquired by means of specialized seminars and other training.

In developing countries the situation is usually very different. Regardless of how long they have been employed, the supervisory personnel have usually not had the opportunity of working with well trained staff who are fully knowledgeable about modern methods of financial supervision. As a consequence it becomes a closed system: they have no one to learn from and so they do not learn. This is by no means any reflection on their abilities. It is merely a situation where they have no role models. In this circumstance, training plays a crucial role in upgrading the supervisory system.

There are several ways in which the knowledge base and job skills of supervisors can be enhanced. One is by means of arranging to visit with other supervisory bodies in developed countries. Much can be learned by informal discussions with these supervisors, observing how they carry out their responsibilities and possibly even accompanying them on on-site inspections. One difficulty is that, naturally enough, the developed country supervisors will have to put their 


\section{Re-Engineering Insurance Supervision}

own responsibilities first, and that may mean they will be able to accommodate a relatively small number of such visitors in any given year.

However, in developed countries there are usually many courses and seminars taking place on a commercial basis. Often these will be very useful for developing country supervisors to attend, provided they have first gained sufficient background and have the requisite language skills to ensure that they will benefit.

Supervisory organizations themselves can get together to organize seminars, inviting speakers from other countries to describe their supervisory techniques and approaches. The Comision Nacional de Seguros y Fianzas of Mexico recently hosted such a seminar in Mexico City for members of the Association of Latin American Insurance Supervisors. The seminar took place over five days, with speakers from the United States, Mexico, Canada and other countries.

In the United States there are organizations such as the College of Insurance in New York City, which puts on special courses for supervisory personnel, focusing on techniques utilized in the United States.

Also, we would certainly not underestimate the usefulness of taking courses that are primarily designed for industry personnel. A thorough understanding of the insurance industry, including its technical aspects, is a vital component of good supervision. Sometimes supervisors in developing countries seem reluctant to participate in such courses. In one country the industry was so enthusiastic about seeing the supervisors learn more about the insurance business, that they volunteered to run special sessions of their training courses for supervisory personnel only. Regrettably in our view, the supervisory group declined to participate.

There is also a great deal of written material available (mostly in English however), produced by various organizations that have education and training as one of their objectives. For example, the Life Office Management Association, or LOMA, based in the United States, offers a huge variety of written educational material to members, as well as seminars and other get togethers, where excellent speakers provide good information. LOMA has recently established a Latin American division and educational material is starting to be made available in Spanish. In the United States on the property/casualty front there is also the Insurance Accounting and Systems Association (IASA). The Risk and Insurance Management Society (RIMS) also holds well attended educational meetings. LOMA, RIMS and IASA are also active in Canada. Also, most countries have insurance institutes that produce booklets and other material that can be useful sources of training for insurance supervisors.

A training approach we have found to be very effective is the use of case studies, based on actual situations that have come to our attention during many years of supervisory work in Canada. The case study approach is good because it encourages discussion, it can be presented dynamically (for example, using different teams and role playing), and it is absolutely focused on the real life issues that can arise for the supervisor. Many lessons can be learned from the experiences of others. 
Some of the foregoing may sound daunting, but great strides can be made by explicitly focusing on the need to provide staff training. The process can be "jump started" by working closely with external advisors and supervisory mentors in other jurisdictions.

In closing this section it is well to reiterate the previously mentioned caution with regard to training. It is very important that the training take place at a point in the re-engineering process when staff members will be able to benefit from it. If the training significantly precedes the point in time when it can be applied on the job, much will have been forgotten by the time the opportunity to use the training actually arises.

\section{Economies of Scale and Other Benefits of Working on a Regional Basis}

An important problem in developing countries is the lack of financial resources that can be dedicated to re-engineering the insurance supervisory structure and process.

However, the needs in one country are likely the same as, or very similar to, those in neighbouring countries. Therefore one can greatly improve value for money by sharing resources and working together with countries in the same region.

Financial reporting is one of the most fundamental aspects of financial supervision. If a particular region is comprised of a number of relatively small countries, and if each country has different reporting and filing requirements, it is enormously costly and inefficient for the insurers that want to do business in that region. It is also inefficient for insurance supervisors to maintain the separate infrastructures needed to support their differing approaches.

Therefore harmonized reporting systems have advantages both to insurers and supervisors. The benefits can actually be more broadly based than the supervisory system itself, flowing to the entire country. This is because insurers want to do business on a regional basis, but if there is no harmonization of supervisory requirements they wiil probably select the one country they are most interested in and leave the others for the future. Or they may decide to bypass the region altogether as it's not worth their time to bother with the different information requirements of each supervisor.

Differing needs of different countries within a region can be met by adopting a consistent, harmonized, but modular approach to financial reporting. The first step is to agree on commonly acceptable accounting principles -- we think the best choice is usually international GAAP (or local GAAP if it is reasonably close to international standards). (For more discussion on basic approaches to firancial filing with the supervisors, see "Key Components: Financial Information and Reporting" below.) With the basis of reporting agreed upon, the question becomes how much information and exactly what information will be required by each supervisory group.

This is where the modular approach comes in. No doubt each country will want to receive a basic balance sheet and income statement, as well as some type of solvency or minimum capital calculation and a. listing of investments (call these items Filing 1). The somewhat larger countries will want to augment this by adding detailed exhibits by line of business (call this 


\section{Re-Engineering Insurance Supervision}

Filing 2). Finally, the largest countries in the region may wish to add to the package by requesting various analytical exhibits with respect to the adequacy of reserves, details of reinsurance arrangements, historical summary of ratios and key indicators, etc. (call this Filing 3).

The benefit of this approach for the companies is that they only have to prepare one set of financial statements for the entire region. Different countries within the region will be receiving different parts of the entire package, i.e. some will receive Filing 1 , some will receive Filings 1 and 2 and some will receive all three filings. But as long as they are all prepared on consistent basis it will be an efficient approach for the insurers.

Another major benefit of this approach is that each country will have loss statistics on a comparable basis, so that important regional trends can be analysed for economic purposes and for assistance in government planning. In the Caribbean, for example, regional statistics with respect to hurricane losses are difficult to prepare and interpret because each country tends to require its insurers to file different information, much of which is prepared on a different basis from one country to the next, with differently timed filings. The end result is that country to country information cannot be added together. So not only does the modular approach benefit insurers by avoiding the significant cost of having to prepare information on a number of different bases, but governments of the region also benefit by generating a larger pool of useful economic and financial information. Likewise, when they can get more meaningful statistics on regional loss experience, reinsurers may be able to better design their products to fit the needs of the region and to appropriately price those products. (If the reinsurers don't have ready access to data for pricing, they'll be hesitant to make their capacity available to local insurers. If they have to carry out their own studies, there will be a cost to be borne by the local market.)

Insurance supervisors will also benefit in a number of important ways. First, because the financial information is being prepared for a wider audience than one country, there is reason to believe the companies will be inclined to devote more time and attention to its preparation, thereby giving rise to more accurate and useful filings. Also, the auditing and accounting professions will become more knowledgeable about the requirements, since they probably operate on a regional basis, as do the insurers. Secondly, we talked above about computerization and the benefits that can be gained in that area. If financial information is harmonized on a regional basis, it becomes cost effective to design financial reporting and other software corresponding to that which is common in the developed countries. It will not be worthwhile for software developers to design unique systems for use in each small country. But if there are five or six countries that have agreed to a common financial filing on a modular basis, then it does become cost effective to provide the specialized software for all the companies that are operating within the region. Similarly for software to be used directly be the supervisors for analysis and monitoring. With the underlying information on the same basis, and utilizing a common format (albeit not every supervisor receiving the full package), we are now talking about the cost for one software package as opposed to one for each country. 


\section{Re-Engineering Insurance Supervision}

A further benefit for insurance supervisors is that they will have a larger pool for purposes of staff training. Clearly it will be more cost effective for a group of countries to get together for a training seminar than for each supervisory group to try to organize its own seminar.

In both the United States and Canada, the states and provinces, respectively, have the authority to stipulate their own form of financial filing. However, through the auspices of the National Association of Insurance Commissioners in the United States, and the Canadian Council of Insurance Regulators in Canada, harmonized forms of reporting have been developed. In these cases there is no "modular" reporting because each jurisdiction has the financial resources to look at all the information, as well as a large enough group of companies to make it worthwhile to do so. In Canada a number of provinces do have special information requirements, and these are simply handled by having a few additional pages "for completion only by companies licensed in...". The additional information continues to be on the same financial reporting basis, however. It merely pertains to additional information or calculations that are specific to individual provincial jurisdictions. On a world wide basis, the recent establishment of IAIS is, as mentioned earlier, beginning to act as a point of reference for the harmonization of approaches in insurance supervision. The interest of the Inter-American Development Bank and the World Bank in this area is also illustrated by sponsoring this paper.

The concept of regional harmonization can also be applied to the area of professional support. If auditors and actuaries are upgrading their professional standards in one country, there is much to be gained by extending the process to other countries that may be candidates for participating in a harmonized approach to supervision. If this is not done the scope of the harmonization process will be limited due to the inability of professionals in other countries to take on the responsibilities envisaged by the supervisors in the first country.

\section{B. Operational Considerations}

\section{Key Component: Financial Information and Reporting}

A vital component of every financial supervisory system is information about the supervised companies. The information must be sufficiently detailed to enable the supervisor to obtain a good understanding of what is happening in the companies. Also, the information must be sufficiently timely that it will still be representative of the current situation when it is filed with the supervisor.

The information contained in the supervisory filing is usually on one of two bases: Generally Accepted Accounting Principles (or "GAAP") or Statutory Accounting Principles (or "SAP"). In many countries the supervisor will stipulate the accounting rules that are to be followed, i.e.

SAP. We have already indicated that we think international GAAP is the best way to go, but we describe the advantages and disadvantages of each approach below.

The principle underlying SAP is what is often referred to as a liquidation basis. The supervisor is interested in seeing what the position of the company would be if it had to be closed down and 


\section{Re-Engineering Insurance Supervision}

liquidated. The idea is to write off assets that would not have any marketable value and to write down all other assets to the values that could be realizable on liquidation. There will frequently be specified rules for the determination of maximum asset valuations and write downs. For example, amounts due from agents will typically be disallowed if they have been outstanding for more than a certain number of days, regardless of whether or not there is evidence that they will be uncollectible. Similarly, amounts due from reinsurers that are not licensed in the jurisdiction may be given a zero value, even though there may be no evidence that the amounts will not be forthcoming.

On the liability side of the balance sheet there will usually be rules governing the setting up of additional liabilities or provisions. For example, some classes of business require the establishment of special reserves, even though it is recognized that there is no actual liability for these amounts.

In the income statement, statutory accounting requires that expenses be written off as incurred rather than being amortized over the period of time for which they are expected to provide benefits. Under statutory rules, therefore, a life insurance company will typically show that it is losing considerable sums of money as it builds its business in force because there are significant amounts of acquisition cost. These will be written off immediately under SAP, even though the business that has been placed on the books should produce profits in the future. This means that under SAP, life insurance profits will tend to be understated during a period of growth and overstated when business levels out or declines. The overstatement occurs because all the expenses will have been taken in earlier periods, so that the current periods have no acquisition expense associated with them.

A perceived benefit of SAP is that the statements so produced are very conservative, which is in keeping with the underlying objectives of the supervisor.

However there are a number of disadvantages to the use of SAP. Their conservatism is in some respects a two edged sword. If the supervisor wants to understand what is happening in the companies and to make the best possible decisions, then one might argue that more accurate information would be preferable to more conservative information. In a sense the financial statements provided to the supervisor are like gauges showing the performance of a machine. It is perhaps well to know that the gauges are reading on the conservative side, but one problem is that the degree of conservatism will depend on who is calibrating the gauges, and it is usually the companies because they prepare the statements. So while the supervisor will require a certain minimum level of conservatism through the use of SAP, there may be considerable variation in the extent to which companies exceed that minimum. Deteriorating trends in financial performance can be masked if a company is simultaneously moving from an extremely conservative position to the minimum required level of conservatism. Also we mentioned the situation with life insurance. When a company is expanding its business it will probably be showing losses on a SAP basis because of the cost of writing new business. But another company that is exactly like the first, but which is writing no new business will probably show significant profits because it will have little in the way of expense and is reaping the profits of business sold in past periods. However, is the second company really in a better position than 


\section{Re-Engineering Insurance Supervision}

the first? Most would suggest that writing no new business is not a healthy sign at all. The point is that while SAP is conservative it may not always be very accurate in terms of the information being conveyed.

That brings us to GAAP as a basis of reporting to the supervisors. A couple of key principles under GAAP which differentiate if from SAP (there are others as well) are the going concern principle and the matching principle. The first is an assumption that the company will continue to operate indefinitely into the future (as opposed to being liquidated in the near future under SAP). The second means that because the company will continue to exist, expenditures that will generate revenues in future periods can be amortized over the periods in which the benefits will be realized (as opposed to being written off in the period in which they were incurred as is the case under SAP). Use of the going concern principle, the matching principle and other principles underlying GAAP, produce more accurate statements of income than does the SAP approach.

In the view of most Canadian regulators (to say nothing of the insurance industry) GAAP reporting has brought a number of important advantages, summarized below:

$凶$ The accounting profession has greater resources than does the supervisor for research into accounting issues. When a complex issue arises -- accounting for financial reinsurance transactions is a good example -- the supervisory group in a particular country generally cannot allocate the financial or staffing resources required for its proper consideration, whereas significant resources are available to the professional organizations.

\The corollary to this is that under GAAP, the supervisor is able to focus more on supervisory and solvency issues, as opposed to accounting issues. Sometimes there are heated debates between the regulators and insurers when the regulators are setting the accounting rules, or for an unusual transaction there may be considerable uncertainty as to the accounting treatment that should be followed under SAP. Once you adopt a GAAP basis however, these kind of arguments largely disappear, because the supervisors will make whatever adjustments they wish when they are carrying out the statutory tests and other regulatory adjustments, but the company's income statement will not affected by the adjustments.

When there is a requirement for an independent audit of the filing submitted to the supervisors, as is the case in most countries, the professional standards and practices stipulated by the auditing profession for its members, will usually not apply if the form is not a GAAP statement. Our experience in Canada was that the statutory financial filing tended to be regarded by auditors as a "government form" rather than as a set of financial statements. Things which seemed to defy common sense were sometimes accepted by the auditor without comment. The response from the auditor might be "well we couldn't go along with that treatment under GAAP, but this is not GAAP, and as far as we are aware, it is not contrary to any accounting rule that the supervisors have stipulated as part of SAP."

- $\quad$ Related to that point is that when one does have a GAAP statement, all of the accounting principles and practices set out by the accounting institute for its members do apply. Thus when 


\section{Re-Engineering Insurance Supervision}

the auditor signs the statement, indicating that it "presents fairly the financial position of the company" (or whatever similar wording is used in the country in question) it means that he or she is satisfied that it is within the rules laid down under GAAP. Failure to abide with these rules may result in the auditor losing the right to use their designation as a professional accountant or other sanctions from the professional body. Also, not only is it the statement that will be filed with the supervisors, but also the one which will reviewed by management, circulated with the public, filed with stock exchanges and in short, used for all purposes of financial reporting. For these reasons, a GAAP based filing tends to receive the full attention of the professional auditor.

- When the statutory filing is on a GAAP basis, the main income statement and financial information being reviewed by the supervisor is the same as is being used for decision making purposes by company management, so everyone is on the same wave length.

- A further benefit of the GAAP basis of reporting is that it maximizes public understanding because there is only one set of numbers, prepared on a basis that is consistent with other public companies.

One cannot move from a SAP regime to a GAAP regime overnight. For example, if SAP has been in place, there may not be any specified rules under GAAP for insurance company reporting. This was the case in Canada and two working groups were established by the Canadian Institute of Chartered Accountants (the professional institute of accountants and auditors in Canada), one in respect of life insurance reporting and the other in respect of property/casualty reporting. These working groups included a number of professional accountants and auditors who had considerable experience in the insurance reporting area, members of the insurance industry with financial reporting responsibilities, as well as observers from the supervisor's office.

In the case of property/casualty insurance it took a year or so of discussion for the working group to spell out a detailed basis for reporting that would be in accordance with GAAP. This was circulated to all members of the profession, there was a period of discussion and finally a consensus was reached by the profession as to what would constitute GAAP for property/casualty insurers. The next stage was to work with the insurance supervisors to devise a method of reporting to them which would enable them to have the information they needed, without compromising the GAAP approach.

The compromise was to require companies to file the basic financial statements on a GAAP basis, but to have the statutory filing include a reconciling page to pick up all the areas of difference between GAAP and SAP. The net difference between the GAAP equity and what the equity would be on a SAP basis, is then carried to the GAAP balance sheet and shown as an appropriation of surplus. For example, if GAAP equity is $\$ 25$ million and SAP equity would be $\$ 5$ million less, the GAAP balance sheet shows equity of $\$ 25$ million, of which $\$ 5$ million is designated as a "Reserve Required by Regulator". The reader of the financial statements can therefore see at a glance that although the company has equity of $\$ 25$ million, from the 


\section{Re-Engineering Insurance Supervision}

perspective of the more conservative supervisory approach, $\$ 5$ million of that equity would, in the opinion of the supervisor, not actually be available if the company had to be liquidated. Since the company must also meet the various statutory financial requirements, the $\$ 5$ million amount is also not available to be paid out in the form of dividends.

In this way, supervisors can benefit from all of the GAAP advantages noted above, while also maintaining the benefits (from their perspective) of SAP. A further advantage is that readers of the financial statements actually have more information than would be provided by either GAAP or SAP on its own.

The process in the life insurance field was much the same, but it took significantly longer to develop a practicable approach, primarily because the actuarial reserves constitute such a large portion of the life insurance company balance sheet. Thus in determining GAAP for life insurers it was necessary to find a basis of actuarial reserving which could be accepted by accountants as being within the framework of GAAP. This was difficult to do because the actuarial profession, somewhat like the insurance supervisors, had long followed a conservative approach, as opposed to one which necessarily matched up well with actual economic conditions.

The breakthrough came with the adoption of what is called the Policy Premium Method of actuarial valuation. Essentially this basis of reserving uses assumptions which reasonably match expected future interest rates, mortality, lapse rates and so on for other key parameters. There is a relatively small amount allowed as an overall provision for adverse deviations in the assumptions. Then the reserves are adjusted each year to reflect the extent to which actual experience differs from that assumed in the actuarial reserves.

While GAAP reporting (ideally as close as possible to international GAAP) has broad advantages, it provides for a goodly amount of professional judgement on the part of its practitioners. A difficulty facing developing countries is that they may have a shortage of well qualified auditors and actuaries having the high professional standards required in a GAAP environment.

However, as with the corporate governance approach to financial supervision, we believe that one should not be too quick to dismiss GAAP reporting just because some initial conditions may not currently be met. In many of these cases, there is relevance to the saying "a journey of a thousand miles begins with a single step". By starting to lay the groundwork now, in terms of working with the auditing and actuarial professions, supervisors in developing countries can begin building towards a day when these professional groups can play a greatly expanded role in the supervisory process. In the meantime, much can be done to increase the efficiency and effectiveness of the supervisory process. This may be especially true in the property/casualty area, because in many developing countries the life insurance business is less significant than property/casualty insurance. Therefore problems in rationalizing GAAP with actuarial reserving should not be seen as a necessary impediment to at least moving ahead with property/casualty insurers. 


\section{Re-Engineering Insurance Supervision}

\section{Building the Supervisory System}

\section{(i) Financial Reporting}

As we have mentioned, a crucial aspect of improving the supervisory system is improving the quality, and often the quantity, of information received by the supervisor. We believe it is mandatory to have companies file financial statements in a format agreed with the supervisor (as explained above, we favour international GAAP). This is as opposed to merely filing a listing of specified data items as occurs in some countries. Absent a balanced (and audited) set of financial statements, there is no rigorous framework for data definition and the disciplines of accuracy and consistency can be expected to suffer accordingly.

As stated above, working on a regional basis in designing the supervisory filing is recommended because of the significant economies of scale that are achievable. (See "Economies of Scale and Other Benefits of Working on a Regional Basis".)

In short, the supervisor requires sufficient information to assess the financial positions of the companies and to monitor trends in performance so as to judge where the company is likely to be heading in the foreseeable future. This includes information sufficient to compute a series of financial indicators and ratios, as described below, plus much additional information needed to assess the financial health of the companies.

Some may argue that the completion of such supervisory filings represents an expensive undertaking for insurers, the cost of which must be passed along to policyholders. We do not agree. A good test of a supervisory filing is to ask whether it contains any information that a well informed management team would not require for purposes of managing and monitoring the company's affairs. In other words, in this instance, as in many others, the interests of supervisors and company management should be entirely consistent.

\section{(ii) Financial Analysis}

Prior to the 1970's supervisors in Canada and the United States tended to have their "favourite" ratios, which they believed were the best indicators of upcoming difficulties in financial performance. However, there was no agreement as to which ratios were actually the most efficient predictors of financial performance.

To shed some light on this question, the National Association of Insurance Commissioners in the United States undertook a major study in the early 1970's. The idea was to test literally hundreds of ratios against actual data from companies which had become insolvent in previous years, to see which would have been the most effective in predicting insolvencies. Because of the large amount of data that was available it was possible to test the statistical significance of the predictive abilities of these different ratios. 


\section{Re-Engineering Insurance Supervision}

It was found that a handful of ratios, perhaps between 12 and 15 , would have collectively been able to predict $75 \%$ of insolvencies two years prior to insolvency, and at least $95 \%$ of the time predict insolvericies one year ahead of failure. (The basic ratio tests are listed in Appendix 2.)

Note that this is not the same thing as saying that $95 \%$ of the companies which are outside the "normal" ranges for the ratios will become insolvent within one year. There will be companies that move outside the threshold levels but which in fact do not become insolvent, but, of those that ultimately do become insolvent, $95 \%$ will have been outside the specified ranges on a significant number of the tests.

These ratios carne to be known as "the early warning tests" or "IRIS" ratios, and variations of them have now been adopted in many different jurisdictions.

Some have suggested that because they were derived in the United States they will not necessarily have application to the insurance companies in their countries. The fact is though, that wherever they may happen to be located, these are insurance companies and basically the same financial relationships exist between the different financial variables. In our view the early warning tests provide highly useful, predictive information in every jurisdiction.

That is not to suggest that in particular jurisdictions there may not be special factors that need to be taken account of and separately monitored. For example, as we will discuss in more detail below, in a high inflation environment it will be necessary to devise additional monitoring techniques. As well, it will likely be necessary to "calibrate" the tests for the local market. If $90 \%$ of the companies are outside what is considered to be the "normal" range in North America, the test will provide no assistance as an indicator of unusual risk within that marketplace. Ranges can be established which will show up the highest risk insurers in the local market and although the ranges may be high by international standards, it can be expected that they will be able to be brought more in line with international norms as the market stabilizes and matures.

Clearly as well, the ratios by themselves are not sacrosanct and may be fine tuned to take account of differences in filing requirements and other jurisdictional differences. Supervisors in different jurisdictions may want to add a few ratios or indicators to the package, which they have found to be particularly useful in their marketplace.

Studies in recent years have also shown that more sophisticated statistical techniques can be applied to insurance company financial data to increase the predictive ability provided by the original IRIS ratios.

As useful as the early warning tests are in providing a "warning flag" to the supervisor, it is important to stress that they are a supplement to, rather than a replacement for, other forms of financial monitoring and tracking. For example, in the case of property/casualty insurers, monitoring loss ratios by line of business over time, monitoring expense ratios, tracking growth rates, profitability, investment activity and so on, are all important functions that should not be curtailed merely because one has the results of the early warning tests. 
The ratios were originally developed for use with property/casualty insurers. Comparable ratios for life insurers have been used in some jurisdictions, but their use is not without controversy. This is because of the long term nature of life insurance business as well as the major import of the actuarial reserves. On the first point, one may well ask "if a company is outside of a particular test range now, how much significance does that have in determining whether or not it will be able to meet obligations (i.e. life insurance claims) that won't become due until many years in the future?" The second point relates to the extreme complexity of the actuarial reserves and raises the question as to whether a simple ratio of one or two numbers to one or two other numbers can really provide a useful insight as to what is likely to happen in the future.

Our view is that for life insurers these are definite reasons for tempering the degree of significance one attaches to the ratios. At the same time, however, we are again dealing with certain fundamental variables and if, for example, the equity base of a company is becoming low relative to its liabilities, and relative to the corresponding ratio generally maintained by other companies, it probably does indicate a situation that is worth investigating and monitoring more closely.

In all cases, we see the early warning tests as, in effect, "red warning lights" which suggest that the level of financial risk is increasing and that close attention needs to be paid to developments. "Red warning lights" can sometimes be false alarms, however, and so the ratio test results always have to be accompanied by sound analysis and good judgement. Finally, the usefulness of the ratio results is entirely dependent on the quality of the financial data, once again underlining the need for appropriate accounting measures that reflect the economic values of assets and liabilities.

\section{(iii) The Risk Profile}

The supervisor has limited resources and therefore must focus those resources on the companies where there is the greatest probability of financial difficulty. Ratio analysis, information gleaned from on-site inspections, information picked up in general conversations with people in the industry, articles in trade journals and the media, are all ways in which the supervisor is building up a data base of knowledge which will be used to form an overall assessment as to the risk level in each company. The last thing we want to do in an environment where resources are in scarce supply is to allocate supervisory personnel to situations where there is little risk of financial difficulty. Whatever the means, the supervisor should be attempting to discern the relative level of financial risk, or risk profile, of each company. This includes not only the level of risk for one company relative to another, but also the areas of greatest risk within a particular company.

\section{(iv) The On-site Inspection}

The only way the supervisor is able to find out what is really happening within a company is to visit the company's head office to observe first hand. As useful as early warning tests and other financial data may be, there is no substitute for having skilled personnel acting as "the eyes and ears" of the supervisor. Financial information is always dated, may be inaccurate and cannot 


\section{Re-Engineering Insurance Supervision}

provide insights comparable to the on-site inspection in terms of understanding management's approach to running the company.

The on-site inspection has five main objectives:

1. Understand the insurer and its business environment;

2. Detect solvency problems;

3. Detect non-compliance with legislation;

4. Resolve detected problems early; and

5. Obtain information on system-wide issues.

The latter point refers to issues the supervisor has observed in the company being inspected, but which will likely have implications for other companies as well. These are generally emerging issues where thought and planning is required to formulate a consistent government policy. Some recent examples include the use of derivative instruments by insurers and the outsourcing of core business functions.

The on-site examination has four main phases: planning, on-site investigation, reporting and follow-up.

The planning phase utilizes knowledge of the companies' risk profiles to determine inspection priorities on a company by company basis. Once it has been established which companies represent the greatest level of concern, one can consider the particular areas within those companies which pose the most significant threat to continued financial health. For example, if the company in question has been highly reliant on reinsurance, and its financial position has recently been deteriorating, one will certainly want to look closely at the reinsurance arrangements to be satisfied that if necessary, the reinsurers will be in place and able to discharge their obligations. If this same company has a history of conservatively investing its funds and has a low level of risk in that area, there will probably be little to be gained by spending much time reviewing the investment department. The whole idea is to use the information at one's disposal to establish inspection priorities, both in terms of identifying individual companies for visits and the functional areas within those companies for attention.

An important part of the planning process is to select the team members and to put together a detailed work plan as to what is to be reviewed in the company's offices, including expected time horizons. One supervisor attaches a notional billing rate to the time consumed in the inspection, comparable to that which would be charged by professional consultants. This tends to reinforce the importance of getting value for money and also provides a frame of reference when thinking about what was achieved by the inspection. For example, if an on-site inspection runs up a notional "cost" of $\$ 100,000$, does the cost seem reasonable when balanced against the information obtained? (We repeat, this is not a real cost that has to be paid by the company or the supervisor. It is merely a way of assigning a kind of commercial value to the supervisory process for the purposes of internal management control and evaluation.) 


\section{Re-Engineering Insurance Supervision}

In the on-site phase the inspectors are gathering information which is adding to the accuracy of the company's risk profile. As more information becomes available the supervisor should be constantly questioning whether it changes the risk profile. If so, and the change is in the direction of greater risk, the supervisor may very well decide that additional work is required. The inspectors should also be on the look out for any issues that could have wider implications for insurance supervision (i.e. system wide issues).

It is very important for inspectors to keep in constant communication with company management as they carry out their examination tasks. Inspectors have sometimes thought they had stumbled upon something quite disturbing, and have "confronted" management at the conclusion of the visit, only to find that they didn't have the full story and that the situation was different than they had assumed. This type of thing is not only embarrassing to the supervisory group, but will give rise to bad feelings and a reluctance by management to fully cooperate with supervisory staff.

As a matter of philosophy, we have always found that much more information can be obtained by a friendly and outgoing group of inspectors than by personnel who are over zealous, overly authoritarian or who plainly show by their demeanour that they suspect management of the worst. Inspectors should accept all information with enthusiasm, saving the real analysis and comment for back at the office.

The best source of information is discussion with company management. An inspector who is capable of engaging management in discussion as to current business problems, management's strategy for approaching the marketplace and so on, can usually find out much more in a short time than is likely to be divulged by reviewing documents and financial data.

When the on-site work comes to a close it is important to formally meet with senior management to give them an overview of the inspection's findings. There should be no surprises if the lines of communication have been properly open during the course of the inspection. It is appropriate to provide the management group with a formal agenda prior to the meeting so they can give thought ahead of time to the points they'll wish to raise. While it will not always be possible to agree fully on what needs to be done, there should be agreement as to the facts of the case.

Discussion at the meeting should be limited to important issues that pertain to the long term viability of the company. The bringing forward of a myriad of relatively less important issues merely detracts from the underlying purpose of the inspection -- i.e. to assess the risk profile of the company and to modify that profile if necessary. Items of significance are those which do fundamentally change the company's risk profile, or if it is already considered to be a high risk situation, which serve to confirm that assessment.

The exit meeting should be followed up by a formal letter or report to management detailing the results of the inspection. This should document the reliance that has been placed on outside parties such as the auditors and actuary, describe the areas that were actually reviewed, set out the findings and observations, make any recommendations considered appropriate and, finally, request management for its plans for addressing the issues. 


\section{Re-Engineering Insurance Supervision}

In our experience a powerful tool for dealing with problems is to request management to put together a formal business plan for presentation to the supervisor. Most of the time management and the supervisor will agree on the nature of the problems. The onus is then on the company, not the supervisor, to come up with a reasonable plan for correcting the problems.

The use of a business plan has several significant benefits. First it enables the supervisor to get a sense as to the ability of the management team to recognize and address the problems. If the plan seems unrealistic and unlikely to succeed, it tells the supervisor a great deal about the management team and the likelihood of long term success for the company. However, most often it marks the beginning of an iterative and ongoing process of working with the company to correct the problems. The supervisor will generally have a great deal of experience in seeing how financial problems develop and how they have been successfully overcome. Offering constructive suggestions to management and working closely with management to help them come up with a business plan that is likely to have a higher chance of success, not only provides a real service to the company, it also builds credibility for the supervisor and leads to the probability of even greater co-operation in the future.

The inspection process can then be seen as a continuing and connected cycle consisting of planning for the inspection, carrying out the inspection, reporting on the findings, working with management to see that identified problems are corrected, continuing to add to the knowledge of the company's risk profile through financial analysis and other means, beginning to plan for the next inspection, and so on into the future.

\section{(v) Minimum Capital and Surplus Requirements and the Trend Towards Risk Based Capital}

Many jurisdictions have a minimum capital requirement for companies that wish to obtain a licence to do business. This means that before being granted a licence a company will have to be able to show that it has the requisite amount on hand, free and clear of any liens or other encumbrances.

While such a requirement is clearly a necessary precondition for the commencement of business, it does not do anything towards ensuring that adequate amounts of capital will be maintained as the company grows, increasing its liabilities to the public.

To take care of this requirement most jurisdictions also have an ongoing minimum capital requirement that is a function of a number of operational factors, as a minimum utilizing the liability base of the company.

An appropriately established ongoing minimum capital requirement will provide the supervisor with enough tine to see to it that management is taking action to correct the problems that are leading to the shortfall of capital. If operational measures seem not to be sufficient to remedy the problem, then the supervisor will likely put pressure on the shareholders to inject additional capital into the company. 
For property/casualty insurers in Canada, the minimum requirement used to be capital at least equal to $15 \%$ of total unearned premiums and outstanding claims. This worked reasonably well, and usually gave the supervisor sufficient lead time to work with the company to correct problems before they became irreversible. Inevitably, however, a few situations arose where this simple requirement wasn't up to the task. For example, if a company is growing rapidly its outstanding claims will lag behind the issuance of policies, even assuming that the reserves are not being deliberately understated. Theoretically the unearned premium should be enough to pay the claims and other expenses that will be generated under the policies in force, so the $15 \%$ margin should still be sufficient. In practice, however, one may find that the business is quite unprofitable, especially when there is rapid growth, so that the unearned premiums will give rise to a level of claims that will eat into the company's capital base and which the $15 \%$ margin will not be adequate to cover.

Accordingly it was necessary to adopt a more refined test. The one that was adopted was based on the test in the European Common Market countries. For Canada the minimum capital requirement is a function of three variables. There are actually three separate tests, the applicable one being the one that gives rise to the highest capital requirement. One requirement is like the original test, based on a margin of $15 \%$ of policyholder liabilities. The second test is based on net premiums written over the past 12 months and the third is based on average annual claims incurred over the past three years.

The effect is that if a company is relatively stable and not unduly unprofitable, the most stringent requirement will usually be determined by the $15 \%$ margin on policyholder liabilities. If the company is growing very rapidly the margin required under the premium test will usually require the highest capital amount and hence will become the governing condition as to minimum capital. If claims experience is very poor, the claims test will give rise to the highest capital ratio and will become the operative test.

Until quite recently in Canada there was no formal minimum capital requirement for life insurers. The actuarial reserves were calculated on conservative bases and it was felt that no additional margins were necessary. Unofficially the supervisors expected all life insurers to have a capital base at least equal to $5 \%$ of liabilities, with the liabilities being established in accordance with the conservative actuarial principles.

As discussed earlier, with the movement to GAAP and the adoption of the Policy Premium Method of actuarial reserving, much of the built in conservatism was removed. At that point a more formal minimum capital test was called for.

During this period much work was being done by international financial supervisors in developing a risk based approach to minimum capital requirements for deposit taking institutions. The rules, formulated through the Bank for International Settlements (BIS), took account not only of risks on the liability side of the balance sheet, but also of asset risks in terms of the probability of asset default and so on. This was a natural thing to do because most bank failures were due to problems on the asset side, in terms of overvalued assets, under performing 


\section{Re-Engineering Insurance Supervision}

loans, and so on, rather than stemming from understatement of liabilities, which is typical of what one is likely to see with property/casualty insurers.

It was felt that a similar approach to the BIS rules for banks should be applicable to life insurers because here we also frequently have problems with the asset side of the balance sheet.

Under the BIS approach there is a system of risk weightings, with the capital coverage for each grouping being dependent on the perceived risk. For life insurers in Canada there are four main risk categories: asset default risk, mortality/morbidity risk, interest margin pricing risk and change in interest environment risk. Looking at asset risk, for example, when we consider the risk of default, a government bond may be considered to have zero risk and therefore the base level of capital is required in respect of the bond. On the other hand, a corporate bond rated only BB, would be considered to have a higher probability of default and therefore a higher capital requirement would apply in respect of this asset. Similar approaches are taken for the other components of risk categories.

Still in Canada, the capital base is considered to be in two tiers, being core capital and supplementary capital. The actual classification of "core" / "non-core" is based on three factors: the permanence of the capital, the existence of fixed charges against earnings and the subordinated legal position of the capital relative to rights of policyholders and creditors.

Supplementary capital that is not permanent is credited towards required capital based on years to maturity, ranging from $100 \%$ credit with 5 or more years to maturity, to $0 \%$ credit with less than 1 year to maturity.

The derivation of risk based capital can become very complex -- for example, just the instructions for its calculation from the Canadian supervisor run to some 55 pages. While risk based capital is almost seen as "the way to go", in many developing countries the actuarial and systems resources are not currently available to carry out this complex task. In that event, more simplified approaches will have to be developed for use until such time as the required resources become available.

\section{(vi) The Role of Corporate Governance}

In the "Legal Framework" section of this paper we describe the corporate governance regime that exists in Canada and the benefits it seems to have brought to the supervisory process.

In the developing country context we think the corporate governance approach holds the prospect for a reduction in the amount of supervisory resources that will ultimately be required as the insurance industry grows and matures. The management and board of directors are in charge of a company, and it makes good sense for the supervisory system to highlight that reality. When this is not done, insurance company managers may begin to see the situation as one of "catch me if you can". In other words, the onus falls on the supervisors to find the problems and to raise them with the company. If the supervisory authorities do not ask exactly the right question, they may not find out what they need to know. 
A solid system of corporate governance clearly establishes in law the responsibility of the board of directors and senior management to ensure that the institution is operated in accordance with standards of sound business and financial practice. It also ensures that the directors and management will be exposed to personal liability in the event that the company is not operated in this fashion. Other penalties can be specified but personal liability will be seen by board members as a compelling reason to take their responsibilities seriously.

Professional auditors and actuaries have an important role to play in this type of system, and while the necessary infrastructure may not currently exist in many developing countries, steps can be taken now to begin moving in that direction. In the meantime the groundwork can be laid by requiring a greater degree of independence from boards of directors, moving to reduce the extent to which non-arm's length investments and loans can occur, putting greater responsibility on the board and senior management for conducting business in accordance with sound business and financial practices, requiring that the board appoint the auditor and actuary, and many other steps as well. With regard to the framework of sound business and financial practices mentioned in conjunction with the Canadian situation (see below, "The Role of Corporate Governance: The Canadian Model), we think that most can be adapted to the developing country environment.

\section{(vii) Supervision of the Investment Function}

Almost all countries specify certain rules with regard to the investment of company assets. In the United States and Canada many detailed rules have been dropped in favour of an approach that places the onus on the board of directors for investing the company's funds in an appropriate manner, in keeping with the nature of the company's fiduciary responsibilities (the "prudent portfolio" approach).

Even in these jurisdictions, however, certain broad investment limitations are retained for certain categories of investments that are seen as posing higher than average risk, for example real estate and common shares. Also, in both developed and developing countries, related party

investments have played a significant role in many financial institution insolvencies. When there are related party transactions, lacking the test of arm's length decision making, it becomes very difficult to determine whether or not a particular transaction is in the interests of the financial institution. In Canada such transactions have been largely prohibited, and for those that are not prohibited, a special committee of the board must first satisfy itself that the transaction is in the interests of the institution and that it is taking place at normal market rates.

There are several reasons why many of the detailed investment rules have been dropped. In the Canadian case, the prudent portfolio approach fits very well with the corporate governance regime and so is a natural course to adopt. There are other important reasons for its adoption, however, and we expect those are more relevant in the United States where the corporate governance philosophy has not be utilized to the same extent as in Canada. The main arguments in support of prudent portfolio are as follows: 


\section{Re-Engineering Insurance Supervision}

Modern portfolio theory demonstrates that investment risk is a function of the portfolio in the aggregate rather than being the sum of the risks attached to each holding considered in isolation. Therefore, a system which focuses on individual investments, as is the case with detailed investment rules contained in regulation, does not appropriately reflect the overall risk of the portfolio.

New investment vehicles have appeared with considerable regularity over the past 20 years or so. Rules set out in regulation tend to be slow to change, with the result that some excellent investment categories may be denied to insurers, placing them at a competitive disadvantage with other institutions and raising the cost of insurance to policyholders.

区 Lastly, by using dormant corporations and other techniques, detailed rules can be circumvented, so the end result can be that the investment function is basically unregulated for those insurers that are inclined to work around the rules.

In many developing countries, however, supervisors may feel that corporate responsibility is not yet at a point where the investment function can be left to the board of directors and senior management. At the same time, overly stringent supervision can seriously hamper the financial health of insurers and, if they are in a marketplace with foreign insurers, can give rise to difficulties in terms of being able to fairly compete with companies that are subject to more liberal investment rules.

In these circumstances there are several possibilities that can be considered. One is to merely ensure that the inivestment regulations are reviewed on a regular basis so that sound investment options are not ruled out merely because they have not been referenced in the "supervisory listing". It may also be possible to provide for additional flexibility by including what we would refer to in Canada as a "basket clause". This is a provision which states that notwithstanding the detailed rules, companies can invest a specified portion of their assets, or capital base, in any way in which they choose. For many years in Canada there was a basket clause provision which enabled companies to invest up to $7 \%$ of their assets in investments that did not otherwise qualify. Generally the basket clause would be deemed not to enlarge the companies' authority to invest in categories of assets that were subject to overriding investment limits. For example, if non-arm's length investments are subject to certain prohibitions, those prohibitions would not be affected by a basket clause. Similarly, if the government wants to make certain that insurers will be subject to certain limitations in the field of real estate investment, then a basket clause provision can include a stipulation to make it clear that the real estate limitations will not be overridden by the basket clause.

Investments in securities issued by foreign governments and corporations is also an area where a basket clause can bring some relief. In many countries, domestic securities markets will just not have the depth and liquidity to permit medium to large financial institutions to fully invest their funds. To insist that this be done can force the institutions to invest in lower quality or less marketable assets than is really desirable, because there is not sufficient investment diversification available in the local marketplace. A basket clause can contain a provision 


\section{Re-Engineering Insurance Supervision}

enabling insurers to invest a specified portion of assets in foreign markets, subject to quality standards if desired. Of course one has to be mindful in such cases of the need to maintain a proper matching of assets and liabilities from a currency perspective.

In any case, the basket clause approach can give considerably more flexibility to companies by enabling them to invest in vehicles where there is no inherent reason why they should not do so.

The question of location of investments can also be a matter for discussion. If branch insurers are permitted to operate within a jurisdiction it seems logical to this observer that these insurers should be agreeable to either maintaining sufficient assets in the jurisdiction to cover their liabilities within that jurisdiction (including any capital margins that may be required), or to making other arrangements that will provide the supervisors in the jurisdiction with an acceptable degre of comfort that the assets will be provided as and when necessary. For example, if a branch is able to show that assets are lodged in trust with a bank in the home jurisdiction, and if the bank is licensed in the supervisory jurisdiction, and if the bank will give a statement $t$ the supervisor indicating that it will deliver the subject investments to the supervisor when requested to do so, the supervisors may be agreeable to permitting the investments to be held outside t'ie country. (For more discussion on the supervision of foreign insurers, see "Issues Relating to the Supervision of Foreign Companies" in the "Legal Framework" section below.)

In this case, the supervisors should probably be prepared to extend the same accommodation to domestic insurers. There would be no justification for a domestic insurer to have the bulk of its assets outside the country. It may be reasonable, however, to permit it to hold a portion of its assets outside the country if those assets are held subject to, for example, a broadened basket clause as noted above and if they are not required to meet capital requirements in the home jurisdiction.

\section{The Regulatory Ladder}

A problem for all supervisory jurisdictions is to ensure consistency of approach from one insurer to another, one situation to another and over time. This is probably even more difficult for developing country supervisors because they will often be chronically short of well trained staff and staff turnover may be high.

The regulatory ladder is an approach which will (1) permit supervisory staff to feel comfortable that their recommendations and actions are reasonably consistent over time and from one situation to another, (2) give the supervisor and government confidence that the supervisor's actions will be in accordance with government policy and (3) enable companies to know the strength of the supervisory response that can be expected in various situations and to govern themselves accordingly (i.e. no "surprises" from the supervisor). As is suggested by the latter point, the regulatory ladder should normally be made available to the insurers so that they can benefit from the information.

The regulatory ladder is merely a matrix approach, which for each institution identifies several levels of company risk across a number of different risk assessment categories, such as on-site inspections, financial analysis, reinsurance, capital adequacy, market intelligence and so on. In 


\section{Re-Engineering Insurance Supervision}

keeping with our earlier terminology, these risk levels constitute the broad categories of risk profiles we have said that we want to be able to identify for each company.

An example of the regulatory ladder approach is attached as Appendix 3.

For the purpose of illustration, let us assume that we will have 4 levels of risk, ranging from Level 1, which is very low risk, to Level 4 , which is extremely high risk, probably reserved for companies which are virtually insolvent. For a typical Level 1 company, looking at the financial analysis area, one might expect to see not more than 1 early warning test outside the normal range. As well, there would probably have been profitable operations for the past several years, a stable pattern of reasonable growth and virtually all other financial indicators in the "healthy" range. The on-site inspectors would report that the company has highly competent management, that the financial controls are well thought out and adhered to, that products are well designed and properly priced, that investment strategies are sound, and so on. There would be no information from other sources to suggest one is dealing with anything other than a very sound institution.

At Level 2 one begins to see the emergence of issues that could give rise to serious problems if they are not dealt with. From a financial analysis perspective one might expect to see, perhaps a company that is cutside the normal range on, say, between 2 and 5 early warning tests. The supervisor's financial analysts may also be noticing that some of the trends in basic financial variables are showing adverse development. The on-site inspectors may be reporting problems in the internal control systems, which they consider sufficiently important to be raising with the company. The company may be showing a worrisome trend in its loss and/or expense ratio or some investments may be questioned by the inspectors with regard to their appropriateness for the company, and so on. So while there are no loud alarm bells going off, neither is the company free from supervisory concerns.

At Level 3 one begins to see commensurately more ratios moving out of line, more serious profitability concerns and so on. But by now the concerns have become quite significant. The supervisors believe that if no action is taken, the company could move to Level 4 -- that is, it could face insolvency -- within the next year or less. Therefore at Level 3 strong supervisory measures will be required to deal with the impending problems.

The point is that for each risk level, the supervisors can describe very specifically the symptoms they would expect to find.

The next step is to lay out in a similar fashion what general options would be considered by the supervisors when confronted by a company having a particular risk level. For example, for a Level 2 company, one response might be to write to the company requesting it to outline its plan for dealing with the problems that have been noted. Another option might be to have the company file some additional financial information so as to keep the supervisor fully informed as to developments. A third option might be to schedule the company for a somewhat earlier inspection than would otherwise be the case. For a Level 3 company the supervisor may want to indicate such options as meeting with the board of directors to explain the seriousness of the 


\section{Re-Engineering Insurance Supervision}

problem, limiting the amount of business the company is allowed to write or introducing other restrictions on its operations, receiving a detailed business plan setting out a strategy and time lines for dealing with the problems, including close oversight by the supervisor, and so on.

The text accompanying the regulatory ladder should make it clear that the supervisor's hands are not tied by the supervisory responses listed therein, since circumstances could conceivably arise where some other option, not listed with the regulatory ladder options, could become the option of choice. This should be a rare occurrence, however, if the regulatory ladder options have been carefully spelled out. The text should also make it clear that the supervisors may, depending on the circumstances, avail themselves of some, all or any combination of the options listed for a particular risk level. As with the early warning tests, general indicators are extremely useful, but each situation needs to be evaluated on its own merits.

The regulatory ladder allows the whole process of risk level consideration and the choice of appropriate supervisory responses, to take place in an atmosphere of careful consideration and discussion, which of course is not something that will occur to the same extent in an emergency situation with an insurer.

The various components of the matrix in the regulatory ladder can be made as detailed as the supervisor wishes in terms of spelling out the symptoms of problems and the supervisory responses that will be invoked. It may be that for distribution to the companies a relatively high level format would be used, but that for internal purposes the ladder would be more detailed and precise.

The regulatory ladder can, if the supervisor wishes, serve as a focus for virtually all supervisory procedures. In some countries this is the approach that has been taken. In other countries the regulatory ladder is not developed to the same degree of detail and is considered to be more of a general guideline for the information of regulated companies. In all cases, however, it serves to ensure that there is a consistent approach in dealing with company problems.

\section{Property/Casualty Insurance: Specific Supervisory Issues}

In the previous sections we have dealt at a level of generality with a number of key supervisory issues. Not surprisingly, however, there are specific issues that are unique to property/casualty insurance, and these are covered in this section.

Minimum capital and surplus requirements, whether risk based or otherwise, will differ between $\mathrm{P} / \mathrm{C}$ insurers and life companies because of the differing nature of their balance sheets and operations. We have described these differing requirements in the previous section headed "Minimum Capital and Surplus Requirements and the Trend Towards Risk Based Capital". Another significant area of difference, however, is in the nature of the reserves. Actually, in the case of P/C insurers, the use of the term "reserves", commonly applied, is a misnomer. A reserve is not a true liability in the sense of being owned to someone. A life insurance company has reserves because it is accruing amounts which ultimately are expected to become payable. But 
for a P/C insurer the "loss reserves" are true liabilities: contractual amounts owing to those who have had claims, both known and unknown at the time of drawing up the balance sheet.

One of the areas that makes $\mathrm{P} / \mathrm{C}$ insurance so interesting is that a very large percentage of liabilities are comprised of these "loss reserves". Until the claims are actually paid and settled, the $\mathrm{P} / \mathrm{C}$ insurer can only estimate the amount of liability. For some classes of business, such as property insurance, this does not pose any great difficulty since the insurer will know with considerable certainty what it will cost to replace, say, a house or an automobile. Much more problematic is the situation for what is generally termed "long tail" business such as general liability, pollution liability, product liability, some forms of sickness insurance and so on. The term refers to the length of time that is required to settle these claims and so to finally determine the actual amount of the liability. For some of these types of policies, court hearings and other procedures may extend for years, with the insurer still not discovering what will ultimately have to be paid out to settle the claim.

The great problem from a supervisory standpoint is of course that in this type of situation it is easy for an insurer to systematically understate its liabilities, and so to overstate its profitability, capital margins and general financial health. Sometimes companies can engage in such understatement more from a sense of wishful thinking than through a deliberate effort to deceive. The impact will be the same, regardless of the company's motivation, of course.

To provide a safeguard against this type of situation, it is vital for the supervisors, and companies, to track the run-off of claims so that payments and outstanding reserves in respect of a given year of claims incurred, can be compared over time with the original provisions that were set up to cover those claims. It is only in this way that one will obtain a clear picture as to the adequacy of historical reserving practices.

For example, suppose that a company had reserves of $\$ 10$ million at the end of 1995 for claims incurred in 1995, and we see that in 1996 the company paid \$6 million in respect of those same claims. We also note that at the end of 1996 the company still had reserves, in respect of the 1995 claims incurred, equal to $\$ 6$ million. In total then, the company has paid $\$ 6$ million and has reserves of $\$ 6$ million, so its actual liability at the end of 1995 for the 1995 incurred claims, must have been at least $\$ 12$ million, not $\$ 10$ million as reported. We can continue to track the run-off of the 1995 claims in future years to see if the amount of the deficiency in the reserves increases as more claims are settled. For purposes of simplicity the foregoing ignores the time value of money, but that can be incorporated into the analysis if necessary.

In order to carry out this tracking function, $\mathrm{P} / \mathrm{C}$ insurers must be required to track their claims both from the perspective of calendar year and also on a year of occurrence, or accident year, basis. In some jurisdictions this is not done. This leaves both supervisors and, extremely importantly, company management, with a large blind spot in terms of the actual financial positions of $\mathrm{P} / \mathrm{C}$ insurers.

Attached as Appendix 4 is an example of the type of form that can be made part of the standard reporting package for property/casualty insurers and which facilitates the monitoring of the loss 


\section{Re-Engineering Insurance Supervision}

run off data. As described above, the exhibit tracks loss payments and reserves by year of occurrence, comparing actual figures with the originally reserved amounts. For example, for Royal Insurance Company of Canada (the first page of the Appendix), we can see that for 1991 and prior years the company had established a liability for unpaid claims and adjustment expenses (UCAE) of $\$ 563,866$, and for the same group of claims, had set up a liability for incurred but not reported claims (IBNR) of $\$ 235,786$ (first two rows of the first column of figures). This means that at the end of 1991, for 1991 and prior years claims, the company had established a total claims liability of $\$ 799,652$ (i.e. the sum of $\$ 563,866$ and $\$ 235,786$ ). Moving down the column we can see that during 1992 the company paid out $\$ 225,569$ in respect of these same claims, incurred in 1991 and prior years. At the end of 1992 there was UCAE of $\$ 412,629$ and IBNR of $\$ 152,688$, giving a total liability still outstanding for these claims of $\$ 565,317$. Thus we can see that by the end of 1992 the company had paid $\$ 225,569$ and still had reserves totalling $\$ 565,317$, so that to that point in time, total liability attributable to the 1991 and prior years claims appeared to be $\$ 790,886$ (i.e. $\$ 225,569$ plus $\$ 565,317$ ). This compares very favourably with the company's original estimate of $\$ 799,652$, with the original reserve being $1.1 \%$ greater than actually required to discharge the claims (at least on the basis of the run-off to the end of 1992).

We can continue on down the column to the bottom most row, from which we can see that based on all the history to date, the original estimate of the claims liability (i.e. the $\$ 799,652$ amount referred to above) was $5.23 \%$ greater than appears to have actually been required. In other words, the company was conservative in its statement of the claims liability and its reported net income in 1991 year would have been slightly understated based on the run-off of claims to date.

The figures for Jevco Insurance Company (page 2 of Appendix 4) show a very different pattern however. Here we see that at the end of 1991 the company showed total claims liabilities of $\$ 16,219$ (Column 1, UCAE of $\$ 10,266$ plus IBNR of $\$ 5,953$ ). During 1992 the company paid out $\$ 8,610$ in respect of those claims. But at the end of the year it was still showing a total liability in respect of those claims equal to $\$ 8,775$ (i.e. UCAE of $\$ 4,262$ and IBNR of $\$ 4,513$ ). This means that after only one year the company had paid out $\$ 8,610$ on the claims in question plus still had reserves of $\$ 8,775$, so that the claims which were reserved at $\$ 16,219$ only one year earlier, have already given rise to liabilities of $\$ 17,385$. Thus we can see that at the end of 1991 the company was under reserved on its 1991 and prior years claims by $\$ 1.166$ million. In other words, based on only one year of development, it appears that the company was under reserved on this portion of its total reserves by $7.19 \%$. Frequently when we see this amount of under reserving in only one year, the worst is yet to come because there remains a large component of the total outstanding claims that have yet to run off. In keeping with this pattern, we can see from the last figure in Column 1 that by the end of 1996, Jevco could be seen to have under reserved its 1991 and prior years claims by $54.25 \%$.

Without this run-off information the true liability positions of the companies cannot be accurately estimated. Professional actuaries can use this information, and more detailed break downs of the data by line of business, to assist with much more rigorous analysis of the claims for use in estimating a company's current position. As well, it is possible to use the data to go back and show what the loss ratios would have been on the basis of claim occurrence year rather 


\section{Re-Engineering Insurance Supervision}

than reporting year. (In other words, adjusting the reported loss ratio by year to take account of the run-off by year of occurrence as shown in the Appendix.) The differences between reporting year loss ratio and occurrence year loss ratio give the supervisor a quick means of establishing the impact of claims run off performance. In some countries both of these loss ratio figures over the previous five years are part of the supervisory reporting package, where all such calculations can be carried out as part of a software filing package.

In many jurisdictions companies won't have been recording the required information and therefore will not be in a position to complete an exhibit such as the one shown in Appendix 4. This is a regrettable situation since the lack of these schedules makes the task of establishing adequate reserves very difficult with the result that the level of confidence in the claim reserve amounts is very low. However, starting with the current year the insurers can begin maintaining the required data, and each year they can add one more column to the filing. At the end of five years, and from then on, they will be in a position to file this information, which will enable the supervisor to monitor the accuracy with which reserves have been established.

We cannot over emphasize the importance of this information in assessing the financial condition and performance of a property/casualty insurer.

\section{Life Insurance: Specific Supervisory Aspects}

Life insurers have several areas which give rise to particular issues for supervisors. On the liability side of the balance sheet the most significant item is the actuarial reserves. In terms of assessing the financial health of the company, much will therefore depend on the adequacy of these reserves to cover future obligations. On the asset side, asset quality can often be a major concern. We have referred to asset quality and the importance of actuarial reserving in the preceding sections.

For life insurers, asset/liability cash flow matching is of special importance because the products are typically long term in nature. A mismatch between cash inflows on the asset side and cash flow requirements on the liability side can give rise to serious liquidity problems for a life insurer. A liquidity crunch can quickly become a solvency problem as an inability to fund current cash needs may give rise to a "run on the bank", with the life insurer facing high levels of surrenders and redemptions. The need to rapidly liquidate assets at what may be "fire sale" prices may generate losses that exceed the book value of the company's net worth, i.e. leaving it insolvent.

It is therefore vital for the supervisor to monitor cash flow projections on an ongoing basis in order to be satisfied that proper matching is taking place. In developing countries, which may not have great depth in their financial markets, it can sometimes be difficult for life insurers to find investments that will adequately match liability cash flow requirements. At the same time, for products such as annuities where the main feature is the future stream of cash flows, it is extremely important to be properly matched. The need to utilize investment vehicles which will 


\section{Re-Engineering Insurance Supervision}

facilitate matching may be a reason to permit life insurers to have at least partial access to foreign markets offering a broader range of investment possibilities than is available domestically.

Today actuaries and economists using sophisticated software can structure investment portfolios in such a way that the insurer is not only properly matched but in fact immunized against the potentially adverse affects of changes in interest rates.

Another area where the impact of powerful personal computers and software is showing up is in company modelling. "Off the shelf" software is beginning to become available which, while still requiring input from highly qualified actuaries, is able to provide very precise corporate models which can be used to analyse various "what if" scenarios for life insurers. Life insurance companies are particularly good prospects for the use of computerized models because the business in force can be considered almost as though it were a type of security. Each of the products in force will give rise to reasonably predictable cash flows over time; and mortality, surrender and lapse rates are estimable with reasonable certainty. When a company has a computer model of its business in force it can also construct models for different scenarios in terms of new business. Also, the computer model can be used to foresee the impact on solvency of changes in key business parameters such as interest rates, mortality, lapse rates, expenses and so on.

In fact, such models have become so widely used in Canada that insurance supervisors have placed a requirement in the insurance act which requires each company's actuary to examine the impact of changing economic scenarios on the company's solvency and to report on the findings to the company's board of directors and to the Superintendent. This technique is referred to as Dynamic Capital Adequacy Testing and it is proving to be an excellent tool. A number of situations have been revealed to date where companies were found to be vulnerable to certain combinations of changes in interest rates and lapse rates, for example, which were then able to be satisfactorily addressed. Without Dynamic Capital Adequacy Testing the companies may very well not have realized that they were exposed until it was too late to do anything about it. (Because of the less predictable nature of property/casualty insurance, the so-called DCAT technique is not mandatory for property/casualty insurers in Canada but the Superintendent can require a P/C insurer to obtain a DCAT report when he or she believes it to be in the public interest.)

Another area where these models are being used to great advantage is in the field known as Economic Value Added. Over the last twenty five years or so the usual approach to evaluating alternate business decisions has been to consider the internal rate of return expected to be generated on capital employed and to compare that to an established threshold rate which is related to the company's cost of capital. However, if a company has possession of a very accurate corporate model, it can actually use the model to calculate the present value of its business in force and the present value of business to be written -- the latter under differing product/market assumptions. The decision rule will be to choose the new products and/or the combination of products which serves to maximize the economic value of the firm. 
Successful use of these types of modelling techniques may be another area in which some upgrading of actuarial resources may be required prior to considering the possibility of implementing the approach in developing countries. On the other hand, a less rigorous approach -- simply requesting the actuary to specifically consider, based on their actuarial knowledge, various future scenarios, may still be quite worthwhile from the perspective of both insurance supervisors and boards of directors. As actuarial standards are upgraded over time the modelling approach may become the accepted norm, but in the meantime there may be something to gain, and little to lose, by introduction of the concept.

\section{Role and Importance of a Guarantee Plan}

No matter how solid the supervisory framework, some companies will fail. This need not be a reflection on the supervisory system itself, because there will always be a certain number of events which could not have been predicted and/or could not have been altered. Needless to say, if someone could write a rule book (which is essentially what a supervisory system is) guaranteeing that companies would not go out of business, it would have been done long ago.

However, as long as governments see fit to prescribe financial oversight for insurers -- and we certainly believe that the benefits of such rules far outweigh any disadvantages they may have -then when an insurer does become insolvent there will always be a hue and cry by affected citizens that they should be "rescued" by the government.

There are many arguments for and against the establishment of guarantee plans. The most common arguments against the plans are that they take away the incentive for the public to deal with financially strong, well run companies; and they reduce the incentive for owners and managers to make sound business decisions since there will be someone else "to pick up the pieces". On the other side of the coin it can probably be said that few consumers are in a position to assess the financial strength of their insurance companies and that owners and managers still stand to lose their capital and their livelihoods respectively if their institutions fail. It may be that a system of coinsurance and deductibles can be designed which will ensure that consumers and company people still have an interest in dealing with healthy, soundly operated companies, while providing consumers with some protection from the sort of devastating financial loss that can result from the insolvency of an insurer.

If a guarantee plan is to be established, it must be within a supervisory regime which combines an appropriate legal framework with a properly enforced, fairly administered system of insurance regulation. Otherwise the plan will have to take care of an undue number of failures, and if the plan is directly or indirectly funded by the industry, as is generally the case, then a "domino effect" may be seen, where stronger companies are brought down because of the cost of too many failures. 


\section{Organizational Issues}

\section{Organization Within the Insurance Supervisory Group}

In this section we focus in greater detail on organizational considerations in respect of solvency supervision. We do not specifically address marketplace supervision, partly to keep this paper within manageable proportions, partly because many of the considerations will be similar, and partly because in most developing countries, although marketplace supervision is seen as important, the highest current priority has to do with the financial health of institutions.

When thinking about possible organizational arrangements for the solvency supervisor, an important parameter is the size of the group involved. As we have mentioned earlier (see "Resource Requirements of the Supervisor" in Part II, "Regulatory Infrastructure Issues"), where there a large number of insurers, and a significant staff of say, at least 50 to 100 employees, we think it is usually beneficial to have Financial Analysis and Inspection as two separate divisions within the organization. This corresponds to the typical banking supervisory structure comprised of off-site bank inspectors and on-site inspectors.

The primary reason for our preference in this regard has to do with the attributes considered most desirable for each type of work. As mentioned earlier, in addition to an appropriate blend of academic and on the job training, we want our inspectors to be a group of individuals who enjoy meeting with company officials and whose keen understanding of financial affairs, combined with an outgoing manner and natural inquisitiveness, enable them to effectively assess developments within the companies. For the financial analysis work, on the other hand, it is an analytical mind, excellent skills in reading financial statements and seeing relationships between numbers that will be the most desirable qualities. It is uncommon that one individual will be both a superior inspector and a superior financial analyst.

One difficulty with having separate groups carry out these tasks is that to be effective, excellent communications are required. The inspectors will not benefit from the keen insights of the financial analysts if the analysts do not keep them in the picture as to their findings. Similarly, if the inspectors do not convey their conclusions to the financial analysts, the latter group will have no reason to place any special analytical focus on one company more than another. Therefore a vital component of any system which separates analysts and inspectors for purposes of specialization, is an ongoing strategy for ensuring a constant and effective flow of information between the two groups.

One way of facilitating this is to assign responsibility for specific insurers to specific individuals in each part of the organization. Then you will have a team consisting of one or more inspectors, financial analysts and others, cutting across organizational lines, but sharing a common supervisory interest in a particular insurer. Most of the time it will be the higher risk profile insurers (see the section of this paper headed "Regulatory Ladder") that are assigned to teams in this way, rather than all insurers. Such a team can meet on a regular basis (say, once per month) so that each member can update the others on what has transpired from their perspective since 
the last meeting. From a strategic viewpoint, a consensus can be reached as to the team's goals for the upcoming month, with each member agreeing as to the tasks they will be carrying out over the period.

Some countries further subdivide their inspection groups into financial inspectors and technical or actuarial inspectors. In a large supervisory organization with, say, more than 100 employees, such a structure may well be useful. This would tend to be in countries where the life insurance business represents a reasonable share of the insurance marketplace, because it is in reviewing the calculation of actuarial reserves and monitoring the reasonableness of underlying actuarial assumptions that such technical specialization will be justified.

Another possible operational area is reinsurance analysis. In some markets reinsurance plays an especially crucial role and in these cases it can be worthwhile to have one or two persons -- often retired but highly qualified and experienced executives from reinsurance companies -- who can provide a resource for supervisory personnel, especially the inspectors.

In some cases it will be logical to have a specialized group to take care of new licence applications, the making of recommendations in connection therewith and the processing of other corporate changes such as amalgamations and changes of name. Sometimes this function can also be handled by the financial analysts without the need for a separate group. The parameters that will mainly impact the choice of approach will be the number of new applications and corporate changes expected to. be received and the complexity of the legal and supervisory processes that will be applicable. In most developed countries, licensing criteria are detailed and often there is a considerable amount of discussion with regard to the proposed business plans for new entities, so it is common to have a special organizational division to handle corporate licensing and other corporate changes.

It should be emphasized, that with the creation of additional operational divisions, more attention must be given to ensuring that there will be effective communication within the organization. Otherwise the supervisory body will tend to become a number of separate entities, each working independently. This leads to duplication of effort, inefficiency and ineffectiveness because assessing the financial condition of an insurer is much like putting together a jigsaw puzzle. The more pieces that are available, the sooner one is able to recognize patterns and assemble the whole picture. Similarly, supervisory personnel such as technical inspectors, financial inspectors and financial analysts each have a certain perspective and are collecting pieces from a certain part of the whole picture. If they do not get together to share their insights, they risk the possibility that a serious problem is looming but that no one area has a sufficiently broad perspective to recognize what is really happening. In addition, lack of communication between the operational divisions will certainly give rise to frustration for insurers that find themselves having to deal with a number of different people who are all asking the same questions. Such a situation will not help the supervisory group build credibility with the supervised companies.

Of course the supervisory organization will require other types of expertise as well. For example, there should be access to legal advice. Again depending on the size of the organization, there may be one or more lawyers housed within the organization, or there may be lawyers within the Ministry who specialize in insurance supervision. A reliable and knowledgeable 
source of legal advice is important because the field is complex and presents a number of unique legal considerations. A situation where lawyers are assigned from some larger government pool on an ad hoc basis should be avoided, because lacking continuity and an understanding of the issues, even good lawyers will almost certainly be providing sub optimal advice.

The importance of the information technology area will be covered in more detail below, but clearly in today's world the supervisory organization requires access to competent technological assistance. This doesn't necessarily have to be part of the organizational structure, but those providing assistance should have a good understanding of the work being carried out by the insurance supervisors.

In some jurisdictions the supervisory body will also include an insolvency division. It is important to ensure that such a group is also included in supervisory updates and communications relating to company solvency.

In the above discussion we have not made reference to the possibility of organizing around company type. If the marketplace and the supervisory organization are sufficiently large, it can sometimes be beneficial to organize around type of insurer, i.e. life and property/casualty, with each area having specialized personnel in Life Insurance - Inspection, Life Insurance - Financial Analysis, Life Insurance - Licensing, Property and Casualty - Inspection, and so on. Some may feel that such a structure will lead to duplication, but the number of staff allocated to each group will be roughly proportional to the market share of each of these two main sectors of insurance. Therefore in the aggregate, the required resources should not exceed what would be required on a combined basis.

The main benefit of such a structure is that all operational matters will tend to fall to one group or the other. The head of the Life Insurance area will be fully responsible for all matters having to do with life insurance, and will have the resources to deal with all the issues that arise in that area, and similarly for the head of the Property/Casualty Insurance area. Another benefit is that if the marketplace consists of a large number of companies, a single structure, comprised of one group of inspectors, one group of financial analysts and so on, will mean that a few of the more senior people will have to keep track of a large number of issues relating to different companies. Subdividing the work between Life and Property/Casualty will keep the number of companies per senior executive to a more manageable number.

Of course in many countries business is underwritten by composite insurers that transact both life and property/casualty insurance. In these cases organization by area of industry specialization may not be practical.

Market conduct is an area that will typically be organized as a separate division within the supervisory group -- assuming that it is not housed within a separate organization as mentioned above -- as the issues to be addressed are very different from those relating to solvency. As a part of market conduct activity, it is generally agreed that agents and brokers should be licensed in order to ensure a certain level of knowledge in dealing with the public and also to foster ethical conduct. This is one of the areas where even a relatively low level of technology can give 
rise to major improvements in efficiency in terms of tracking agent/broker complaints, issuing licences and licence renewals and so on. In most countries there will be many more intermediaries than insurance companies, so while a manual system of insurance company licensing may give rise to no particular problems, the issuance, renewal and tracking of a much larger number of agents and brokers can soon become a major user of human resources, particularly given that the law may require the insurance company affiliations of each intermediary also to be tracked as part of the licensing process.

Again depending on the market size, a separate unit may be needed to handle insurance company and intermediary complaints from the public. The value of frequency of complaints as an indicator of increasing financial risk should not be overlooked, so complaints should be carefully logged and the number of complaints by company monitored. It is usual to consider the ratio of complaints to market share as an indicator, so if an insurer with a $10 \%$ market share is generating $20 \%$ of all complaints received from the public, it is a signal that some investigation is required. Of course for such indicators to be effective, there has to be a sufficiently large number of companies and complaints to make the figures meaningful. Channels of communication should be put in place to ensure that inspectors, financial analysts and other interested supervisory personnel are kept informed of the complaint indicators, just as with more traditional financial indicators.

Additional discussion on staffing and organizational structures for solvency regulation may be found in Appendix 5.

\section{Relationship of Marketplace Supervision to Solvency Supervision}

A fundamental question is whether solvency supervision and marketplace supervision should be contained within the same organizational structure. In the United States a one organization model has certainly been the norm, with each state insurance commission being responsible for both solvency and market conduct. A different approach has been followed in the United Kingdom, Australia and Canada.

Australia recently considered the issue explicitly as part of the major review of its supervisory structure. Taking account of the particular circumstances in Australia, the commission of inquiry recommended that market conduct and product disclosure supervision, for all types of financial products, should by carried out by a single body, with solvency supervision for all members of the system resting with a second organization. The commission has further recommended that "strong mechanisms should be established to ensure appropriate co-ordination and co-operation between the two agencies".

In the U.K. there has been considerable debate over the past few years regarding the organization of the supervisory system. As with Australia, the current model is for marketplace supervision and solvency supervision through separate organizations. 
In Canada the "twin peaks" or separate structures model for marketplace and solvency supervision has, at least roughly speaking, been the case as well. Unfortunately in Canada it might be better to refer to it as the "many peaks" model because marketplace supervision has constitutionally rested with the provincial governments (of which there are ten), while solvency matters in respect of federally chartered institutions has been within the bailiwick of the federal government. Many within the Canadian insurance industry would probably suggest that the various provincial governments, and where applicable, the federal government as well, have not harmonized their supervisory activities to the extent that might be seen as optimal (although the level of harmonization seems to have been increasing in recent years -- a positive development).

In making a decision in this area much will depend on organizational and jurisdictional considerations for the country as whole. In general, single supervisor models offer ease of communication between the two policy making areas and should result in a high degree of consistency of approach. On the other hand, some may suggest that the interests of consumers, as represented by marketplace supervisors, may not always align perfectly with the interests of solvency supervisors, and that the best results will come when there is co-ordination, but a degree of independence, between the two areas.

\section{Insurance and Banking Supervision Within Same Organization}

There are several common organizational structures utilized by insurance supervisory organizations. The particular arrangement will usually be a function of the specific situation in the country concerned.

There is often a question first of all as to whether the insurance supervisory group should be organizationally included with the banking supervisors. In some countries banking supervision is under the aegis of the central bank, in other countries bank supervision rests with a separate organization.

There can be important advantages to including the insurance group with banking. Over the past ten to fifteen years, we have seen a global trend for life insurers to develop products that are in many ways similar to banking products. Most would agree that similar financial products should be subject to similar supervisory policies, irrespective of the type of institution that issued the financial instrument. However, when the supervisory organizations for banks and insurers are completely separate there is a tendency for them to each move in their own direction in terms of policy, with the result that supervisory approaches and supporting rules can become markedly different. Combining both banking and insurance supervision within a single supervisory entity will tend to ensure consistency of approach.

Another benefit of this approach, at least from an insurance perspective, is that it can tend to encourage reasonable parity in the allocation of supervisory resources. In virtually every country, the government recognizes that the role of the banking system is vital to the exercise of government monetary policy, so that bank supervision is given high priority. Banking supervisors tend to be well trained, well equipped technologically and generally provided with 


\section{Re-Engineering Insurance Supervision}

the tools to do their jobs. The role of insurance supervision is more subtle -- we argue that it is also extremely important in building the financial infrastructure of the country -- but because of its lower profile, insurance supervisors sometimes find that they do not have access to the same array of resources. Including both groups within the same organization tends to ensure that access to resources will more truly reflect the important role of each group.

The arguments against combining bank and insurance supervision within one entity tend to be less compelling, in our view. Some will suggest that if insurance is included with bank supervision, the insurance aspect will simply be overwhelmed by the banking side. This can happen, but it should not be too difficult to arrange the organization in such a way that it will not occur. Others may suggest that banking and insurance are still very different industries and that a high degree of specialization continues to be warranted at the supervisory level. We think fewer and fewer observers are of that view.

On balance, we tend to the view that in most circumstances it will probably make the most sense to combine both types of supervision within one supervisory group. There may be particular circumstances in individual countries where other arrangements will be more efficient or effective, but in general, the trend seems more and more to be towards consolidated supervision by banking and insurance supervisors.

Appendix 5 contains more information regarding staffing and organization.

\section{The Legal Framework}

\section{Corporate Existence}

An initial question arises in connection with the legal framework under which insurance companies will have their corporate existence. In some jurisdictions, insurers, like most other types of corporations, have all of the powers of a natural person, which means that they are only restricted in their activities to the extent specified by law. In these jurisdictions therefore, the laws governing the powers, responsibilities and activities of insurers will be framed in terms of what they are not permitted to do or in terms of limitations to powers which would otherwise be unfettered.

Other jurisdictions use what in common law countries is known as the "special act" approach. In this case, insurers only have the powers that are set out in the law. Anything that is not specifically permitted, is prohibited.

The latter approach will obviously make for a more constrained operating regime than will the former. It is also easier to administer and poses fewer problems from a supervisory perspective because companies can do only those things which the legislators have specifically contemplated as being appropriate and desirable. 


\section{Re-Engineering Insurance Supervision}

The downside of this approach is that the world is rapidly becoming a more complex place, and company activities and ways of doing business are constantly evolving. Many of these changes will be ruled out under a special act regime, at least until the legislators can consider and approve specific changes in the law. There are many other matters competing for the legislators' time, with the result that changes can often be long delayed, leaving insurers unable to compete effectively with other types of financial institutions or with insurers domiciled in jurisdictions having more flexible supervisory environments.

This is the strength of the natural person regime: companies have the freedom to change their activities and ways of doing business as they deem necessary in a competitive marketplace. It is the supervisors and lawmakers who have to think about introducing new legislation if they wish to subject certain activities to limitation.

The choice of legal framework may therefore depend on the rapidity with which one expects the operating environment to change and the extent to which controls may be necessary. If there is concern about the possibility of companies changing too quickly, and perhaps without sufficient prudence and responsibility to safeguard the public interest, then the special act approach may be the most desirable route. Otherwise the natural person philosophy will probably be the best approach.

\section{Entrance Requirements}

Here we are talking about the criteria for permitting companies to get into the business of insurance. In most countries the law will set out a number of minimum requirements that will have to be met by any company wishing to transact the business of insurance. The most common of these are summarized below:

区 Minimum Initial Capital: This will depend to some extent on the scope of economic activity envisaged for new insurers. However, unless the marketplace is extremely small, with correspondingly low policy amounts, we find it difficult to foresee a minimum capital threshold of less than US\$1 million, and probably US\$3 million is more realistic. One has to keep in mind that the only commodity being sold by an insurance company is the financial security provided by its capital base. Any insurance company having capital of less than US\$1 million does not have much to sell. If some existing companies have a capital base which is below the selected threshold, we suggest that they be given a period of time, say one or two years, to reach the newly required minimum level. (Note: We refer here to the capital required to be on hand prior to the issuance of a licence to commence business. In Section 4, below, we deal with the need to prescribe an ongoing minimum capital requirement which will be a function of the company's liabilities and, in the case of risk based capital, assets as well.)

$凶$ Financial Statements: To gauge the financial capacity and experience of the owners, copies of audited financial statements of corporations that will be shareholders in the new insurer, covering a period of the last five years. If the shareholders will be individuals, then they should file statements setting out their personal financial positions. If the applicant is an existing insurance company from another jurisdiction, then copies of the supervisory filings for the past 


\section{Re-Engineering Insurance Supervision}

five years should be provided. If the applicants are corporations that are subsidiaries of other corporations, and where it could be presumed that these other corporations would provide the real source of capital for the new venture, then five years of financial statements should also be filed in respect of these other corporations.

Ownership Structure: A detailed organizational chart should be provided showing the direct and beneficial ownership of the proposed company and all affiliates.

冈 Business Plan: Prospective new entrants should provide a detailed business plan acceptable to the supervisor, illustrating a good familiarity with the insurance marketplace, including the marketplace in the country to which application is being made. The business plan is a critical aspect of the information to be provided by the new entrant. It should include the following:

$\checkmark \quad$ biographies of individuals acting as sponsors of the new entity as well as those who will become directors and officers of the company;

$\checkmark \quad$ proposed ownership structure and initial financing arrangement;

$\checkmark \quad$ statement of investment policy that will be followed by the new entity;

$\checkmark \quad$ a three year financial forecast including balance sheets and income statements prepared in accordance with the accounting requirements of the jurisdiction of application, showing projected solvency test results and other ratios required by the supervisor, underwriting results by major class of business and all underlying assumptions;

$\checkmark \quad$ classes of insurance to be underwritten and a description of the products to be sold, the marketing strategy to be followed, the geographical dispersion of the business, the distribution methods, the reinsurance arrangements, key management personnel, the computer systems and software to be utilized and the means of providing policyholder service.

- Management: Officers and directors accepted by the supervisor as "fit and proper" persons to manage an insurance company, and also able to demonstrate that they have an appropriate level of insurance industry experience;

- Good Conduct: In any case where the applicant or sponsors are not known to the supervisor, enquiries should be made to ensure that they do not have a record of undesirable conduct elsewhere.

- Name: The name of the proposed entity should not be the same as nor so similar to the name of another corporation as to cause confusion to the public;

- Records: If the applicants are from outside the jurisdiction, and if the insurance act is not already clear on the point, they should give an undertaking as to the records they will maintain in the jurisdiction and which will be available on an ongoing basis for inspection by the 


\section{Re-Engineering Insurance Supervision}

Superintendent.

- Foreign Applicants: Where the applicant is an existing insurer from another country, the supervisor should expect to see a reasonable period of profitable operation in the home jurisdiction (from 3 to 5 years) writing the same lines of business as are being requested from the supervisor, a significant asset base in the home country, information satisfactory to the supervisor that the company is complying with regulatory requirements in the home jurisdiction, that the regulatory regime itself is sound and well respected and that the home country of the applicant insurer has market entry rules that are reasonably comparable to those described above.

All of the foregoing must be carefully considered with a view to satisfying the supervisors that the applicants have a viable plan, that they have the financial resources to support the plan and that they have the experience and sound reputations necessary to provide the public with a high level of insurance expertise.

\section{Composite Companies}

We encourage countries not to permit the use of composite insurers. In cases where this has traditionally been done, we favour not approving any new applications for composite company authority, with supervisory encouragement for companies over time to gradually spin off their life and nonlife businesses into separate corporate entities, which can still be under common ownership.

We make this suggestion because we believe the fundamental nature of life business and property/casualty business is very different. Life insurance is a long term vehicle where asset matching is very important. Property/casualty insurance is of short term duration with liquidity being of critical importance. Probably most importantly, the life insurance business is, more and more and in most countries, concerned with the sale of investment and saving type products, which are more similar to many banking products than to traditional life insurance. Property/casualty insurance, on the other hand, is a vehicle for spreading risk and providing for the protection of assets, not for savings or investment. Accordingly, the management perspectives required of executives in each industry are very different, as are the underlying investment strategies and other areas of expertise required in the two facets of the business. Placing the two business types within a single corporate structure, give rise in our view to greater management challenges for corporate executives, to say nothing of supervisory personnel.

\section{Minimum Capital Requirements}

Above we have described criteria with regard to getting into the business of insurance. Here we consider the financial requirements for being permitted to stay in the business.

We have mentioned a minimum initial capital requirement, but it will be clear that as the new entity grows, the liability base will grow also, so that even if the absolute amount of capital remains undiminished (and in fact it is likely to be reduced as a result of unprofitability in the 


\section{Re-Engineering Insurance Supervision}

start up phase of operation), it will be shrinking relative to the company's total liabilities. The larger the company becomes, the greater is the monetary exposure due to the occurrence of large claims, estimation problems, declines in asset values and so on. Therefore it is almost universally agreed that after start up, an appropriate degree of security to policyholders will only be maintained on a going forward basis if the capital base is maintained above some minimum amount which is a function of the company's exposure to risk.

One of the simplest ways to accomplish this is to stipulate a minimum capital formula as a function of the company's liability base, especially for property/casualty insurance where the liability base tends to reasonably reflect the risk exposure.

In the European Common Market countries and others which have adopted similar approaches, a three component requirement is used for property/casualty insurers, with the capital requirement being based on the greater of (subject to various adjustments and refinements):

- $15 \%$ of policyholder liabilities (i.e. outstanding claims and unearned premiums);

- $15 \%$ of gross premiums written during the previous 12 months, subject to a reduction to take account of reinsurance; and

- $22 \%$ of average annual gross claims incurred over the previous 36 months, again subject to a reduction for reinsurance.

The reduction for reinsurance is based on the percent of liabilities ceded, but in many jurisdictions the maximum reinsurance credit is fixed at $50 \%$. The rationale for this is that if a company is holding itself out to the public as an insurer, it should have sufficient capital to support at least $50 \%$ of its gross obligations to the public without relying on reinsurance support. If it wishes to utilize a higher amount of reinsurance there would be nothing to prevent it from doing so, but it would not obtain any relief from the minimum capital test by reinsuring more than $50 \%$ of its business.

The situation for life insurance companies is more complex because the liability base is primarily comprised of actularially calculated amounts. In this case much will depend on the actuarial approach. If the actuarial reserves are conservatively stated then it is possible that no additional capital margins will be required. On the other hand, if the actuarial reserves have been established on the basis of less conservative assumptions, additional capital margins may be necessary.

The Bank for International Settlements has established a framework for bank capital requirements which takes into account risks inherent on both the asset and liability sides of the balance sheet, known as "risk based capital requirements". Using these same principles, supervisors in the United States, Canada and other countries, have devised minimum capital requirements for life insurers. Unfortunately the risk based approaches require a good deal of 
actuarial expertise for implementation, and this level of professional support is not available in many countries.

A very simple approach for life insurers, although likely to be far less effective, is to stipulate a capital requirement which is a fixed percentage of the company's total liabilities. In Canada before the advent of risk based capital requirements, a rule of thumb was that the capital base of a life insurer should be at least equal to $5 \%$ of its liabilities. At that point in time, however, the actuarial reserves were stated on quite a conservative basis. If a simple percentage of liabilities approach is to be used, the supervisors will have to select a threshold level which takes account of the reserving conventions in their country and with which they feel comfortable.

In the case of composite companies the total capital requirement would be determined independently for the life insurance and property/casualty insurance business and then aggregated for the company as a whole.

Whatever on going capital requirements are established, they should clearly be spelled out as part of the legal framework.

In recent years, rating agencies have become much more pervasive in terms of the number of companies which receive ratings. This has made it increasingly feasible to incorporate the rating agencies' output into the system of solvency supervision. For example, because of the ever present danger of earthquake in the Mexican marketplace, catastrophe reinsurance is a necessity for every insurer in that country. Capacity considerations suggest that for the most part, this coverage will have to be provided by international reinsurers. However, it is very difficult for supervisors concerned with entry requirements, to assess the financial positions of reinsurers from all over the world, having different financial reporting regimes and so on. Accordingly, it was decided that a graded reserving system would be established, and that reinsurers having the highest ratings from recognized international rating agencies would have unfettered access to the market. For reinsurers having slightly lower ratings, ceding companies would have to establish a reserve in respect of ceded liabilities, with the amount of the required reserve increasing as the rating agency grading of the reinsurer becomes lower. This is an example of how the work of the rating agencies can be incorporated into the supervisory process.

Rating agencies use the same methods described in this paper to assess the viability of insurers: meetings with management and discussion of their business plans, review and analysis of financial information. Rating agencies do not have the force of law to back up their requests for information, however, nor do they provide ratings for any but the largest insurers where it is commercially worthwhile for them to do so. Nevertheless the Mexican example shows that there can be situations where the output of rating agencies can provide a worthwhile supplement to the traditional supervisory process. 


\section{Re-Engineering Insurance Supervision}

\section{The Rolle of Corporate Governance: The Canadian Model}

Events in recent years have led Canadian policy makers to place increasing emphasis on corporate governance as a pillar of the supervisory system. By "corporate governance" we mean a system of laws and regulations which places primary responsibility for ensuring that an institution remains viable, on the board of directors and senior management of the institution. This is done by laying out a broad framework that is intended to ensure that the board of directors will have access to the information required for proper decision making. Checks and balances are established to provide a degree of independence to the board and to make sure that actions are in line with the best interests of the institution (as opposed to the interests of the shareholders, for example). As well, a system of sanctions are in place so that boards will be able to be held accountable if their actions are not consistent with "standards of sound business and financial practice".

The new approach evolved as a result of events in Canada, but we have found the underlying principles to be of keen interest to supervisors elsewhere. A particularly desirable attribute in the developing country context is that it tends to reduce the amount of direct supervision required by government personnel, thereby freeing up scarce resources for use in other areas. In fact, the corporate governance approach is in a sense, a limited form of self-regulation in the realm of solvency supervision.

In any case, in the event that it may be helpful to supervisors in other countries, we have included in Appendix 1 an outline describing some of the reasons for the growing emphasis on corporate governance by Canadian supervisors, as well as a description of the framework currently in place.

\section{Supervisory Tools}

In the section above, and more particularly in Appendix 1, we have talked about ways in which the companies, their auditors and actuaries can play a key role in the supervisory process. The legal framework must also include specific supervisory tools that will be available to the Superintendent. By "supervisory tools" we mean the practices, procedures and courses of action that the supervisor will be authorized to utilize in seeing to it that insurers comply with the laws, are financially sound and dealing fairly with the public. Such provisions are subject to the ability of the company concerned to have a hearing with the Minister or other appropriate government representative, to ensure fairness in the system. The actions described below should not, in our view, be appealable to the courts, as this enables financially troubled companies to effectively stall any supervisory action until there is no money left in the company. To ensure due process the legislation should provide the affected company with the opportunity for a hearing by the Minister or an impartial tribunal, within a stipulated period of time.

Set out below is a listing of some of the tools with which we are familiar and which we think can be effective in pretty much any country: 


\section{Re-Engineering Insurance Supervision}

Special Audits: In addition to the normal staff inspections, where the supervisor believes that it would be in the public interest, he should be able to require the independent public auditor to extend the scope of the audit or to carry out a special audit, focusing on areas indicated by the Superintendent. In Canada, the Insurance Companies Act empowers the Superintendent to require the auditor of a company to make a special audit pertaining to "the adequacy of procedures adopted by the company for the safety of its creditors, shareholders and policyholders, or any other examination as, in the Superintendent's opinion, the public interest may require". At the discretion of the Superintendent, the cost of such a special audit may be charged to the company.

Imposition of Conditions: The Superintendent should have the power to impose conditions upon a company's ability to operate. For example, the Superintendent should be able to order a company not to exceed a certain volume of business over a specified period of time (e.g. not more than $\$ 20$ million in gross premiums and not more than $\$ 10$ million in net premiums over the next 12 months), or not to write more than a certain volume of business relative to its capital and surplus (e.g. net premiums written in next 12 months not to exceed 3 times current level of surplus), or to impose geographical limitations (e.g. no business outside the country). Another form of limitation is to prescribe a date on which the company's authority to transact business will expire, which may be different from the normal expiration date of the licence, unless the company has been able to meet certain conditions (e.g. increase its capital level such that it complies with the minimum capital requirements set out in the insurance act). In short, the Superintendent should be able to impose any condition whatsoever with regard to a company's ability to transact business, subject to the company having the right to a hearing in front of the Minister.

\etter of Direction: The Superintendent should be able to serve a company with written notice that it must change its practices in specific ways described by the Superintendent or take steps which in the opinion of the Superintendent are necessary to deal with financial or operational problems.

\ Power to Take Control of the Insurer: While it is preferable to cause a company to correct deficiencies before such drastic action is required by the supervisor, there may come a time when direct intervention is necessary to stop the bleeding. Such a provision would normally require Ministerial approval, with the Minister having to be satisfied that such action is in the public interest. There would also usually be some type of appeal mechanism, although any such process must be stipulated beforehand and in such a way that it will not effectively thwart the ability of the supervisor to take control.

These are powerful provisions. Normally the interests of the supervisors and company management will coincide, as both want to see the company financially sound and profitable. Therefore it is usually possible for the supervisory staff to work closely with company management to see to it that the company's business strategy is modified in ways that will strengthen the company. The supervisory powers outlined above would only be resorted to in cases when more co-operative approaches have not proven practicable. Taken together they 


\section{Re-Engineering Insurance Supervision}

provide the supervisor with a wide range of potential actions to head off solvency related problems.

Within the context of the corporate governance approach, the single most important incentive to properly manage the institution may be the prospect of personal liability on directors. If directors authorize actions which are outside the realm of sound business and financial practices, and which ultimately lead to insolvency, then policyholders and creditors would be able to institute legal proceedings in an effort to recover their losses. It would be up to the courts to decide whether or not individual directors had in fact done everything reasonably possible to ensure that the company was soundly managed.

\section{Ensuring a Competitive Marketplace}

To ensure a competitive marketplace we see the following as basic necessities:

1. A sufficient number of companies to ensure a reasonable range of consumer choice.

2. Technically competent personnel within the industry who are able to knowledgeably select and price insurance risks.

3. An informed public with access to information about insurance products.

4. A sufficiently large pool of claims statistics so that each company has access to credible data for purposes of product pricing.

1. We talk elsewhere in this paper about the role of market conduct within the supervisory area. Appropriate market conduct supervision also helps to ensure a competitive marketplace by discouraging cornpanies or intermediaries from adopting business practices which unfairly discriminate against consumers and which would thereby place them at a competitive advantage over others.

Another factor that will help to encourage a competitive marketplace is a system of insurance supervision which is not subject to political interference. If companies can simply approach the Minister to have the supervisor overruled on a particular issue, the industry will quickly recognize that the name of the game is to influence the Minister rather than to concern oneself with the actual regulations. When this occurs, market competition is replaced by a system where business advantage is accrued by means of political favouritism rather than the support of consumers. Clearly, political interference can be a major obstruction to a truly competitive market.

We have mentioned above that the number of companies carrying on business is also a determinant of the level of competition in the marketplace. In this regard, we tend to favour a market that is open to foreign insurer participation, although there are two schools of thought as to whether this will be of benefit to the marketplace. On the one hand, some will argue that the 


\section{Re-Engineering Insurance Supervision}

presence of foreign insurers will tend to bring with it a certain level of experience and insurance acumen from which the entire market can benefit. As well, these foreign insurers have expertise in the determination of premiums, so they should be able to establish premium levels which are actuarially sound and also sufficient to generate reasonable levels of profit, thus serving as a model for the local insurers. Others will say, however, that because the local market is apt to be such a small business area for a foreign insurer, the insurer may under price the local companies just to get the business, without regard for profitability. Probably both scenarios occur at different times and in different places.

\section{Issues Relating to the Supervision of Foreign Companies}

In many countries, foreign interests can partake in the domestic insurance market in either of two ways: (1) they can incorporate a domestic subsidiary company which will be wholly owned by the foreign insurer or (2) they may operate as a branch within the jurisdiction.

A branch presents several advantages and disadvantages from a public policy perspective. Some of the advantages are:

\Domestic policyholders are protected by the full financial resources of the company as a whole. In other words, the world wide capital and surplus of the company is available to deal with the claims of domestic policyholders. Reinsurers often operate on a branch basis, because if they were to set up subsidiary companies wherever they operate, their capital and surplus would be locked into the many different corporate entities in different countries. In that event they would not be able to mobilize their full financial resources to respond to a major catastrophe in any one country.

$凶$ The entrance criteria should ensure that the only branches which are admitted are those which are highly solvent, well experienced, having excellent reputations and solid management. The calibre of financial supervision in the home jurisdiction can also be taken into account when considering an application for entry. (See "Entrance Requirements" under "The Legal Framework", above.)

On the other hand, there are also potential disadvantages with branch operations:

\If financial difficulties do develop in the home jurisdiction, assets may be withdrawn from the branch jurisdiction so as to provide a higher degree of protection for domestic policyholders.

In order to achieve economies of operation, a branch may find it beneficial to process most of its business in its home jurisdiction or elsewhere, where there are existing computer and other systems. This can leave the branch jurisdiction with little ability to carry out meaningful inspections. Also, if the company were to actually become insolvent, there may not exist in the branch jurisdiction sufficient information regarding policies and claims to successfully liquidate the company's affairs. This is a highly unsatisfactory situation, since neither the insurance supervisors nor the courts in the branch jurisdiction will have any authority in the home 


\section{Re-Engineering Insurance Supervision}

jurisdiction. Policyholders in the branch jurisdiction may then find themselves at the end of the line with other general creditors when it comes to gaining access to the estate of the insolvent insurer.

There are ways in which these disadvantages can be dealt with, however.

First, in order to ensure adequate financial protection for domestic policyholders, it is common to require that branches maintain assets in trust within the country, in amounts that correspond to the minimum assets that would be required by a domestic company having the same asset/liability position. In other words, the foreign branch is usually required to meet the same minimum capital requirement as a domestic company, with the difference that the branch's investments and securities are required to be maintained under the control of an independent third party trustee so as to ensure their availability if required. Normally the foreign branch would maintain other bank accounts in the country, under management's control, to deal with day to day business. If the branch wishes to dispose of certain investments in its trust account it would have to replace them with others, ensuring that at all times the amount in the trust account is at least equal to the minimum required amount.

On the question of record keeping, the insurance act may require branches to keep sufficient information in the country to permit the annual audit by the outside auditors and to enable the supervisors to carry out a satisfactory inspection.

The area of access to records is a difficult one because in this age of "virtual" companies, one doesn't want to interfere with logical and reasonable attempts to operate on an efficient basis.

In some cases it may be possible to address supervisory concerns by electronic means. For example, if the head office of the company keeps a complete electronic copy of the data base for the branch, updated daily, in the country where the branch is located, then the supervisors could be sure that there will always be a complete record of the branch's financial records within the country.

It will likely not be satisfactory to have electronic access to branch financial information via the main data base at the company's head offices. This is because if there are financial problems and a receiver is appointed in the home jurisdiction, the foreign jurisdiction will probably lose its ability to access the records at head office. By contrast, if there is an up to date electronic copy of the branch records in the branch jurisdiction, then the supervisors in the branch jurisdiction can take control of that data base and have the information required to sort out the branch's obligations in their country.

Related to the question of access to records, another important requirement when dealing with branch operations is to ensure that one person is in charge of the branch's operations in the country, that they have a permanent place of business there and that they are normally resident in the country. If this is not done and financial problems arise, the supervisor can discover that there is no one in the country who actually has an understanding of what the branch was doing from a business perspective. In Canada, every branch has to appoint an official agent who will 


\section{Re-Engineering Insurance Supervision}

be responsible for service of legal notices and other official documents and who will have legal responsibility for the branch's operations in the country. If the branch is a relatively large one, it will have officers such as a general manager or a president of the Canadian division, and one of these officers would normally also be appointed as official representative of the branch.

Recent developments at an international level, such as the establishment of the International Association of Insurance Supervisors, are facilitating co-operation and co-ordination between supervisors in different countries. This is making it somewhat less difficult for supervisors to assess the financial positions of companies from other jurisdictions and to make judgements regarding the licensing of foreign insurers.

Apart from the points mentioned above, we believe the requirements for branches should be the same as for domestic insurers.

\section{Winding Up}

When a significant number of insurers are operating in today's volatile business and economic climate, is almost certain that a few will not survive, even if the calibre of supervision is very high. As mentioned earlier, excellent supervision will significantly reduce the number of insurers that would otherwise fail, but risk can only be managed, not eliminated. In some countries a major portion of the supervisor's overall workload is related to the liquidation of insolvent insurers.

Probably the most basic objective of the supervisory system is to protect policyholders from loss. When a company fails there will almost certainly be losses, but even here, a certain amount of forethought can mitigate losses to the public.

There are two principal points to take into account. First, when an insurer reaches the point that its liabilities exceed its assets, the supervisor must take steps to close the doors. Unfortunately it is all too easy to accept the inevitable pleas from the shareholders to the effect that all will be well, as long as more time is made available by the supervisor. And it is surprising how long a company can continue to operate, running down its resources to the point where there is virtually nothing left for policyholders having outstanding claims, so that these unfortunate individuals are left with virtually nothing to cover their claims. The point to remember is that an insolvent insurer is like a plane with failing engines. As long as the insurer is allowed to continue operating, the supervisor is permitting more passengers to get on the plane, even though there is ample evidence that the craft is no longer air worthy. This is something the supervisor should never permit.

The second point is to make sure there are mechanisms in place to provide for company liquidation on a basis which provides a reasonable degree of protection to the remaining asset base of the company. In some countries this is accomplished by providing in the law that the expenses of liquidation are to be assessed against the remaining companies in the industry on the basis of their individual market shares. In this way the assets of the insolvent company are 


\section{Re-Engineering Insurance Supervision}

preserved and available for discharging insurance obligations rather than being consumed in the expenses of the liquidation.

Another mechanism that helps to protect claimants when an insolvency has occurred is to spell out in the legislation the priority of claimants. Insurance claimants (i.e. persons having unpaid claims under policies and those who are entitled to refunds of unearned premium) can be given preference over other business creditors. And for property/casualty insurers, unpaid claim amounts can be given preference over unearned premiums. Unearned premiums due to individual policyholders are usually quite small amounts, although in the aggregate they typically constitute a significant proportion of total liabilities. By comparison, unpaid claims tend to be much larger amounts on an individual basis, but with many fewer cases. Consequently, if a person having an unpaid claim suffers a shortfall of, say, $20 \%$, that $20 \%$ may represent a heavy financial burden. On the other hand, for a person who is due an unearned premium, a loss of $20 \%$ is probably quite a small loss in absolute terms.

The heavy financial loss that can arise for those with unpaid claims will be greatly reduced if unpaid claims are given priority in liquidation over the refund of unearned premiums. If the asset shortfall is $20 \%$, and the average unearned premium is $\$ 1,000$, then the average unearned premium claimant will loose $\$ 200$, which is not likely to be a crippling blow. If the average unpaid claim is $\$ 50,000$ a $20 \%$ loss amounts to $\$ 10,000$. But having in mind that in total the unearned premium amounts likely represent a significant proportion of the liabilities of the insurer, it may be possible to pay $100 \%$ of unpaid claims by increasing the average loss of the unearned premium claimants to, say, $\$ 400$, which is still not a devastatingly large loss. Thus by ranking unpaid claims ahead of unearned premiums, those with significant monetary losses receive a much higher level of protection that would otherwise be the case, albeit at the expense of those who have paid their premiums but who have had no claims. The justification for this approach is that the fundamental purpose of the insurance policy is to compensate for what would otherwise be a crippling financial loss. Unearned premium claimants have not suffered such a loss and therefore their premium is considered to be "fully earned" in the insolvent insurer.

\section{E. The Time Horizon: Developing a Supervisory Strategy}

In the foregoing pages we have discussed at some length, various models and approaches to insurance supervision. It is essential to recognize, however, that one cannot move overnight from a system where there has been little or no supervision to one which is highly sophisticated. As with any business or organizational endeavours, it will be necessary for us to decide first of all, what kind of system we ultimately want to have. In other words, taking account of the particular issues and circumstances facing our jurisdiction, what system do we currently believe (things tend to change over time, so we may modify our view in the future) will best provide for the public interest in terms of solvency and marketplace supervision of our insurance industry?

This will no doubt require a good deal of thought and consultation with the interested parties. Once the vision of the end state is determined, one can think about what will have to be done and 


\section{Re-Engineering Insurance Supervision}

how much time will reasonably be required to do it. Here one has to bear in mind the reality of time delays inherent in obtaining changes in legislation, working with a varied population of companies and so on. One also has to plan out in detail what changes will have to take place and how long each can be expected to take. It is often helpful to sketch out the various stages and steps diagramatically, attaching time lines to the key activities.

For purposes of discussion, let's suppose that our best estimate is that it will take seven years to reach the point that we currently view as being a kind of ideal supervisory system. In our experience, it is usually possible to think of quite a number of things that can actually be accomplished fairly quickly, because they are within the power of the supervisor to control.

Items falling into this category generally include:

凶 staff training to familiarize employees with various supervisory models and strategies for working with insurers to overcome financial and other types of problems;

冈 changes in supervisory work practices such as implementing a form of early warning test ratios;

冈 putting in place a regulatory ladder;

冈 improving the efficiency and effectiveness of other work procedures within the supervisory organization, including general financial analysis and on site inspections; and

generally making the supervisory process more effective and efficient by increasing the amount of assistance provided by computerization and systems.

Matters such as modernizing the financial reporting regime will require more time because here consultation and discussion with the industry will be necessary. Also in this category may be organizational changes within the Superintendent's office, as these usually cannot be carried out without various discussions and approvals from within the government.

Depending on the legislative timetable for the particular country, more time consuming changes are usually those requiring new legislation. Areas which may require new legislation could include revised minimum capital requirements, revised rules pertaining to companies' investment powers, new powers for the Superintendent and new requirements for foreign branches.

The longest term changes are those which require not only new legislation but also changes in the external business environment. For example, if the intention is to move over time to an environment where corporate governance will play a more significant role, it may be necessary first of all to work with the professional organizations representing the country's accountants, auditors and actuaries. The supervisor will have to be satisfied that the members of these organizations have the requisite levels of skill and knowledge, through their professional training programs, to take on some of the work that may historically have been carried out by the 
supervisor. Changes in the legislation will also be required to set out new responsibilities for the board of directors, auditors and actuaries. In a plan envisioned to take place over a period of seven years, carving out a meaningful corporate governance regime may take the full seven years, depending on the starting point of course.

The key is to establish goals, determine realistic time frames for achieving the various components of what you expect to be the final system, monitor your progress over time and be prepared to revise your plan as new information becomes available, circumstances change and unforeseen situations arise. Having in mind the speed with which the financial services businesses are evolving world wide, it is almost certain that over time it will be necessary to modify your original plan.

Overall we are confident that within one to two years most supervisory organizations will be able to make the transition to the new paradigm of insurance supervision, at least in the majority of areas. Areas which the supervisor can influence, but not directly control, such as raising the standards of auditors and actuaries, and moving to a GAAP based reporting system, will doubtless take somewhat longer.

\section{F. Finding the Right Balance}

Some of the parameters we have discussed include technology, the role of corporate governance, self-regulation, staff training, professional support, data gathering and interpretation, solvency and market conduct of companies.

It is necessary to blend all of these parameters in such a way that the end result will address the issues facing the particular jurisdiction. Clearly the first step in deciding how that blending process should be effected, is to think about the issues currently facing the country. Are there special situations resulting from unusual economic circumstances, political conditions, the business environment? When one is endeavouring to upgrade and modernize an insurance supervisory system, one of the first steps is to gain an overview of the whole system. What problems are giving rise to the greatest concerns for the supervisors? What do industry leaders think about these problems? Do they see different issues as being key to industry and supervisory progress? What is the financial health of the industry? Is it generally profitable? Have there been an unusual number of insolvencies over the past few years? If so, did the causes tend to be asset based, such as depressed real estate values or defaulting bond issues? Or were insolvencies more often related to operational matters such as under pricing of products, poor product design, unsatisfactory reinsurance arrangements, etc.

The answers to these questions will help determine where to place the emphasis in the supervisory re-engineering work. For example, if industry solvency problems have tended to be asset and investment based as opposed to operationally based, then the initial supervisory rebuilding would probably be directed towards improved financial reporting, (especially the reporting of investments, including the possibility of more timely and detailed information regarding investment activity), the development of investment guidelines (pending the 


\section{Re-Engineering Insurance Supervision}

supervisor's ability to initiate desired new investment legislation) and the development of better rules and procedures for the valuation of real estate and other assets.

If investments are seen as a problem area one would probably not put the highest initial priority on, for example, increasing the efficiency of the on-site inspections, because the on-site inspections will in most cases not reveal a great deal about investment activity which cannot be obtained more easily and efficiently by means of company filings. What one may want to do in the inspection area would be to have some of the inspectors participate in specialized training in the investment area and/or design a special type of on site inspection for companies having more serious issues in the investment realm. In the latter case the inspectors could meet with the portfolio management people of the insurer to talk to them about supervisory concerns, to better understand the company's investment policies and objectives and to help to build a relationship with the personnel involved so as to encourage future dialogue and discussion.

Generally speaking, staff training, especially in techniques of financial analysis and on site inspection, is an area that can give rise to important gains in productivity and effectiveness at an early stage in the supervisory re-engineering process. This is doubly beneficial because not only is the quality of the work improved, but also the staff has greater confidence, leading to higher morale and job satisfaction and also to an ability to more easily understand the other supervisory changes in the offing.

It is also important to retain the assistance of someone with experience in these areas. No two organizations are the same, no two countries have exactly the same circumstances and the issues facing the insurance industry in each marketplace will be somewhat different. A consultant cannot do your work for you, but working together with a consultant who has an in depth understanding of the issues, who is sensitive to supervisory concerns, approaches and realities, will place you in a much better position to plan and implement the changes that need to be made.

\section{Issues in Marketplace Supervision}

\section{A. Introduction}

Most of this paper has been concerned with solvency supervision, which is typically the most significant concern of insurance supervisors and governments in smaller and developing countries. On the other hand, the public's experience as users of the insurance/financial system is also an important determinant of the confidence they will have in that system. If consumers' experience is that they will not be treated fairly by insurers, it will undermine their confidence in the system just as surely as insolvencies and other financial issues. International assessments of the country's insurance system may initially focus on the financial health and solidity of the industry, but domestic opinion will quickly be impacted by the realities of the marketplace. In turn, domestic views as to the credibility of the insurance industry will influence the views of foreign investors when they seriously investigate business conditions in the country. 


\section{Re-Engineering ][nsurance Supervision}

In this section of the paper we describe a number of mechanisms that have been used in other countries to help establish a level playing field between insurers and consumers and to add to the stability of the insurance marketplace.

\section{B. Level Playing Field and Consumer Disclosure}

The starting point must be consumer knowledge. Insurance is a complex business and it sometimes appears that vendors of insurance products, and those who design them, have a vested interest in complexity. And so they do, in the sense that as long as consumers don't have a good understanding of the products they are buying, the salesperson will be at an advantage. We are talking here primarily about the products of life insurers. This is first, because life insurance products are increasingly regarded as investment vehicles, where there is great competition for the consumer dollar. Second, life insurance products tend to have higher commission rates than is typical for property/casualty products, so there can be quite an incentive for the seller to "push" certain products. And third, property and casualty insurance tends to be pretty much of a commodity in every country, so that the needs tend to be well understood by the consumer even though, in actual fact, few consumers take an interest in the details of coverage until there is a claim.

The issue of knowledge really has two dimensions: we need to make sure the sales person has it in sufficient degree, and we have to make sure that an adequate amount of information, relevant to the consumer's personal situation, is conveyed by the salesperson to the consumer.

Insurance salespeople generally do require licensing by the government, and most governments establish standards of knowledge that must be attained, usually demonstrated by requiring the successful completion of an examination to qualify for licensing. Therefore we can generally assume that in fact the salespeople do have a certain level of knowledge. Even in so-called developed countries, however, the level of knowledge and understanding can be surprisingly low. Thus a gradual increase in the examination standards for licence qualification may very well be a valid means of improving the situation for consumers.

However, for the purposes of discussion here, let us assume that the salespeople do possess enough knowledge to understand the products and their uses.

The problem we will focus on is how to ensure that the agent or broker actually communicates an appropriate amount of relevant information to the consumer, such that the consumer's product choice will be an informed decision. There are a number of approaches that can be implemented:

区 Plain Language: Rather than having the terms of all contacts expressed in legal jargon, experts in plain language writing can express the terms in language that will be sufficiently precise to hold up in a court of law, while at the same time being much more straightforward and easy for the lay person to understand than is typically the case with an insurance contract. 


\section{Re-Engineering Insurance Supervision}

囚 Salespersons' Code of Ethics: A code of ethics can be designed, either as part of the supervisory regime or as part of a self-regulatory program undertaken by the agents and brokers themselves, which will require each salesperson to disclose certain key information to the prospective policyholder. Such information can include the fact that the person is a licensed life insurance sales representative -- because consumers are often given the impression that they are dealing with an "investment advisor" or similarly titled individual. In some provinces of Canada the sales person must also reveal that they are reimbursed on a commission basis, although they are not required to reveal the amount of the commission. In some countries even the amount of commission must be disclosed. Another item to be disclosed is basic product information. Each salesperson can be required to provide a description of the product being purchased, written in plain language, and setting out the main benefits and risks associated with the product. Due to its nature and the possibility of misinterpretation, this would usually be provided by way of a brochure designed by the life insurer in respect of each of its products. The consumer can be asked to acknowledge receipt of the brochure by signing or initialling a receipt which is retained by the salesperson.

Needs Analysis: Having a proper understanding of the products being sold and the situations in which each would typically be utilized to meet client needs, the salesperson is in a position to inquire into the needs of the prospective buyer to find out what factors are motivating the consideration of an insurance product. The sales person should then be able to match the product characteristics with the consumer need to ensure that there is a good fit. If the need does not match with the product characteristics, a dissatisfied consumer is an almost certain outcome. The salesperson may be required to briefly document the discussion on client needs/product characteristics, and to provide a copy of same to the prospective client, so there will be a record, accepted by the consumer, as to why the particular product was recommended by the salesperson. Such a discussion puts consumers in a much better position than otherwise because they will have a basic understanding as to the main benefits of the product. They can then also have at least a reasonable degree of confidence that such benefits are in line with their own needs. A requirement for a needs analysis can be included in a Salespersons' Code of Ethics.

Cooling Off Period: It is always a good idea to provide consumers with a statutory right to change their minds. During discussion with an amiable and highly motivated salesperson, the contract purchase can seem like a good idea, but later, when there is time to consider the purchase in more detail, the consumer may feel that they have made a mistake. A cooling off period of ten days or two weeks gives the consumer time a reasonable time in which to rethink the situation. If the consumer wishes to opt out of the contact during the specified cooling off period they are entitled to do so without penalty.

Other Sources of Insurance Information: While salespeople are clearly the primary channel for the provision of information, other approaches can also be helpful. For example, the government can prepare useful brochures concerning special aspects of insurance, such as the coverage typically provided by an automobile policy, how to go about filing a claim with your insurance company, how to compare the main features of the basic types of life insurance, the responsibilities of insurance salespeople in their dealings with consumers, and so on. In some 


\section{Re-Engineering Irisurance Supervision}

countries such brochures are distributed free of charge by placing them in information displays in shopping malls and other public places for easy access by consumers. More specialized brochures can also be distributed by more targeted means. For example, in one jurisdiction a brochure entitled "How to file a claim for auto insurance benefits" is provided to police officers for distribution at the scene of car accidents. Similarly, "Making a claim for disability insurance benefits" is displayed in hospital emergency waiting rooms.

Steps such as those enumerated above can help to put the salesperson and the consumer on a more equal footing. Well informed consumers are much more likely to purchase products that meet their needs, and when needs are being met there will be many fewer complaints. Over time this will increase confidence in the insurance system and facilitate foreign investment.

\section{Consumer Recourse and Complaint Monitoring}

There will always be some situations in which the salesperson has not acted responsibly or the consumer has not fully understood the information that has been provided. Thus there needs to be a vehicle for handling these situations, both in order to clear up misunderstandings on the part of the consumer and also to bring to light any salespersons who may be acting unscrupulously.

In some jurisdictions there is actually an insurance ombudsman -- a government appointed official whose job it is to investigate consumer complaints in the insurance area and to raise concerns directly with the insurers and the government. More commonly such complaints are investigated by the insurance supervisor's office.

We have already mentioned the supervisory benefits of this work in terms of highlighting possible financial or managerial problems in insurers which receive a disproportionate number of complaints.

There is also a benefit to be gained from a public perspective by investigating such complaints and putting the conus on the company involved to take steps to deal with any systemic problems.

The experience in Canada with salesperson complaints in the life insurance business was that typically when a complaint was justified and the agent or broker had been found to have been misleading the public, the insurer disavowed all knowledge of what had been happening, but agreed to terminate the agent as its representative. This was not very satisfactory from a public perspective because in some cases there was no doubt that the insurer had been aware of what was happening, but it was in the insurer's interest to "turn a blind eye" to the unsavoury activities. Other unscrupulous sales people could then be recruited to replace those whom they were forced to terminate. At the same time, the insurance supervisor had no legal recourse through which the insurers could be subjected to fines or other forms of penalty.

In Ontario, Canada's most populous province, the rules were therefore changed so that "every insurer ... shall establish and maintain a system that is reasonably designed to ensure that each agent complies with the Act and the regulations", that said system will "screen each agent for 


\section{Re-Engineering Insurance Supervision}

suitability to carry on business", and that "an insurer shall report to the Superintendent if it has reasonable grounds to believe that an agent who acts on behalf of the insurer is not suitable to carry on business as an agent". In this way the insurers are also made to shoulder a significant part of the responsibility for ensuring that consumers are not exposed to unscrupulous salespeople. This approach is in keeping with the corporate governance philosophy favoured in Canada and described earlier in this paper.

The monitoring of complaints by the supervisor enables the authorities to verify that insurers are doing their part in maintaining a healthy insurance marketplace, and if they are not, to take steps to deal with problem situations.

\section{Monitoring Marketplace Activities}

The tracking of written and telephoned complaints as referred to above will give the supervisor a good idea as to the sources of complaints. In larger jurisdictions it is not uncommon to have a group within the supervisor's office responsible for carrying out a specialized form of on site market conduct inspection. The objective of such an inspection is to review insurer practices in dealing with consumers, both at the level of claims handling and also in terms of proper disclosure and sales practices by agents. If there are actual statutory requirements in place as to insurers' responsibilities in this area, as is the case for Ontario mentioned above, then supervisory staff will be in a position to apply specific criteria. For example, does the insurer have "reasonable systems in place" to monitor the sales practices of its representatives? Are those systems actually applied in a consistent manner.

Most insurance companies say that they are interested in providing consumer service and meeting consumer needs. One way in which they can improve their ability to do this is to ensure that all complaints are centrally logged and investigated. If an abnormally large number of complaints are received about a certain product, or a certain agent or a certain insurance agency, it is almost certainly a sign that something is not working as it should. From a business perspective it is very much in the interests of the insurer to find out what is going wrong and to rectify the situation.

Many companies have found that by sending out well designed follow up material to consumers after a purchase, they can determine whether the sales experience has been satisfactory from the consumer's perspective. They can also double check that their agents are providing the required information to consumers. Most insurers who follow this practice also find that consumer loyalty is increased because consumers appreciate a company taking the trouble to follow up in this way.

Thus not only does proper investigation of complaints, combined with pro active steps to head them off, protect the insurer against possible difficulties with the insurance supervisor, it is also good business because it leads to the design of better products, helps to build a more effective sales force and increases product and company loyalty. 


\section{Re-Engineering Insurance Supervision}

\section{E. Role of Dispute Resolution}

In some countries a formal system of dispute resolution has also helped to increase confidence in the insurance system. While recourse to the courts is usually an option, it is often not a very satisfactory solution for the resolution of many types of insurance problems. Disputes over coverage, including claims, are often too minor to be efficiently dealt with through what is typically a somewhat ponderous and over loaded court system.

A system of dispute resolution is usually designed in two stages. The first stage is mediation, which consists of having the parties meet with a trained mediator, knowledgeable with regard to insurance contracts and coverages. The mediator discusses the contentions of each party with a view to bringing them together. Quite often there have been misunderstandings between the parties, and the mediator can be successful in resolving the differences, either by means of a compromise or by assisting one of the parties to understand why their position is not valid.

The second stage of the dispute resolution process is usually binding arbitration, which can only be proceeded with after the mediation process has been completed. The arbitrators are often lawyers with specialized knowledge of insurance and contract law, but they may also have other backgrounds, with additional training in arbitration techniques and insurance.

The main advantage of the dispute resolution process is that lengthy and expensive court battles are avoided, which not only saves time and money for the parties to the dispute, and so for the insurance system as a whole, but it also avoids even greater pressures being placed on the court system. In a number of countries, automobile insurance claims virtually always go to court, often with years passing before the actions are heard. Such approaches undermine the efficacy of the entire insurance system, with predictable impact on both the credibility of the insurance industry and the country's reputation as a financial and business centre. Foreign investors will certainly not be attracted by a business environment where even what seem to be straight forward insurance disputes take years to settle through a hugely over burdened court system, if they are ever heard at all.

Therefore dispute resolution helps to increase the efficiency with which the insurance system can meet its objective as a mechanism for spreading risk on a fair and even basis over large numbers of policyholders. Dispute resolution systems are sometimes formally established by the government, in which case they may be organized as a part of the insurance supervisor's department. In other cases dispute resolution systems have been established apart from government, by an enlightened insurance industry which understands that fair and speedy settlement of insurance disputes is very much in the interests of the industry.

\section{F. Rate Regulation}

In some jurisdictions insurance premiums have become insupportably low, so that even when combined with investment income there is not sufficient revenue to pay claims and cover expenses, leading to insurance company insolvencies. This phenomenon of untenably low 


\section{Re-Engineering Insurance Supervision}

premiums can occur when there is no industry pooling of rating and claims statistics, so that individual insurers, unless they are very large, do not have credible data which can be used for premium setting purposes. And unlike most other businesses, property/casualty insurers don't know the ultimate cost of the product they are selling until long after it has been sold. Accordingly, pricing must be based on actuarial predictions as to the expected frequency and severity of losses. In practice, this factor also gives rise to a certain "elasticity" in pricing -- for large commercial risks, for example, there may be a tendency to bid down the price in order to get the account, hoping against hope that no major loss will occur while your company is carrying the risk, or that the premium can gradually be increased in future years. In the absence of a credible data base, insurance company managers can all too easily fall prey to this type of "wishful thinking underwriting", which can lead to substantial losses.

High rates of inflation can also lead to premiums being insufficient to cover claims because premium rates are based on the claims experience of prior periods, but are applicable to future periods. If tomorrow's claims have to be paid with what in fact are yesterday's dollars, and the latter have only a fraction of their earlier value, then the premium will have been understated, possibly very significantly depending on the rate of inflation. Another factor which can contribute to insufficient premiums is under reserving for claims, either purposeful or inadvertent, so that the true cost of claims is not fully recognized, sometimes for an extended period of time.

Theoretically premium rates could also be unnecessarily high, resulting in additional cost to consumers and returns to shareholders which are higher than warranted to compensate for the risk of investing their capital. In practice, we must say we have never actually encountered such a situation, presumably because in the absence of price fixing, competitive pressures will tend to push rates down. Also, in smaller and developing countries, when insurance is perceived by the populace to be too expensive, it tends to be foregone, again tending to push down the price.

In many jurisdictions governments require premium rates to be filed with the supervisor for approval. This is most often the case for auto insurance premiums in jurisdictions where there is compulsory auto insurance, although in some countries rate approval applies to all classes of insurance business. As an example from the auto insurance area, in the province of Ontario, Canada, the Insurance Act indicates that no company may charge a rate for auto insurance which is greater than is reasonably required to make an acceptable return on the shareholders' equity required to support the business, nor may it charge a premium which is so low as to imperil the company's solvency. In other words, premiums to be neither too high nor too low. These are the criteria that guide the supervisor when considering applications for auto insurance rate approvals.

When premium rates are filed with the supervisor they are supported by actuarial analyses, supposedly demonstrating that the two criteria just mentioned have been met. The supervisor also has actuaries who specialize in auto insurance pricing. If they disagree with the filing company's actuaries they can withhold approval and a debate will take place with regard to the appropriateness of the rates. Whether or not the rates are entirely appropriate, the process almost certainly increases the discipline underlying the insurance pricing process. The process need not be unduly bureaucratic because a "file and use" system will permit the company to begin using the new rates if the supervisor does not object within a certain period of time. 


\section{Re-Engineering ] [nsurance Supervision}

A difficulty with direct government involvement in the establishing of premium rates is that there can be a temptation on governments, for political reasons, to keep rates artificially low. If claims experience is poor, then the costs must be passed along to the insuring public in the form of higher premiums -- that is the concept of insurance. So to be effective, premium regulation must be carried out in an environment of objectivity, with rate reviews strictly based on actuarial criteria. Another important factor is to ensure that the process is not subject to undue delay. If an insurer needs a rate increase of $10 \%$ and has direct premiums of $\$ 100$ million per year, a six month delay in approving the increase means a $\$ 5$ million shortfall in the company's ability to cover its claims and expenses.

One can argue about the virtues or otherwise of direct government intervention in the rate setting process. But if inordinately low premium rates are an important contributing factor in a high insolvency environment, government intervention will occur in any event during the liquidation process. If it significantly reduces the number of insolvencies, it may be preferable to take action more directly by way of a premium approval process.

\section{G. Unlicensed Insurers and Intermediaries}

Unfortunately there are fraudulent insurers who specialize in coming into a country, selling products which will never provide any benefits, and then disappearing along with the premium income. Of course the premiums charged by such "insurers" can be very low, given that they will not be paying any claims.

Unsuspecting consumers may be sold these fictitious policies, and when a claim occurs the results can be disastrous. The business owner who insures his plant and equipment, experiences a serious fire, and then discovers that his insurer does not actually exist, is in a terrible situation.

Normally it is hoped that the insurance supervisor will be able to avert this type of situation through the requirements for company licensing, minimum capital and the other requirements whose purpose is to make sure that only licensed companies do business, and that all licensed companies are solvent.

Nevertheless, it is difficult to prevent unauthorized insurers and intermediaries from entering the marketplace, at least until they have sold enough policies that their activities come to the attention of the supervisor. A complicating factor is that in most jurisdictions consumers are not prevented from buying insurance from insurers outside the country, because there will likely be specialized coverages required from time to time which will just not be available within the country. Normally, however, unlicensed insurers would not be permitted to actively solicit business within the country if they are not licensed there.

When fraudulent insurance is sold it is often through licensed intermediaries, since they are the ones who are in contact with persons who need insurance. Of course in most instances they will claim that they did not know that the insurer was not legitimate. 


\section{Re-Engineering Insurance Supervision}

While there are no guaranteed means by which the public can be protected from fraudulent unlicensed insurers, there are a number of deterrents used in different jurisdictions. A menu of these are set out below:

囚 "Special broker's licence" required to sell any policy issued by an insurer that is not licensed. The Special Broker's Licence requires the posting of a bond or deposit with the supervisor (in case of problems) and also is issued only to large, well established and reputable brokerage concerns, since their staff can be expected to have sufficient expertise to verify the credentials of any unlicensed insurer with whom they put consumers in contact. Other brokers cannot claim that they were "tricked" into representing a fraudulent insurer because they will know that the Special Licence is required in order to put any client in touch with an insurer that is not licensed.

囚 Excise tax on premiums charged by insurers not licensed in your country, payable by the policyholder, unless the coverage is not available within the country. This discourages consumers from shopping abroad for insurance, which may expose them to fraudulent or unregulated insurers that are not solvent. The excise tax has to be collected by the broker and remitted to the government. A problem with this approach is that it is difficult for the government to know whether the proper amounts of tax are being remitted by the brokers.

Disclosure form provided by broker and signed off by policyholder. With this approach the broker is required to provide any consumer who, for whatever reason, decides to purchase insurance from an unlicensed insurer, with a detailed disclosure form indicating that the unlicensed company is not subject to the solvency requirements applicable to licensed insurers, may not have funds in the country to facilitate the payment of claims and that neither the government nor the supervisor will be able to be of assistance if there are problems obtaining payment. The form is required to be signed by the consumer, with one copy for the consumer and the other retained by the broker for his or her records.

Liability of agent or broker. The law can make the intermediary who sells the policy of the unlicensed insurer, liable for any legitimate claims that are not paid by the unlicensed insurer, if the broker has been negligent in looking into the credentials of the unlicensed insurer. In other words, if the broker has been fooled by a clever unlicensed insurer, he or she might not be held liable in the event of non payment of claims. On the other hand, if the broker has scarcely bothered to check into the situation (and having in mind that the broker is supposed to have some expertise in these areas, or so it is being represented to the consumer) then the broker could be found liable for claims not paid by the unlicensed insurer.

X Cease and desist orders. The supervisor can be authorized to issue a cease and desist order in respect of any insurer, or person unlawfully representing an insurer, that does not hold a valid licence. This can be quite effective in rooting out an unscrupulous unlicensed insurer and/or their representatives if they are setting up shop in your country. It would be rare that a fraudulent insurer would try to defend a cease and desist order in court. They will generally find if easier 
just to go to other jurisdictions where the supervisor does not have such authority.

Depending on the particular circumstances within a jurisdiction, any combination of the above deterrents may be effective in keeping the country free of these fraudulent operations. Probably the best deterrent of all is to ensure that the local insurance market remains competitive and efficient so there is little incentive for the public to seek out cut rate operators.

\section{H. Marketplace Supervision: Conclusion}

The monitoring of marketplace activities by both the insurance supervisor and by individual insurers, the presence of dispute resolution facilities where there is a need for them, the licensing of key individuals in the insurance cycle, the protection of consumers from fraudulent insurers and sometimes even direct intervention in the price setting process, can all help to provide a more stable insurance market. Perhaps the most important constituent of a stable marketplace is a well informed insurance consumer, who almost by definition, will also be a more satisfied consumer.

All of these things have the potential to increase public confidence in the system of insurance and the system of financial supervision generally within the country. This in turn will help to inspire confidence on an international scale.

\section{Special Problems for Smaller Countries}

\section{A. The Question of Resources}

Small countries having very limited budgets face a number of difficult challenges in their efforts to improve the efficiency and effectiveness of the insurance supervisory system. For example, it is usually hard to attract and retain personnel who have the qualifications referred to above (see "Supervisory Infrastructure Issues"). In addition, budgets for computer equipment and systems will probably be less than what is required to do a proper job.

There are ways in which economies can be realized, however.

We have already discussed the benefits that can be obtained by working on a regional basis. The regional basis of supervision offers the potential of great benefits to the industry as well as to the supervisors and their governments, so it can truly be a "win-win" situation. For a group of reasonably contiguous countries sharing the same language, harmonized supervisory requirements, including financial filings, will mean less difficulty in attracting staff, because there will be a larger number of opportunities for advancement and a larger pool within which one's expertise can be applied. Economies will also be realizable in staff training because several countries will be able to share the staff training costs. There could also be important savings in terms of computer hardware by obtaining volume discounts on orders. Even more pronounced will be savings on the development of computer software. Specialized software can be extremely expensive, and if a number of countries having identical requirements can reach 


\section{Re-Engineering Insurance Supervision}

consensus on software design, the savings can be enormous. Finally, the supervisory system in each of the individual countries will tend to be more effective when there can be a sharing of information and experience in the administration of what is essentially the same legal framework.

Another point to keep in mind is that the supervisory approaches and techniques we have talked about in the preceding sections, are almost certainly more efficient than many of the techniques currently being employed. In these cases, even if the current budget is frozen, one should be able to do a more effective job for the same amount of money that is currently available.

We have also spoken about the value of staff training. In the case of the smallest countries the benefits are even more marked. With a small staff a high degree of specialization is usually out of the question. Staff members are often forced to be generalists, so that, for example, one group of employees carries out the on site inspections and is also responsible for all of the financial analysis work. Training programs can be designed for the specific purpose of cross training individuals so as to provide greater flexibility in the deployment of staff.

In general, the best training approach when limited budgets are a factor, is what is known as "train the trainers". As the name implies, the idea is to select a few key personnel in each area and undertake to have them well trained. Then as part of their job specifications, these employees can be put in charge of training other employees within the supervisory agency. While it is true that some training programs can be expensive, we have found that international agencies such as the Inter-American Development Bank, the World Bank and so on, will often be inclined to provide financial support to such efforts.

Training is also available in some cases directly with supervisory agencies in developed countries. This type of training is free, except for the costs of travel, accommodation and food while visiting with the developed country supervisors.

Another area of assistance that may be particularly relevant in smaller countries is the industry association in the country concerned. In most cases the industry association, recognizing that its members will also benefit from a more skilled group of supervisory employees, will be pleased to assist with the basic training of the supervisory staff in respect of fundamentals of the insurance business. In Canada, supervisory staff regularly attend seminars and training sessions which are primarily designed for industry employees. In addition to the training advantages of such sessions, it is an opportunity for supervisory staff to make contacts with people in the industry, which we believe is generally beneficial as well.

Many of the areas for upgrading the supervisory system do not actually require any budget, and these are the areas to focus on initially in cases when monetary resources are a serious problem. For example, redesigning the financial filing so that it provides all of the information needed to calculate the Early Warning Tests and other key financial indicators will often be within the capabilities of the supervisory staff.

The supervisor should also bear in mind that the insurers themselves are also a resource in that many of the ratios and other necessary information can be computed by the insurers and filed in a 
form that is exactly as the supervisor designates. This has the double benefit of making sure the supervised companies are also well aware of the ratios, trend analyses and so on that are being reviewed by supervisory staff. Our experience in Canada has been that by requiring insurers to file, not just financial data, but information, including five year trends in key ratios and indicators as well as other financial and operational information, all set out in a way that makes for easy interpretation, insurers have become much more interested in the exhibits and use them themselves for rneasuring and tracking their performance. In short, if the required filing consists of a well designed package of information it will not only be useful to the supervisor, it will also become an important management tool for the insurers.

As with improvements in the financial analysis area, a large budget is not required to carry out the inspection procedures in a way that will provide maximum value for effort. As we have already discussed, three straightforward concepts are involved: (1) identify companies having higher than normal levels of financial risk, (2) identify the functional areas within those companies where these risks are most likely to be evidenced, and (3) focus the inspection efforts in those areas.

By contrast, cornputerization is an area where large amounts of money can be required to develop specialized systems. Sometimes such systems will be worth the major investment that is required. On the other hand, smaller countries should be aware that "off the shelf" software is available in the developed countries for analysing the financial positions of insurance companies, including in many cases a comprehensive data base comprised of virtually all the information filed with the supervisors. In Canada there are two such commercial software systems available, both of which are frequently utilized by interested parties to carry out various analyses of Canadian insurers and reinsurers as well as industry trends. Such software can often be redesigned for relatively little cost to meet the needs of insurance supervisors in developing countries. While such software may not have all the features of "customized" software, we think most supervisors will find it quite powerful.

Notwithstanding all of the foregoing, smaller countries must also ensure that pay levels and public service job levels for insurance supervisory staff are commensurate with the responsibilities being undertaken. We have met individuals in a number of countries who are truly dedicated, in the sense that they continue to do their best in a situation where they are significantly under compensated, even by the standards in their own country, and where they could receive far greater monetary rewards by taking a position in the insurance industry. While this type of dedication is admirable, it should not be necessary. Countries that do not reasonably compensate their insurance supervisory personnel will experience high levels of turnover and will tend to have staff who are not of the calibre required to implement the challenging reforms discussed in this paper.

While smaller countries do have special problems, there are ways in which these problems can be addressed. Admittedly there will be challenges, but we believe that even for the smallest of countries, modernized insurance supervision can be a reality. 


\section{Re-Engineering Insurance Supervision}

\section{B. Importance of Support From the Ministerial Level}

It is of course true in every country, no matter what its size or state of economic development, but in smaller countries the full support of the responsible Minister is absolutely crucial to the success of any re-engineering of the insurance supervisory system.

Here are some reasons why the Minister may agree that a carefully thought out package of initiatives will be extremely worthwhile:

$凶$ The country's own citizens, international investors and other governments must have full confidence in the financial infrastructure of the country if the country is to maximize trade, encourage tourism and generally participate in the global economy.

While the banking structure and bank supervision are vital to achieving this goal, the insurance industry is also a major generator of financial cash flows and the supervisory regimes must be comparable.

Ⓘn the public mind, including at an international level, financial problems in the insurance sector will be interpreted as instability in the financial system generally, which will have serious adverse effects in terms of achieving the goal of international recognition and acceptance of the country's financial system.

An approach which emphasizes the importance of corporate governance will, over time, help to avert a need to constantly add to the number of supervisory personnel required to do the job. It will also build a corporate infrastructure within the country which will be more responsible and accountable to the public, government and shareholders.

$凶$ Funding assistance is available from international agencies because they recognize the importance of building sound financial institutions as a base for a developing economy.

Additional assistance can generally be arranged through the participation of supervisory agencies in developed countries.

When the re-engineering work is underway it will also be vital to keep the Minister and his or her staff updated as to the progress being made. We suggest that status reports be prepared on a regular basis for circulation to those concerned, including the Minister. As well, it is usually helpful to meet with this group from time to time so that information can be provided in a more personal way and to give those attending an opportunity to ask questions and to engage in discussion. If outside consultants are involved in the project it is generally helpful to arrange for them to participate in these meetings.

The insurance industry also has a vital interest in the proceedings and we suggest that any industry organizations be provided with status reports from time to time. As we have mentioned earlier in this paper, industry input is crucial when the project is being planned because industry 


\section{Re-Engineering Insurance Supervision}

personnel are in a position to make a worthwhile contribution, particularly in terms of dovetailing supervisory requirements, to the extent possible, with existing company practices, thereby contributing to the greater efficiency and effectiveness of the system as a whole. Similar comments apply to the country's organizations of professional accountants and actuaries, especially in terrns of financial reporting requirements, audit requirements, solvency test design and other technical matters.

Once the project has been designed and approved by the Ministry, we suggest that for the most part communications with the industry and professional organizations be more in the nature of updates. You will probably not want to give the impression that you are looking for a never ending series of suggestions and ideas for discussion.

\section{Building Professional Support for the Supervisory System}

Throughout this paper we have emphasized the benefits to be attained by gradually increasing the role of corporate governance in the supervisory system.

An important aspect of this approach is the function of professional advisors such as auditors and actuaries in providing reasonably unbiased advice, reporting results and information to boards of directors and to the supervisor. In smaller countries this can present a difficult problem as the network of professional advisors is often very limited. As well, there may be little in the way of formal standards with regard to professional qualification. A third common difficulty is that standards as to the procedures and practices that will be followed by the professional advisors are not specified. Therefore significant inconsistencies may occur in the treatment of similar situations within companies, depending on the personal view of the professional advisor. Needless to say, the possibility of major inconsistencies will make it difficult to allocate the auditors and actuaries an important role in the supervisory process.

One way in which the situation can be improved is by taking a regional approach as we have suggested in conjunction with some other issues discussed earlier. Professional organizations of auditors and actuaries, no matter how disparate their professional situations may currently be, can see the advantages of playing a more central role in the supervisory/corporate governance process. They therefore have an incentive to raise the standards to a level with which the supervisor and the government can be satisfied. (In doing so, they will of course not only provide benefits to the supervisory system, but they will also provide an important benefit to the country as a whole. International businesses and investors want to locate where there is a system of sound and reliable professional advisors who can assist them with local and regional business issues.)

By working with their professional colleagues in nearby countries they can often move more quickly to establish satisfactory standards, especially if one or more of the neighbouring countries actually have standards in place that are closer to what is being sought. 


\section{Re-Engineering Insurance Supervision}

A similar strategy is to actually "borrow" the standards from another country. For example, we understand that in the country of Barbados, the accounting profession has adopted the Handbook of the Canadian Institute of Chartered Accountants. In this way a smaller country that would not have the resources available to an organization such as the Canadian Institute of Chartered Accountants, is able to benefit from the larger organization's research and professional developments.

Of course it is likely that international firms of auditors and actuaries will be represented in the country. These firms, with their international connections, will often be in a position to provide particular assistance in dealing with these issues.

Whichever specific options are followed, discussions between the supervisors and the professional advisors will be vital to making progress. If the decision is made to develop domestic standards which will meet the needs of supervisors, business people and the professional groups themselves, it will be necessary to work with those groups over a period of time. We have earlier referred to the need to set up working groups comprised of members from the office of the supervisor, the professional advisors and the industry in order to develop standards and reporting protocols that will meet the requirements of each group. This is not an easy task, and will often have to take place over a period of several years. (For more discussion on this, please see "The role of Professional Standards in the Auditing, Accounting and Actuarial Areas.")

\section{Special Supervisory Requirements in the High Inflation Environment}

In our previous discussions regarding Early Warning Tests and the monitoring of other financial variables, we did not consider the special problems that will arise in a high inflation environment.

When inflation is at a rate such that the time value of money becomes a significant source of distortion from one reporting period to the next, all variables will have to be deflated to provide meaningful period to period comparisons. For example, when looking at growth rates and rates of change one should be comparing real rates of change rather than absolute rates of change. Therefore every numerical period to period comparison must be on the basis of inflation adjusted numbers rather than inflated numbers. When comparing two variables from the same period, such as the ratio of net premiums written to capital and surplus, it will not be necessary to make any adjustment as both variables will have been subject to the same degree of inflation.

Financial filings can be modified to require the use of deflated comparative figures, as long as the index of inflation is specified to ensure consistency.

Real estate is an area that raises serious supervisory issues in a high inflation environment. With other, more liquid types of investments the market values will be impacted by inflation, but they should be able to be sold at their inflated prices. With real estate the impact of inflation can be substantial, but it is often far from clear that the true market values of the properties concerned are growing at the general rate of inflation in the economy. If real estate is routinely written up 


\section{Re-Engineering Insurance Supervision}

to take account of inflation, the supervisors may be deluding themselves as to the real financial positions of companies with significant real estate holdings. If the rate of inflation is quite high, it will not be a very long time before a considerable portion of companies' surpluses are comprised of the write up of property values. If the properties are not readily marketable at these prices, then a large part of surplus will be represented by a non realizable asset. Financial supervisors will generally not give credit for non realizable assets when they calculate minimum solvency requirements and other financial ratios that are dependent on a company's equity base. Therefore it may be necessary to apply a factor to the equity base to take account of the non realizable portion of real estate write ups when making these crucial solvency calculations.

Ratios involving net income or other income statement measures, may likewise be impacted by real estate write ups if the accounting treatment is to pass such adjustments through the income statement. Again, supervisory adjustments may be in order.

As we have mentioned previously, retired bankers are often a good source of advice for the supervisor in looking at real estate values and making judgements about the treatments that might be appropriate. It is often possible to retain, on a contract basis for a specified period of time, individuals having a vast amount of hands on experience in dealing with and evaluating real estate transactions. Such individuals can provide invaluable assistance to the supervisor in situations where unusual supervisory issues arise because of high rates of inflation.

\section{Conclusion}

Throughout this paper we have tried to stress the co-operative nature of the supervisory process. Boards of directors and management of companies have by far the greatest amount of knowledge about their companies' operations. Thus it will be to the benefit of both the financial system supervisors and the supervised institutions themselves if these corporate personnel formally assume responsibility for ensuring that their organizations operate in accordance with sound business and financial practices. We have also emphasized how the substantial resources of auditing and actuarial firms, and their professional institutes, can be aligned with the interests of financial supervisors, boards of directors and company management, to support a system of supervision that fosters the development of dynamic, financially sound and profitable financial institutions. Other resources such as industry associations can also play a helpful role in the supervisory process. Self regulation can be an area for further exploration, especially in the supervision of the activities of sales intermediaries. It can be argued that the entire corporate governance approach is a form of evolutionary move towards industry self regulation, although even in the developed countries this is far from the present reality.

Developing countries have much work to do in the area of supervisory upgrading, but at the same time we are optimistic that they can build on the experiences of the developed countries, profiting from the learning experiences of those countries in terms of approaches that have worked and those which have not. Where special techniques are required in the developing country environment -- and we think those situations are fewer than might first be supposed -- they can 


\section{Re-Engineering Insurance Supervision}

usually be framed as modifications of tried and true approaches from developed countries rather than having to be considered as entirely new procedures. 


\section{Appendix 1}

Corporate Governance as a Key Supervisory Approach 
Appendix 1

\section{Appendix 1: Corporate Governance as a Key Supervisory Approach}

\section{Background}

A number of the writer's approaches to supervisory upgrading in developing countries are influenced by the system of financial supervision as it has evolved in Canada, which emphasizes the role of corporate governance. Accordingly, it may be useful to provide an overview of this system and some of the factors that have led to its design.

In the mid-1960's, new employees at Canada's insurance supervisory agency (such as the writer) were proudly told by old timers that Canada hadn't had an insurer insolvency since the late 1920's, and no Canadian life insurance policyholder had ever suffered a loss as a result of an insolvency. The reasons for this outstanding record were considered to be obvious: Canada had high supervisory standards with high calibre supervisory personnel to match.

Unfortunately we can now report, with the benefit of hindsight, that this confidence was misplaced. While the supervisory system may have be comparable to that found in other developed countries, what we had actually witnessed was probably more the result of an unprecedented period of prosperity and economic growth after 1945. In fact it was probably this prosperity which was responsible for the excellent supervisory record -- a case of a rising tide raising all the ships.

In the early 1980's, Canada's economy began to run into rougher waters, with greater volatility in interest rates and inflation than we had seen previously. The rate of inflation actually reached an annualized level of close to $20 \%$ in 1982 , driving interest rates above that level. This was relatively tame compared to what has had to be faced by some other countries, but it posed difficult problems for many financial institutions that had not anticipated the possibility of such conditions. As well, we saw the appearance of "stagflation", or inflation and economic stagnation impacting the economy at the same time. These factors had particular impact on insurers because, as in other countries, insurers had increasingly come to rely on investment income as their main source of profit.

Coinciding with the emergence of this more difficult macro economic environment, a more entrepreneurial group of manager/shareholders was taking an interest in the financial sector. Until then in Canada, financial institution ownership and boards of directors had tended to be the domain of long established banking and insurance groups. These traditional institutions seemed to have an awareness of the importance of their fiduciary responsibilities and were conservative in their risk taking. In contrast, some of the new entrants to the financial institution business viewed trust companies, insurance companies and even banks as just another vehicle for generating returns for the owners. Moneys brought in by way of premiums or deposits were not regarded any differently than revenues from their other businesses. Canada's financial supervisors had been much more used to dealing with the former group than the latter. 
Insolvencies are complex matters, making it difficult to generalize, but most would probably agree that greater economic variability combined with less conservative institutional management and boards of directors, were significant factors in the insolvency of a number of small banks, major trust companies, property/casualty insurers, and most recently, several life insurers. In 1993, Confederation Life, one of the country's largest life insurers with total assets of approximately US $\$ 20$ billion, was closed by the supervisors.

\section{Recent Developments}

The institutional failures were reviewed by various government committees and a number of important changes in the supervisory structure were made as a result. Some of the most significant of these were (1) the placement of tight restraints on the ability of institutions to enter into transactions with affiliated corporations or persons, (2) greater power to the regulators in terms of being able to order companies to change their business practices, (3) some restraints on the utilization of reinsurance, and (4) changes in the investment powers of companies, including changes in the rules regarding investments in real property and mortgages.

However, after the spectacular failure of Confederation Life, government policy makers seemed to conclude that continuing to "beef up" the supervisory regime, by giving the regulators more powers, continuing to add to the complexity of supervision and so on, was a no win game. Another approach was needed.

There were two basic facts supporting this conclusion. First of all, in a number of cases the insolvencies had been anticipated by the regulators well before the actual event. The problem, however, tended to be twofold: (1) they could not take action until able to effectively "prove" that the institution was insolvent, by which time it was too late to do otherwise than wind up the company and (2) concerns expressed by the regulators had not been adequately dealt with by management and boards of directors. Some felt that the key was to empower the regulators to move at an earlier stage, as an institution's financial position was deteriorating. However, the government was reluctant to empower regulators to move much sooner because what if the regulators were wrong? Supposing the company will be able to overcome its difficulties and return to financial health -- as management and the shareholders will usually argue is the case.

This is by no means an academic concern, because while it is true to say that the regulators were almost always of the view before an insolvency that a company was headed for failure, it may very well also be true that they had the same feeling about other institutions which actually were able to overcome their problems and regain their financial health. This should not be surprising, because just as an investment dealer or mutual fund may be able to boast that it had recommended the best performing stock of the year to its clients, the institution probably also recommended many other stocks having very different levels of performance. Also, as any supervisor will surely admit, regulators, like other members of the human species, are certainly not immune from making incorrect judgements. In this situation, a wrong decision can irreparably damage those who have invested their capital in the institution, as well as possibly take away the livelihood of many employees. Therefore there must be a high probability that errors are not made. 
The other major factor that, we believe, led the government away from a "more of the same" approach to insurance supervision, is that when one looked at the problems that had arisen in the failed institutions, they often involved decisions and strategies adopted by the companies, which, after the fact, one could sometimes criticize as being misguided, but which usually could not be characterized as being illegal or contrary to the insurance act. Like all businesses, insurers enter into contracts, develop new products, enter new markets, make investment decisions and so on, and any one, or more, of these can turn out to be the wrong course of action, leading to financial difficulties. Clearly, legislative action cannot preclude the possibility of such situations from occurring.

The main change, and in our view, the most important change in the Canadian supervisory regime over the past many years, was to turn away from a view that the supervisory system by itself can prevent insolvencies.

\section{Corporate Governance Requirements}

The government moved down a new road by supplementing the more traditional approach with a series of requirements intended to ensure that the board of directors will be fully responsible for the overall direction of the institution and for seeing that it operates in accordance with "standards of sound business and financial practice". Both general and specific responsibilities are placed on the directors, and the provisions of the law are intended to make sure they will have the tools needed to carry out these responsibilities. The main features of the corporate governance model are outlined below:

- Board has duty of care, to manage the company in accordance with standards of sound business and financial practice.

- Board must establish an audit committee, consisting of at least three directors, a majority of whom are totally independent of the shareholders and none of whom are members of management, to review the annual financial statements before approval by directors, review other returns specified by the Superintendent, ensure appropriate internal control procedures are in place, review such investments and transactions that could adversely affect the well being of the company as the auditor or any officer of the company may specify, meet with the auditor to discuss the annual or other returns and transactions, meet with the actuary of the company to discuss the parts of the returns completed by the actuary, meet with the internal auditor or other appropriate officer and the management of the company to discuss the effectiveness of internal control procedures.

- Board must establish a conduct review committee, consisting of at least three directors, with membership requirements identical to the finance committee, to establish procedures for the review of any transactions with related parties. (Most transactions with related parties are prohibited by law but the conduct review committee is responsible for reviewing and approving, prior to the transaction, any non-prohibited transaction between the insurance company and a 
related party). The main criteria for approval are that the transaction occurs at prevailing market rates and the that the transaction not be prejudicial to the interests of the insurer.

- Board must establish procedures, to resolve conflicts of interest, to restrict the use of confidential information and to designate a committee to monitor these procedures.

- Board must establish written investment and lending policies, standards and procedures, to ensure that the company follows "investment and lending policies, standards and procedures that a reasonable and prudent person would apply in respect of a portfolio of investments and loans to avoid undue risk of loss and obtain a reasonable return".

- Board must appoint a CEO, who is ordinarily resident in Canada.

- Board composition, is to consist of at least 7 directors, at least $75 \%$ of whom must be Canadian residents, and of whom at least one third are fully independent of the company and its shareholders.

- Board appointments, include responsibility for the independent auditor and the actuary who will carry out the valuation of the company's liabilities.

- The company must follow accounting principles that are in accordance with the Handbook of the Canadian Institute of Chartered Accountants (Canadian Generally Accepted Accounting Principles).

- The company must be audited each year by a qualified firm of Canadian Chartered Accountants, led by a partner of the firm who has at least five years of experience in carrying out financial institution audits.

- The company must obtain an actuarial valuation of its actuarial and other policy liabilities each year from an actuary who is a Fellow of the Canadian Institute of Actuaries, in accordance with Canadian Generally Accepted Actuarial Practice.

- The auditor and actuary have to report to the board and the Superintendent if either becomes aware of a situation which they believe could materially affect the well being of the company.

- In the event of the termination of the auditing or actuarial relationship with the company, the auditor or actuary have to put the reasons for the change, to the best of their knowledge, in writing to the Superintendent with a copies to the board and the newly appointed auditor or actuary.

- Board members can be indemnified against liability only if they have "acted honestly and in good faith with a view to the best interests of the company" and "had reasonable grounds for believing that the impugned conduct was lawful". 


\section{Standards of Sound Business and Financial Practice}

The foregoing changes mainly became effective in 1992. Since that time there has been a further progression, with the life insurance and property/casualty insurance industries developing draft "Standards of Sound Business and Financial Practice", which are intended to provide a framework for boards of directors in terms of the higher risk areas where they should be focusing their oversight activities. The generic Standards currently being developed indicate the areas in which the board should be developing specific policies for management to follow. Each company's board will develop operating policies to govern their activities in the areas covered by the Standards. It is anticipated that over the course of the next several years these guidelines will be formally incorporated into regulations.

For life insurers, the current draft Standards cover the following areas:

- Capital Management

- Credit Risk Management

- Foreign Exchange Risk Management

- Securities Portfolio Management

- Real Estate Appraisals

- Interest Risk Management

- Liquidity Management

- Internal Controls

- Product Design \& Pricing Management

- Underwriting \& Liability Management

Due to the different risk profile of property/casualty insurers, several of the above categories are considered unnecessary, but some other business areas take on a higher degree of importance. For property/casualty insurers the Standards are still in a preliminary stage, but it is anticipated that they will include the life areas plus several additional areas that have greater importance for property/casualty insurers, such as reinsurance and possibly "Earthquake Risk Management".

By placing additional responsibilities on boards of directors, governments should be able to reduce future demands for additional supervisory resource. Even so, as the regulated industry becomes larger and more sophisticated, supervisors will understandably find that they need additional manpower, computers, more complex legislation and so on.

While we would argue that current realities are such that every supervisory agency requires a certain minimum resource base (see "Resource Requirements of the Supervisor"), the corporate governance model at least opens the door to the minimization of such a process. A relatively small but skilled and well equipped group of supervisors can be highly effective when their 
efforts are supplemented by a much larger group of boards of directors who have, or should have, intimate knowledge of their organization's activities. With the directors in turn backed up by professional actuaries and auditors, we have, in effect, vastly increased the scope of supervision, but without the need for any similar increase in government resources.

A further advantage is that to the companies, the involvement of boards of directors and professional advisors will not be seen as, and will not be, intrusive forms of supervision.

In making these comments we hasten to add that we are by no means suggesting that the type of framework just described is in fact the system that should be adopted universally. In fact, as we have noted in the body of this paper, in many (perhaps most) developing countries, the prerequisites of such a system are not presently in place. One major element is a reliable, well trained cadre of professional advisors in the form of auditors and actuaries. As we point out, in most developing countries the development of such groups is an issue that must be addressed as part of the supervisory re-engineering process. 


\section{Appendix 2}

\section{Early Warning Ratios for P/C Insurers}


Appendix 2

\section{Appendix 2: Early Warning Ratios for P/C Insurers}

The table below summarizes the series of ratios that are typically used to "flag" potentially higher risk companies on the basis of their current balance sheets and financial results.

\begin{tabular}{|c|l|l|l|}
\hline Test No. & \multicolumn{1}{|c|}{ Ratio } & \multicolumn{1}{c|}{$\begin{array}{c}\text { Unusual Values } \\
\text { Over }\end{array}$} & \multicolumn{1}{c|}{$\begin{array}{c}\text { Unusual Values } \\
\text { Equal to or Under }\end{array}$} \\
\hline 1 & Gross premiums written to equity & 9 & \\
\hline 1 A & Net premiums written to equity & 3 & -33 \\
\hline 2 & Year over year \% change in net writings & 33 & \\
\hline 3 & Percent surplus aid to surplus & 15 & \\
\hline 4 & Two year overall operating ratio (\%) & 100 & based on market \\
\hline 5 & Investment yield & based on market & -10 \\
\hline 6 & Year over year percent change in equity & 50 & \\
\hline 7 & Liabilities to liquid assets (\%) & 105 & \\
\hline 8 & Amounts due from agents to equity (\%) & 40 & \\
\hline 9 & One year reserve development to equity (\%) & 20 & \\
\hline 10 & Two year reserve development to equity (\%) & 20 & \\
\hline 11 & Estimated current reserve deficiency to & 25 & \\
\hline & equity (\%) & & \\
\hline
\end{tabular}

These tests are often adapted by local supervisors to take account of market conditions in their own country. The "unusual ranges" shown above are more or less for companies operating within the North American environment. For some of the ratios, and in some countries, little adjustment of the normal range will be required. In other countries more significant adjustments will be needed. We would usually expect to see roughly ten percent of the companies outside the normal range on a given test. If there are market conditions that affect a particular group of test parameters it might be reasonable to have a higher percentage of the companies outside the range for that test. For example, in a newly developing market where capacity is still quite limited, the unusual value for test 3 , which measures a company's dependency on reinsurance commissions for profitability, might be somewhat higher than the $15 \%$ shown in the table, which is generally accepted as a yardstick in more mature markets. For similar reasons, in a developing market we would normally expect test 2 , net premiums written to capital and surplus, to have a higher value on average than we would see in a developed market.

In a normal year (a year with a large drop in the stock market, or a year in which there is a catastrophic event such as a severe earthquake, for example, might not be a "normal" year) about $15 \%$ of the companies will be outside the normal range on 4 or more tests.

In each country the supervisors will want to run the tests to see what results are yielded. Then the "unusual ranges" can be calibrated to take account of local conditions. 
Appendix 2

There are many sources for the details as to how these ratios and variations thereon, are calculated. The National Association of Insurance Commissioners in the United States can provide significant amounts of information on the use of the ratios to interested supervisory groups. Similarly, insurance supervisors in developed countries such as Canada, Australia, the countries of the European Union and so on, will without exception be able to provide information on exactly which ratios they use, their prescribed normal ranges and other useful information. 


\section{Appendix 3}

The Regulatory Ladder 


\section{Appendix 3}

\section{The Regulatory Ladder}

\begin{tabular}{|c|c|c|c|c|c|}
\hline mak & \multicolumn{4}{|c|}{ Examples of Observed Risks } & Examplesor \\
\hline & $\begin{array}{l}\text { Financial } \\
\text { Analysis }\end{array}$ & $\begin{array}{c}\text { On-Site } \\
\text { Inspections }\end{array}$ & $\begin{array}{c}\text { Auditor and } \\
\text { Actuary }\end{array}$ & $\begin{array}{c}\text { Market } \\
\text { Intelligence }\end{array}$ & \\
\hline $\begin{array}{l}\text { Level } 4 \\
\text { Company } \\
\text { not viable, } \\
\text { insolvency } \\
\text { imminent }\end{array}$ & $\begin{array}{l}\text { Capital and surplus } \\
\text { on real value basis } \\
\text { almost at zero level ... }\end{array}$ & $\begin{array}{l}\text { Senior management and } \\
\text { directors unable to realize } \\
\text { the magnitide of the } \\
\text { problems fucing the } \\
\text { company. Some directors } \\
\text { may be resigning. } \\
\text { Financial information bears } \\
\text { litrle relation to reality. } \\
\text { Major transactions with } \\
\text { related companies... }\end{array}$ & $\begin{array}{l}\text { Unable to sign financial } \\
\text { statements or acturial } \\
\text { certification. }\end{array}$ & $\begin{array}{l}\text { Modit specoulation that } \\
\text { company won't survive. } \\
\text { Public cancelling policies. } \\
\text { Brokers switching to other } \\
\text { carriens. }\end{array}$ & $\begin{array}{l}\text { Institute procedura for re } \\
\text { habilitation or liquidation. }\end{array}$ \\
\hline $\begin{array}{l}\text { Level } 3 \\
\text { Future } \\
\text { financial } \\
\text { viability in } \\
\text { serious } \\
\text { doubt }\end{array}$ & $\begin{array}{l}\text { More than } 10 \mathrm{key} \\
\text { ratios (of total of } 20 \text { ) } \\
\text { outside of normal } \\
\text { range. Financial } \\
\text { trends have diverged } \\
\text { sharply from industry } \\
\text { norms. Delays in } \\
\text { provision of financial } \\
\text { information. } \\
\text { Analysts are secing } \\
\text { many transections } \\
\text { with afmliated } \\
\text { corporations. } \\
\text { Premium volume too } \\
\text { high for current level } \\
\text { of capital and surplus }\end{array}$ & 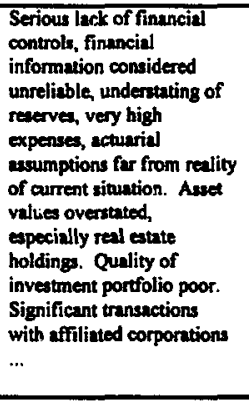 & 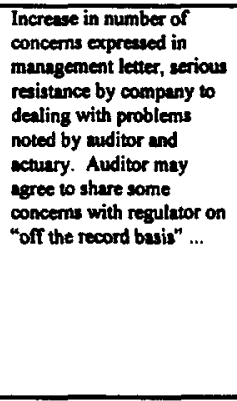 & 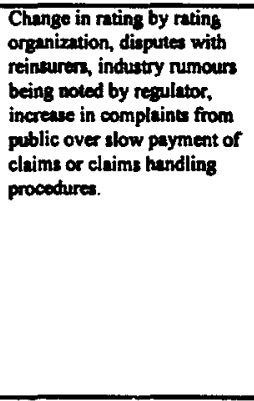 & 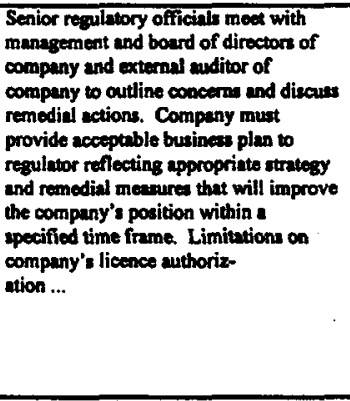 \\
\hline $\begin{array}{l}\text { Level } 2 \\
\text { Emerging } \\
\text { risk to } \\
\text { financial } \\
\text { viability of } \\
\text { company }\end{array}$ & $\begin{array}{l}\text { Between } 6 \text { and } 9 \\
\text { ratios outside of } \\
\text { normal range. } \\
\text { unsatisfactory trend } \\
\text { in key finnencial } \\
\text { parameters... }\end{array}$ & 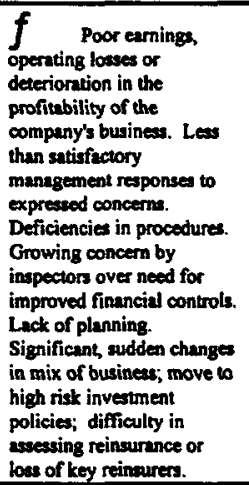 & $\begin{array}{l}\text { Some important ooncerms } \\
\text { being expresced in } \\
\text { manugement letter. } \\
\text { Company responses } \\
\text { showing defensiveness } \\
\text { and some leck of co- } \\
\text { operation ... }\end{array}$ & & 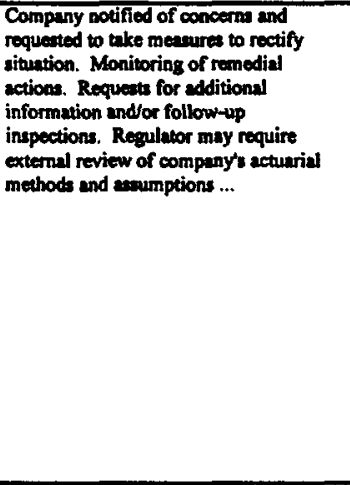 \\
\hline $\begin{array}{l}\text { Level } 1 \\
\text { No major } \\
\text { problems, } \\
\text { normal } \\
\text { activities }\end{array}$ & $\begin{array}{l}\text { Fewer than } 5 \text { key } \\
\text { ratios outside of } \\
\text { normal range. }\end{array}$ & $\begin{array}{l}\text { Inspectors report that } \\
\text { mangement team is strong } \\
\text { apper wo have well thought } \\
\text { out bueineess strategy, good } \\
\text { financial controls, } \\
\text { consevvative investment } \\
\text { policy. Profitable } \\
\text { opentions. }\end{array}$ & $\begin{array}{l}\text { Routine reports, no } \\
\text { significant concerns } \\
\text { expresed in management } \\
\text { letter. }\end{array}$ & & \\
\hline
\end{tabular}


The above has been provided to several jurisdictions in Latin America as a schemutic example of the regulatory ladder concept. Each cell of the matrix can be expanded into considerably more detail. An additional risk level could also be added to provide a somewhat higher level of detail. If the supervisory organization has other divisions such as Reinsurance Analysis and Actuarial, colurnns could be added for those functions as well. 


\section{Appendix 4}

\section{The Claims Run-Off Exhibit}




\section{Company: Royal Insurance Company Of Canada}

1991 UCAE, end of year
IBNR, end of year
1992 Paid during year
UCAE, end of year
IBNR, end of year
\%Ratio: excess (deficiency)
1993 Paid during year
UCAE, end of year
IBNR, end of year
\%Ratio: excess (deficiency)
1994 Paid during year
UCAE, end of year
IBNR, end of year
Ratio: excess (deficiency)
1995 Paid during year
UCAE, end of year
IBNR, end of year
\%Ratio: excess (deficiency)
1996 Paid during year
UCAE, end of year
IBNR, end of year
\%Ratio: excess (deficiency)

1991 and

Prior Years 563,866

235,786

225,569

412,629

152,688

1.10

125,043

322,111

95,392

3.94

81,815

243,151

76,695

5.92

84,643

168,196

57,784

7.08

55,962

135,631

49,171

5.23
1992

245,144

163,950

99,904

101,511

97,913

68,160

15,744

93,745

45,880

35,796

71,779

29,231

20,703

54,941

18,028

6.49
1992 and

Prior Years

1993

1993 and

Prior Years

1994
470,632

596,758

275,453

163,552

97,559

336,896

122,575

5.50

120,439

239,975

87,015

6.95

76,665

190,572

67,199

6.05
244,078

176,734

111,901

80,180

108,301

79,177

38,039

90,481

44,159

30,554

76,594

29,097

11.84
177,739

445,197

201,752

5.45

$158,478 \quad 127,64$

$330,456 \quad 119,37$

$131,174 \quad 77,69$

8.53

107,219

267,166

96,296

7.49
282,73

217,29

114,41

34,46

102,60

44,07

6.9

Appendix 4 Page 2:

The Claims Run-Off 
Company: Jevco

Insurance Company

\begin{tabular}{|c|c|c|c|c|c|c|}
\hline & 1991 and & & 1992 and & & 1993 and & \\
\hline & Prior Years & 1992 & Prior Years & 1993 & Prior Years & 1994 \\
\hline 1991 UCAE, end of year & 10,266 & & & & & \\
\hline IBNR, end of year & 5,953 & & & & & \\
\hline 1992 Paid during year & 8,610 & 10,487 & 19,097 & & & \\
\hline UCAE, end of year & 4,262 & 2,444 & 6,706 & & & \\
\hline IBNR, end of year & 4,513 & 1,478 & 5,991 & & & \\
\hline \%Ratio: excess (deficiency) & -7.19 & & & & & \\
\hline 1993 Paid during year & 4,667 & 3,218 & 7,885 & 10,832 & 18,717 & \\
\hline UCAE, end of year & 3,764 & 1,201 & 4,965 & 4,142 & 9,107 & \\
\hline IBNR, end of year & 1,794 & 37 & 1,831 & 2,333 & 4,164 & \\
\hline \%Ratio: excess (deficiency) & -16.13 & & -15.63 & & & \\
\hline 1994 Paid during year & 4,716 & 1,260 & 5,976 & 4,428 & 10,404 & 7,76 \\
\hline UCAE, end of year & 1,776 & 776 & 2,552 & 1,115 & 3,667 & 2,22 \\
\hline IBNR, end of year & 975 & 1,157 & 2,132 & 1,893 & 4,025 & 1,43 \\
\hline Ratio: excess (deficiency) & -27.90 & & -46.06 & & -36.36 & \\
\hline 1995 Paid during year & 2,079 & 1,133 & 3,212 & 2,639 & 5,851 & 2,79 \\
\hline UCAE, end of year & 1,780 & 291 & 2,071 & 246 & 2,317 & 62 \\
\hline IBNR, end of year & 1,042 & 288 & 1,330 & 756 & 2,086 & 1,28 \\
\hline \%Ratio: excess (deficiency) & -41.16 & & -61.25 & & -55.66 & \\
\hline 1996 Paid during year & 3,183 & 564 & 3,747 & 1,166 & 4,913 & 1,19 \\
\hline UCAE, end of year & 1,480 & 963 & 2,443 & 991 & 3,434 & 87 \\
\hline IBNR, end of year & 282 & 60 & 342 & 245 & 587 & 65 \\
\hline \%Ratio: excess (deficiency) & -54.25 & -83.53 & -85.91 & -46.24 & -89.80 & -50.9 \\
\hline
\end{tabular}




\section{Appendix 5}

\section{Staffing and Organizational Structures}




\section{Appendix 5: Staffing Requirements and Organizational Structures for Solvency Supervision}

In this Appendix we set out as a guide, staffing complements and organizational structures that might typically be found in the solvency supervision area of supervisory organizations. We emphasize that the information contained herein is only a guide and actual requirements will be highly dependent on the particular requirements and circumstances of the jurisdiction.

\section{A. Staffing}

In the paragraphs that follow we outline a two stage approach for estimating staffing levels: (1) consider the inspection area to be the core functional area and estimate staff levels for that area, and (2) consider staff levels required for other areas to be a function of the number of inspectors.

As a "rule of thumb", our experience is that for inspection work, and with a reasonable base of companies to supervise (say at least 50 insurers), one would normally expect an insurer to inspector ratio somewhere in the range of from 10 to 1 at the low end to 5 to 1 at the higher end. For example, for a jurisdiction with 100 insurers, we would might expect to see an inspection staff of between 10 and 20 persons.

As the number of supervised insurers drops below 50, the decline in the required number of inspectors will not be directly proportional to the reduction in the number of insurers, and probably a minimum base level for any inspection group is about 3 inspectors. For example, for a population of 25 supervised insurers we would think one would have to plan on an inspection group of from 4 to 7 (rather than 2.5 to 5 as would be predicted from the ratio range mentioned above).

We must emphasize, however, that much will depend on two variables: the current financial environment in the industry and the current state of the supervisory system. The latter variable is in turn a function of several other variables, the main ones being: (1) the degree of reliance that may be placed on outside parties such as the independent auditors and actuaries and (2) the extent to which technology is available to assist the inspectors with their work.

Clearly if the industry is in a state of financial crisis or there are an abnormal number of companies experiencing solvency problems, then more resources will be required, other things being equal. Independently of this, if the supervisory system is relatively sophisticated, and the inspectors are able to focus at a high level of company operations rather than having to be preoccupied with issues relating to the accuracy and completeness of the financial statements, then correspondingly less supervisory effort will naturally be needed. Similarly, if the inspectors are using computers with large amounts of supervisory information available on-line, including historical data on the companies, previous inspection reports and so on, and if the calculating requirements of the analytical work are carried out by computer, then the efficiency of the supervisory office will be increased and fewer personnel will be required. In general we believe that the financial health of the supervised companies will be at least as important a determinant of staffing requirements as will the degree of computerization available to inspectors. 
On the above basis, we would expect that in a jurisdiction where companies are experiencing many solvency problems, and where the supervisory system (including the role of professional advisors and use; of technology) is not very advanced, then a base of 100 insurers may call for a staff of 20 or so inspectors. At the other end of the spectrum, in a country like Canada, where the industry is relatively stable, where the infrastructure of professional advisors is such that considerable reliance may be placed upon their work, and where computer support is routinely provided, then a supervisory work load of 100 companies should probably require no more than 10 inspectors.

For financial anialysts, we would say that normally one would target a ratio of 1 financial analyst to every 2 inspectors, using the guidelines mentioned above to determine the required number of inspectors. If the inspectors are also going to be doing the financial analysis, then we might use the same framework to determine the additional number of inspectors that may be needed. For example, if, based on the number of companies, condition of the industry and degree of computerization, we conclude that an inspection staff of 20 is going to be needed for the actual inspection work, then we would think an additional 10 inspectors may be necessary if they are also going to be responsible for the analytical work. In other words, if the financial analysis is going to be done by the inspectors, then we would consider it necessary to augment the inspection staff by about $50 \%$. Combining the financial analysis and inspection activities within one organizational unit may give rise to a slight saving in staff because of reduced time for interdivisional communications. Overall, however, we wouldn't consider the impact of this to be very significant. In the example mentioned above it may be reasonable to add 9 inspectors rather than 10.

To provide support to the inspectors and financial analysts one would usually expect to see actuarial and other technical specialists on staff. In the United States and Canada, there are different designations for life actuaries and casualty actuaries and so the insurance supervisory organization would generally contain representatives of each group, with numbers depending on the size of the life insurance and property/casualty insurance industries respectively.

As mentioned in the body of this paper, in the property/casualty area one or more reinsurance specialist positions can also provide a beneficial level of support. This will be especially important in markets that are exposed to contingencies such as hurricanes and earthquakes. The reinsurance specialist will serve as a resource person to assist the inspectors with the assessment of reinsurance arrangements and to review particular agreements having unusually complex or unique features. The actuarial staff should be able to provide some assistance in this area as well, and in many cases the reinsurance may in fact be an actuary.

Sometimes the technical/actuarial inspectors will be classified as inspectors and will visit the insurers as a member of the inspection team. In other jurisdictions technical support personnel work mostly from the supervisory office, providing advice and support to the inspectors in the field, with only occasional visits to the companies' offices. We suspect that the latter method of deployment may be more efficient since the specialized expertise should always be focused in areas where it is really needed, whereas the inclusion of specialists on the inspection team may 
sometimes result in their visiting companies that do not require their full attention. On the other hand circumstances differ from place to and we suggest that supervisors decide their approach based on what they think will work best in their own situation.

With regard to the number of technical support persons who may be required, again much will of course depend on the circumstances within the jurisdiction. In general however, we would venture to say that technical support (actuaries, reinsurance specialists, etc.) will range from 1 to 2 per 10 inspectors. Therefore a 20 inspector division might be complemented by from 2 to 4 technical specialists, with, ideally, a minimum of 1 actuary even if the inspection group is at the minimum level of 3 or so inspectors. In some jurisdictions trained actuaries are in short supply and so the actual number of actuarial positions may be less than the ideal.

When the supervisory group has adopted a fairly high level of technology -- for example, all inspectors and financial analysts are using personal computers in their day to day work -- there will be a need for at least one information technology support person. Inevitably staff will have problems and questions on an on-going basis, there will be configuration problems with software and hardware, there is the need to avoid viruses and so on, so that at least one specialist will be required in this area. (We have not included Information Technology support positions in the sample organizational charts below because we consider them to be similar to other support functions such as Human Relations.)

Most larger supervisory organizations will have a stand alone policy group which will be responsible for looking at "big picture" issues and devising regulatory solutions which will be in line with general government policy. A policy group will also help to ensure that issues are dealt with consistently from one case to another and that the same principles are applied in each case.

Another group that is sometimes found in larger supervisory organizations is Legal Support. This unit would be comprised of one or more lawyers who spend all of their time providing supervisory staff with recommendations and opinions on legal matters. For example, operational staff may wish to know whether the insurance act will support a particular action they wish to take, or they will often have questions as to the interpretation of insurance act provisions in the context of regulatory issues with specific companies.

The foregoing discussion pertains to the operational area of the supervisor's office. Of course the office will also require support in other areas such as human resources, finance, administration and so on. We assume that these areas will be staffed in conformance with normal governmental requirements so that there is no need to deal with them in detail here.

All of the foregoing are nothing more than rough guidelines, which hopefully will be of assistance for purposes of resource planning. We stress again, however, that much depends on the particular situation. Also, in setting out the foregoing thoughts we in no way wish to suggest that there are not other staffing combinations and arrangements which will provide high levels of efficiency and effectiveness. In our view, the abilities and expertise of the supervisory staff will be a more important determinant of success than will the actual scheme of organization, although 
Appendix 5

the "right" organizational structure will enable staff members to maximize their contribution to the achievement of supervisory objectives.

One final point is that both inspection work and financial analysis are the types of activities that really have no upper bounds in terms of resource utilization. In both cases, and especially in the case of inspections, one can always go into more and more detail in understanding the activities of an insurer. It is often difficult for inspectors to keep their investigations at an appropriately high level, as human nature is such that it is easy to become overly immersed in details. Supervisory managers must keep in mind that it is seldom at the level of fine detail that significant solvency trends and developments are either revealed or remedied. 


\section{Appendix 5}

\section{B. Organizational Structures}

All organizational chart examples assume a difficult financial environment, a low level of regulatory sophistication and a low degree of technological development. The organizational charts pretain to the operational components of solvency regulation and exclude areas such as Human Resources, Finance and Administration.

Example 1: Large jurisdiction -250 insurers. Total Staff of 92 , of whom 50 are inspectors, 20 are Analysts. All inspection and analysis positions are specialized as to Life Insurance and P/C Insurance.

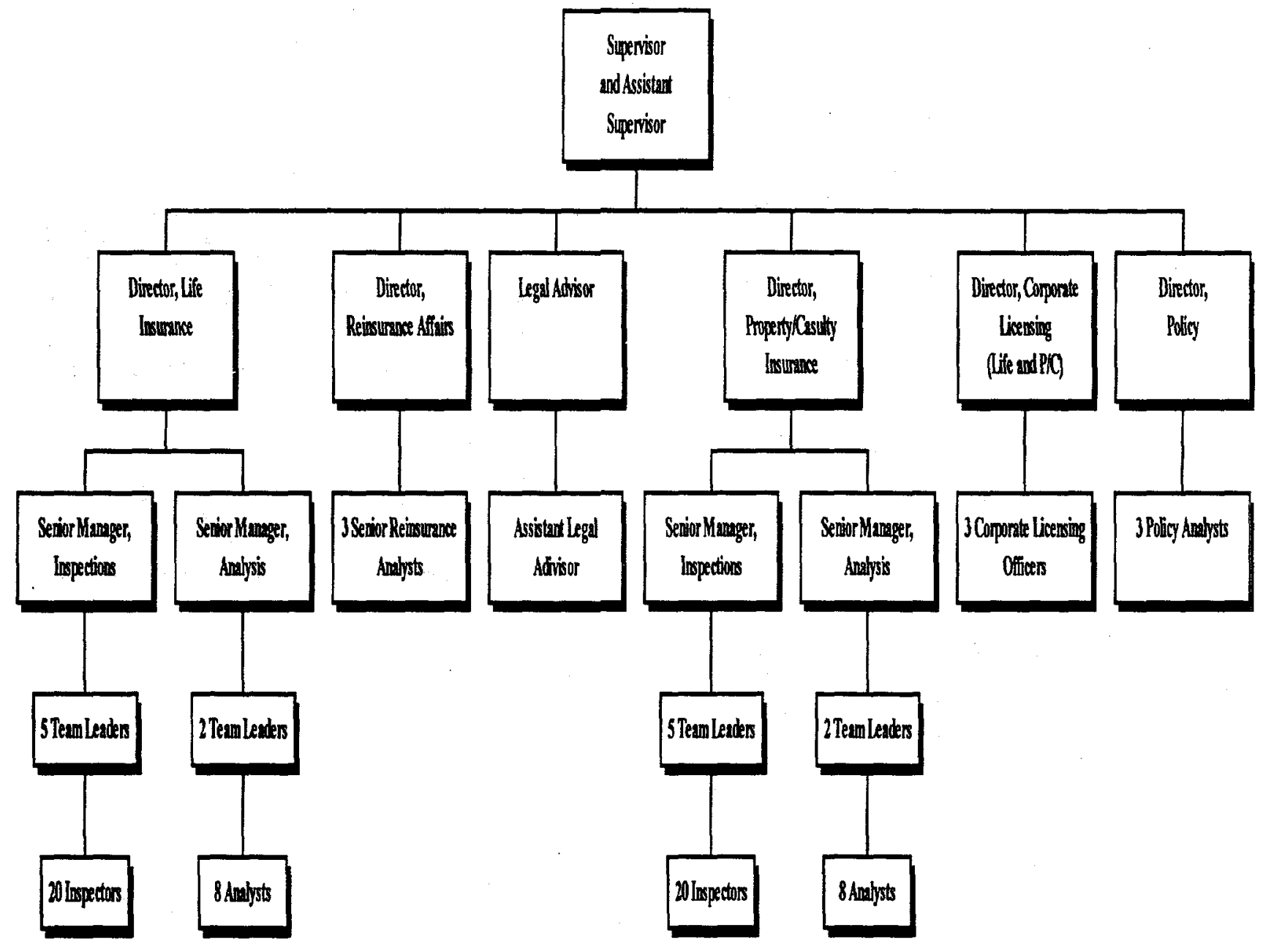




\section{Appendix 5}

Example 2: Alternate structure for same situation as Example 1. Total Staff of 90, of whom 50 are Inspectors and 16 are Analysts. Life and P/C combined under 1 Director but responsible for analysis and interpretation of financial trends for all insurers. Compared to Example 1, and Director Technical Analysis / Actuarial, with 3 Actuarial Analysts.

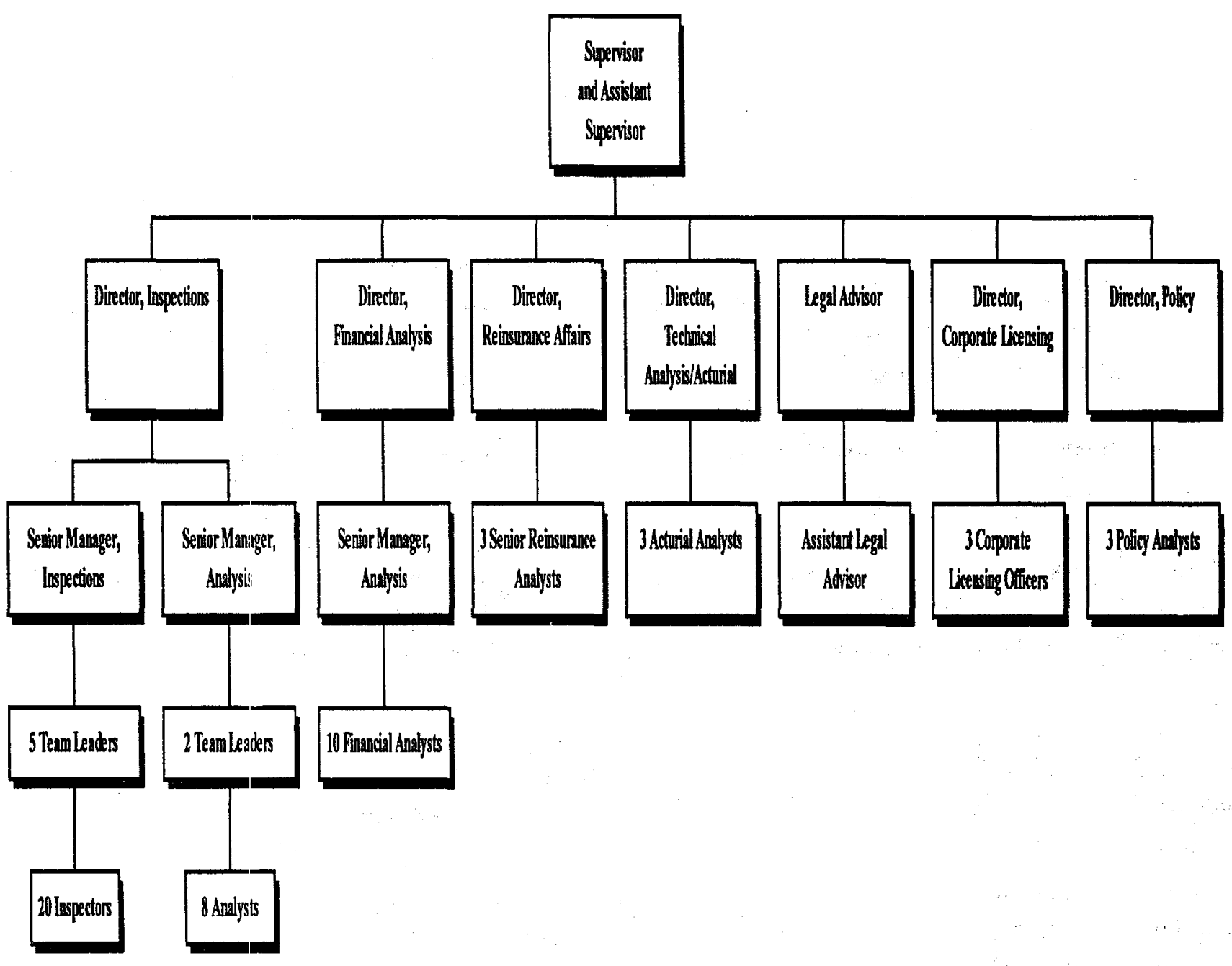




\section{Appendix 5}

Example 3: Smaller jurisdiction with 60 supervised insurers. 13 Inspectors and 5 Financial Analysts. 26 staff in total. Analysis headed up by its own Director.

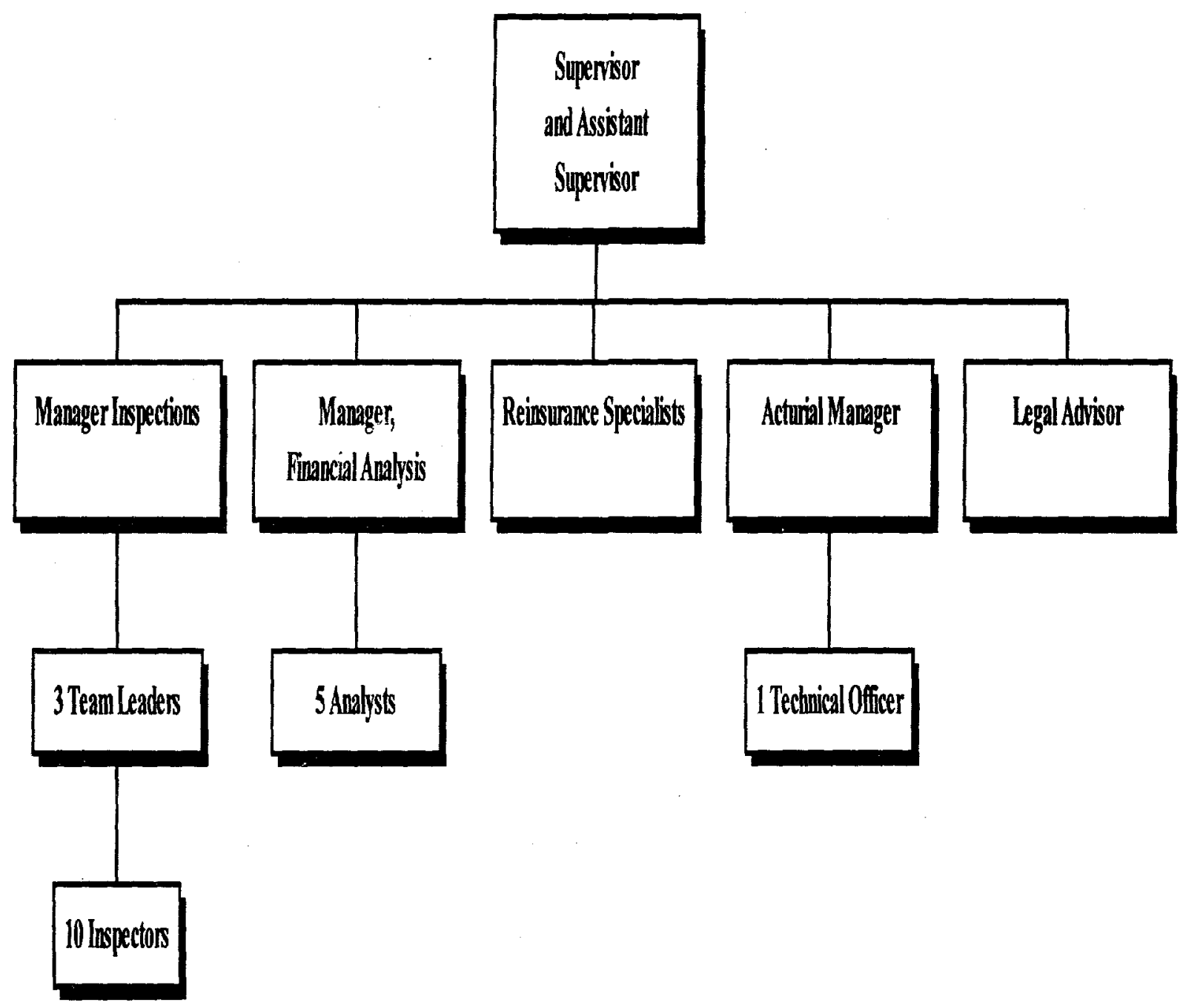




\section{Appendix 5}

Example 4: Same situation as Example 3. Total Staff of 24, including 13 Inspectors and 4 Financial Analysts. Inspection and Financial Analysts combined under one Manager but functions still dealt with separately below the Manager.

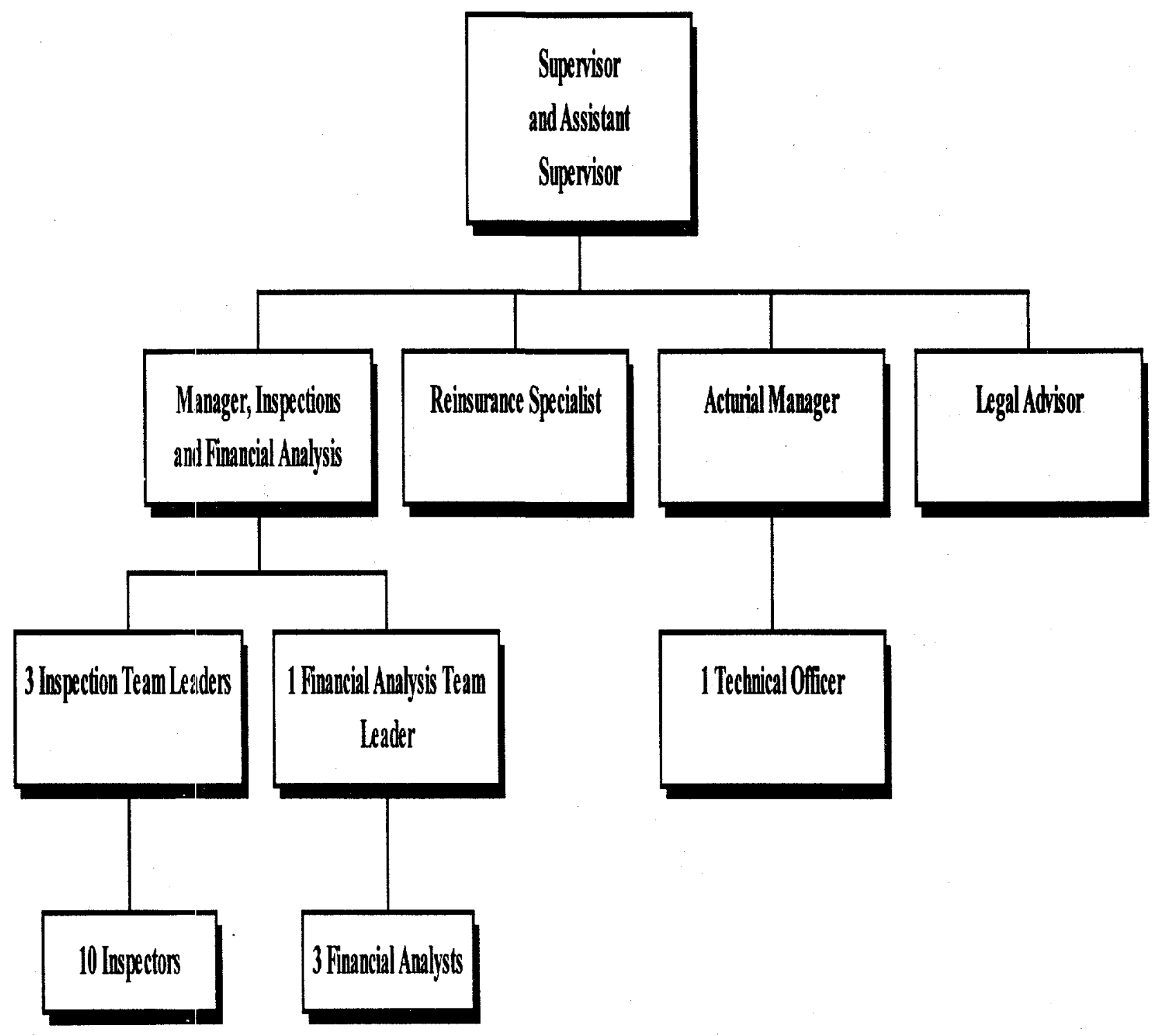




\section{Appendix 5}

Example 5: Alternate structure for same situation as Examples 1 and 2. Total staff of 83, including 60 Inspector / Analysts. No differentiation between Life and P/C. Analysis duties combined with inspection.

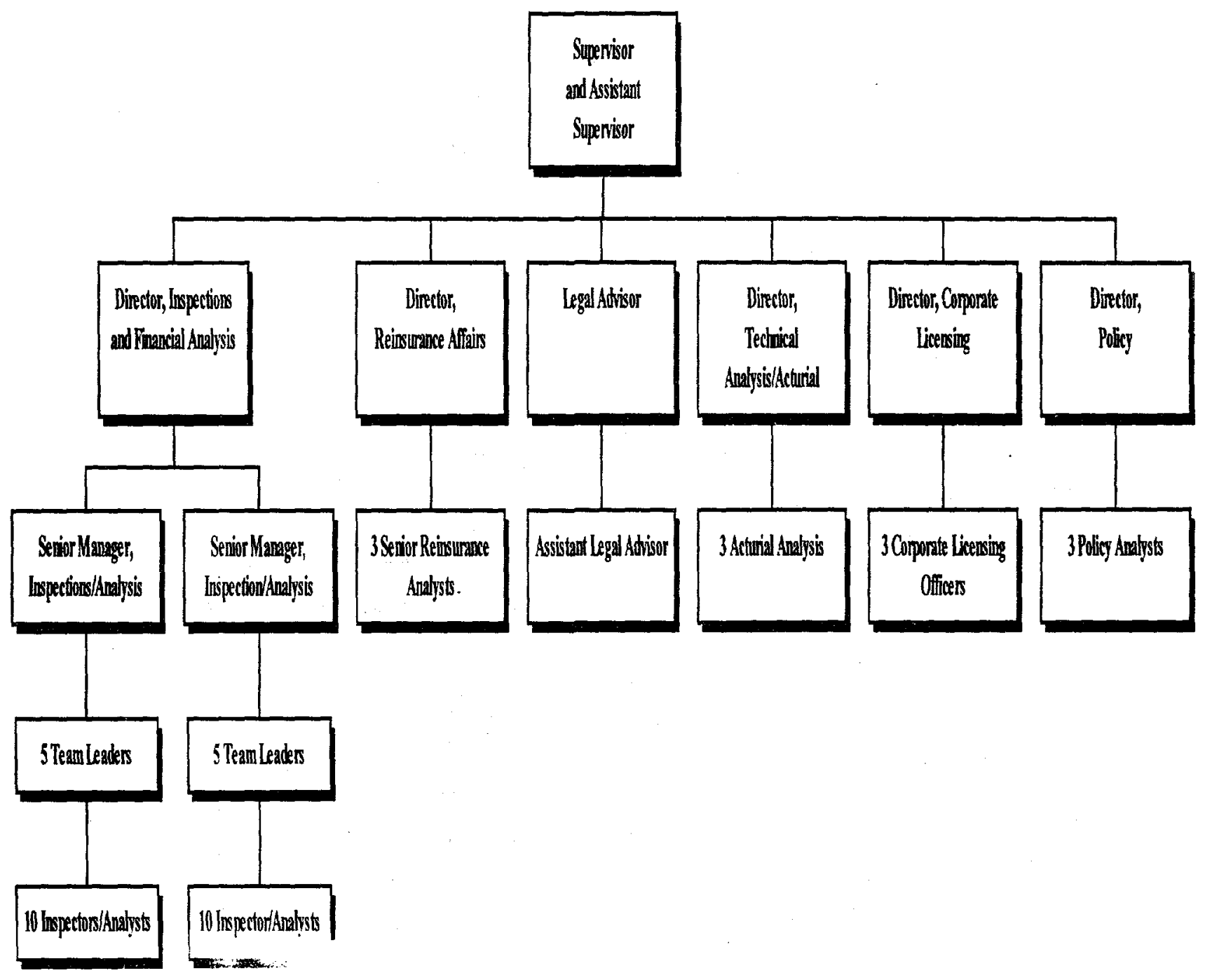


Appendix 5

Example 6: Very small jurisdiction, 25 Insurers. Total staff 15, of whom 10 are inspector/ Analysts.

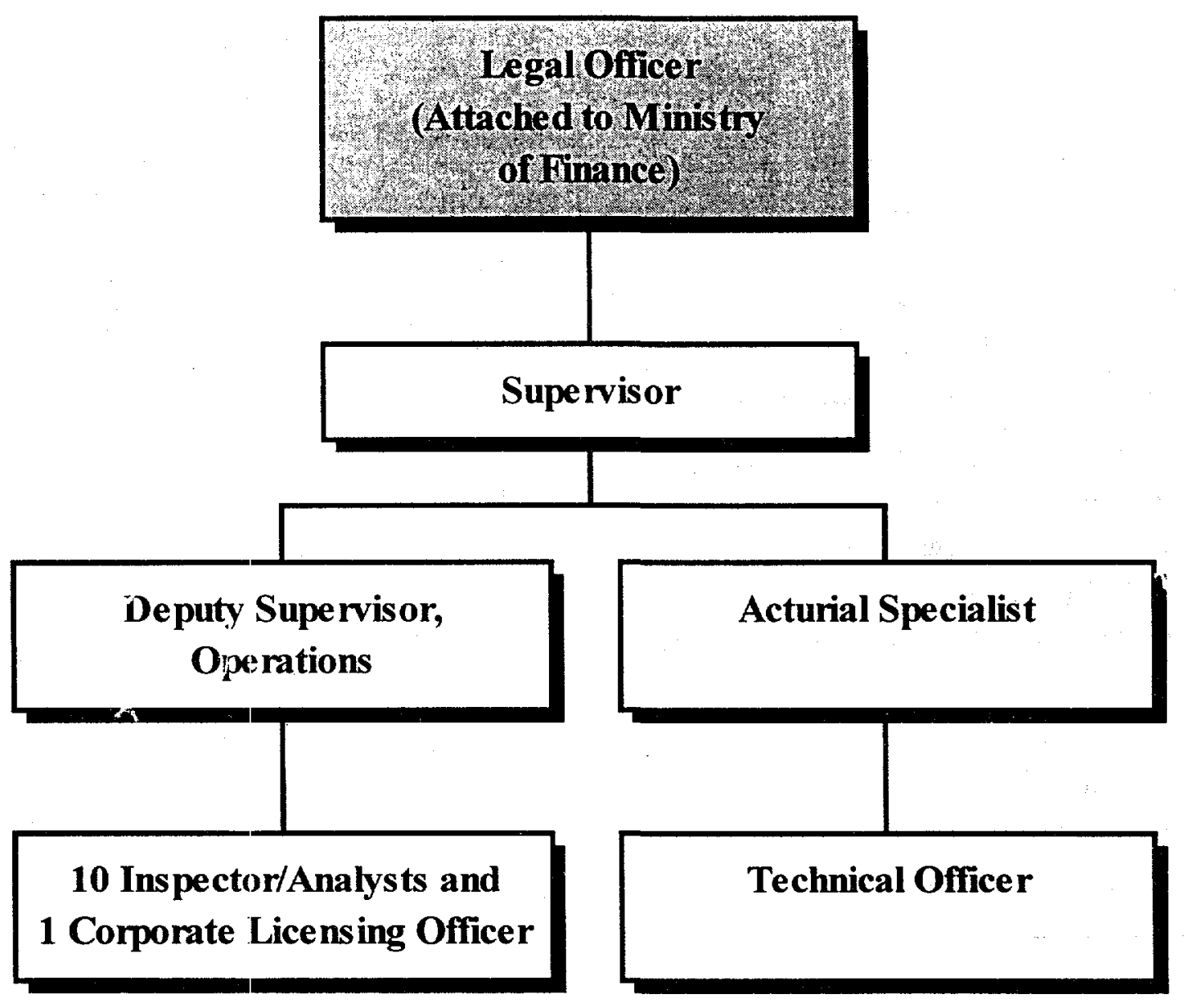




\section{BIBLIOGRAPHY}

A. M. Best, Best's Policy Reports: Universal Life Insurance, April, Oldwick, New Jersey (1995).

Australia Treasury: Financial System Inquiry - Final Report, S.D. Wallis (Chairman), Commonwealth Government Publications, Parkes Place, Australia (1997). http://www.treasury.gov.au/Publications/FSI

Babbel, David F. and David R. Klock, An Insurance Primer: Review of the U.S. Insurance Industry, Dr. Phillips Institute for the Study of American Business Activity, University of Central Florida, Orlando (1993).

Casualty Actuarial Society, Foundations of Casualty Actuarial Science. (1997).

Comite Europeen Des Assurances, Codification of European Insurance Directives. Paris, (1994).

Cummins, J. David, Ed., Investment Activities of Life Insurance Companies, Richard D. Irwin Inc., Homewood, Illinois (1977).

Cummins, J. David, and Mary Weiss, Structure, Conduct and Regulation of Property Liability Insurance Markets, Working Paper, Wharton School, Philadelphia (1991).

Ettlinger, Kathleen H., Karen Hamilton, Gregory Krohm. State Insurance Regulation. Insurance Institute of America, Malvern, (1995).

Geehan, Randall, "Economies of Scale in Insurance: Implications for Regulation", in B. Wasow and R.D. Hill (eds.) The Insurance Industry in Economic Development, Columbia University Press, (1986).

Grace, Martin F., "Cycles and Volatility: A Cross Country Analysis Examining Differences in Regulatory Requirements" in The Proceedings of the International Insurance Society 157-169 (1990).

Grace, Martin F., and Nichael M. Barth, The Regulation and Structure of Nonlife Insurance in the United States, World Bank, Policy Research Working Paper 1155, Washington (1993).

Hooker, N. D., Bulmer, J. R., Cooper, S. M., Green, P. A. G. and Hinton, P. H., "Riskbased Capital in General Insurance", British Actuarial Journal, Vol 2 (2): 265-323 (1996).

Huebner, S.S. and Kenneth Black Jr., Life Insurance, Prentice-Hall Inc., Englewood Cliffs, NJ (1982). 
Insurance Accounting \& Systems Association, Inc. Property-Casualty Insurance Accounting. Durham, (1994).

International Association of Insurance Supervisors, Principles, Standards and Guidance Papers, Basle (September 1997).

Joskow, Paul, "Cartels, Competition and Regulation in the Property Liability Insurance Industry," 4. Bell Journal of Economics 375-427 (1973).

Kimball, Spencer, Insurance and Public Policy, Univ of Wisconsin Press, Madison (1960).

Klein, R. W., "Issues in Financing Insurance Regulation and NAIC Services", National Association of Insurance Commissioners, Working Paper (1996).

Lemaire, Jean and Krupa Subramanian, Insurance Regulation in Europe and the United States, Huebner Foundation Monograph 16, Wharton School, Philadelphia (1997).

Manders, J. M., Vaughan, T. M. and Meyers, Jr R. H., "Insurance Regulation in the Public Interest: Where Do We Go from Here", Journal of Insurance Regulation, 285-340 (1994)

McIsaac, Donald, Information Costs, Risk, and the Regulation of Insurance, World Bank, FPD Note 13, Washington (1994).

McIsaac, Donald, and David F. Babbel, The World Bank Primer on Reinsurance, World Bank, Policy Research Working paper 1512, Washington (1995).

McNairn, Colin H.H., Consolidated Insurance Companies Act of Canada: Regulations and Guidelines 1997, Carswell - Thomson Professional Publishing, Toronto (1996).

Meier, Kenneth J., The Political Economy of Regulation: The Case of Insurance, State University of New York Press, Albany (1988).

Brady, Justin, Joyce H. Mellinger, Kenneth Scoles, Jr., The Regulation of Insurance. Insurance Institute of America, Malvern, (1995).

National Association of Insurance Commissioners, Financial Regulation Standards and Accreditation Factbook, Kansas City, (1998).

National Association of Insurance Commissioners, International Insurance Solvency Survey. Kansas City, (1996).

National Association of Insurance Commissioners, Examiners Handbook. Kansas City, 
(1998).

National Association of Insurance Commissioners, Accounting Practices and Procedures. Kansas City, (1998).

National Association of Insurance Commissioners, Troubled Company Manual. Kansas City, (1994).

Organization of Economic Co-operation and Development, Insurance Solvency Supervision, Paris (1995).

Organization of Economic Co-operation and Development, Supervision of Private Insurance in Europe, Paris (1963).

Organization of Economic Co-operation and Development, Policy Issues in Insurance, Paris (1993).

Pauly, Mark, Howard Kunruether and Paul Kleindorfer, "Regulation and Quality Competition in the U.S. Insurance Industry", in Jorg Finsinger and Mark Pauly, eds., The Economics of Insurance Regulation. St. Martins Press, New York (1986).

Rabe, Thomas, "Life Insurance Regulation in the United Kingdom and Germany", in Dimitri Vittas (ed.), Financial Regulation: Changing the Rules of the Game, World Bank, EDI Development Studies, Washington (1992).

Skipper, Harold D. Jr., Foreign Insurers in Emerging Markets: Issues and Concerns, IIF Occasional Paper, International Insurance Foundation, Washington (1997).

UNCTAD, Insurance in Developing Countries: An Assessment and Review of Developments (1989-1993). Geneva, (1994). UNCTAD/SDD/INS/2/Rev. 1

UNCTAD, The Promotion of Life Insurance in Developing Countries. Geneva, (1982).

United States General Accounting Office, Insurance Regulation: The Insurance Regulatory Information System Needs Improvement, GAO/GGD-91-20, November 1990.

United States General Accounting Office, Insurance Regulation: Problems in the State Monitoring of Property/Casualty Insurer Solvency, GAO/GGD-89-129, September 1989.

Vignial, Cecile, Insurance Regulation and Supervision in Economies in Transition: Second East-West Conference on Insurance Systems in Economies in Transition, OECD (1997)

Vittas, Dimitri, Sequencing Social Security, Pension and Insurance Reform, World Bank, Policy Research Working Paper 1551, Washington (1995). 
Vittas, Dimitri, Tunisia's Insurance Sector, World Bank, Policy Research Working Paper . 1451, Washington (1995).

Wilkie, A. D., "Mutuality and Solidarity: Assessing Risks and Sharing Losses", British Actuarial Journal, Vol 3 (5): 985-996 (1997)

Winter, Ralph A., "Solvency Regulation and the Insurance Cycle", 29 Economic Inquiry 458-471 (1991).

Wright, Kenneth M., The Life Insurance Industry in the United States - An Analysis of Economic and Regulatory Issues, World Bank, Policy Research Working Paper 857, Washington (1992). 


\section{Policy Research Working Paper Series}

Title

WPS2007 Regional Integration Arrangements: Static Economic theory, Quantitative Findings, and Policy Guidelines

WPS2008 Volatility and Contagion in a Financially Integrated World: Lessons from East Asia's Recent Experience

Dean A. DeRosa

Author

Date

Contact

for paper

November 1998

Pedro Alba

Amar Bhattacharya

Stijn Claessens

Swati Ghosh

Leonardo Hernandez

WPS2009 Poverty and the Economic Transition: Peter Lanjouw How Do Changes in Economies of Scale Affect Poverty Rates for Branko Milanovic Stefano Paternostro Different Households?

WPS2010 The Real Impact of Financial Shocks: Ilker Domaç Evidence from the Republic of Korea Giovanni Ferri

WPS2011 Measuring Poverty Using Qualitative Perceptions of Welfare

Menno Pradhan Martin Ravallion

WPS2012 Export Quotas and Policy Constraints Sanjay Kathuria in the Indian Textile and Garment Industries

Anjali Bhardwaj

WPS2013 A New Database on Investment and Capital for Agriculture and Manufacturing

WPS2014 Land Institutions and Land Markets

WPS2015 The Mechanics of Progress in Education: Evidence from CrossCountry Data

WPS2016 Financial Services for the Urban Poor: South Africa's E Plan

WPS2017 Corporate Growth, Financing, and Risks in the Decade before East Asia's Financial Crisis

WPS2018 Prerequisites for a DevelopmentOriented State in the Democratic Republic of the Congo
Al Crego Donald Larson Rita Butzer Yair Mundlak

Klaus Deininger Gershon Feder

Alain Mingat Jee-Peng Tan

Jo Ann Paulson James McAndrews

Stijn Claessens Simeon Djankov Larry Lang

Mondonga M. Mokoli Hans P. Binswanger
November 1998

November 1998

November 1998

November 1998

November 1998

November 1998

November 1998

November 1998
November 1998
P. Sader 33902

R. Vo

33722

L. Tabada 36896

D. Fischer 38656

M. Greaves 81876

P. Sader 33902

L. Tabada 36896

P. Kokila 33716

M. Fernandez 33766

A. Poghosyan 30898

A. Thornton 80409

H. Binswanger 31871 


\section{Policy Research Working Paper Series}

\begin{tabular}{|c|c|c|c|c|}
\hline & Title & Author & Date & $\begin{array}{l}\text { Contact } \\
\text { for paper }\end{array}$ \\
\hline WPS2019 & $\begin{array}{l}\text { The Effects on Developing Countries } \\
\text { of the Kyoto Protocol and Carbon } \\
\text { Dioxide Emissions Trading }\end{array}$ & $\begin{array}{l}\text { A. Denny Ellerman } \\
\text { Henry D. Jacoby } \\
\text { Annelene Decaux }\end{array}$ & December 1998 & $\begin{array}{l}\text { T. Tourougui } \\
87431\end{array}$ \\
\hline WPS 2020 & $\begin{array}{l}\text { Trade Liberalization, Fiscal } \\
\text { Adjustment, and Exchange Rate } \\
\text { Policy in India }\end{array}$ & $\begin{array}{l}\text { Delfin S. Go } \\
\text { Pradeep Mitra }\end{array}$ & December 1998 & $\begin{array}{l}\text { C. Bernardo } \\
31148\end{array}$ \\
\hline WPS2021 & $\begin{array}{l}\text { Balance, Accountability, and } \\
\text { Responsiveness: Lessons about } \\
\text { Decentralization }\end{array}$ & Anwar Shah & December 1998 & $\begin{array}{l}\text { A. Shah } \\
37687\end{array}$ \\
\hline WPS 2022 & $\begin{array}{l}\text { The Implications of Foreign Aid } \\
\text { Fungibility for Development } \\
\text { Assistance }\end{array}$ & $\begin{array}{l}\text { Shantayanan Devarajan } \\
\text { Vinaya Swaroop }\end{array}$ & December 1998 & $\begin{array}{l}\text { C. Bernardo } \\
31148\end{array}$ \\
\hline WPS2023 & $\begin{array}{l}\text { Capital Inflow Reversals, Banking } \\
\text { Stability, and Prudential Regulation } \\
\text { in Central and Eastern Europe }\end{array}$ & $\begin{array}{l}\text { Samuel Talley } \\
\text { Marcelo M. Giugale } \\
\text { Rossana Polastri }\end{array}$ & December 1998 & $\begin{array}{l}\text { M. Geller } \\
85155\end{array}$ \\
\hline
\end{tabular}

